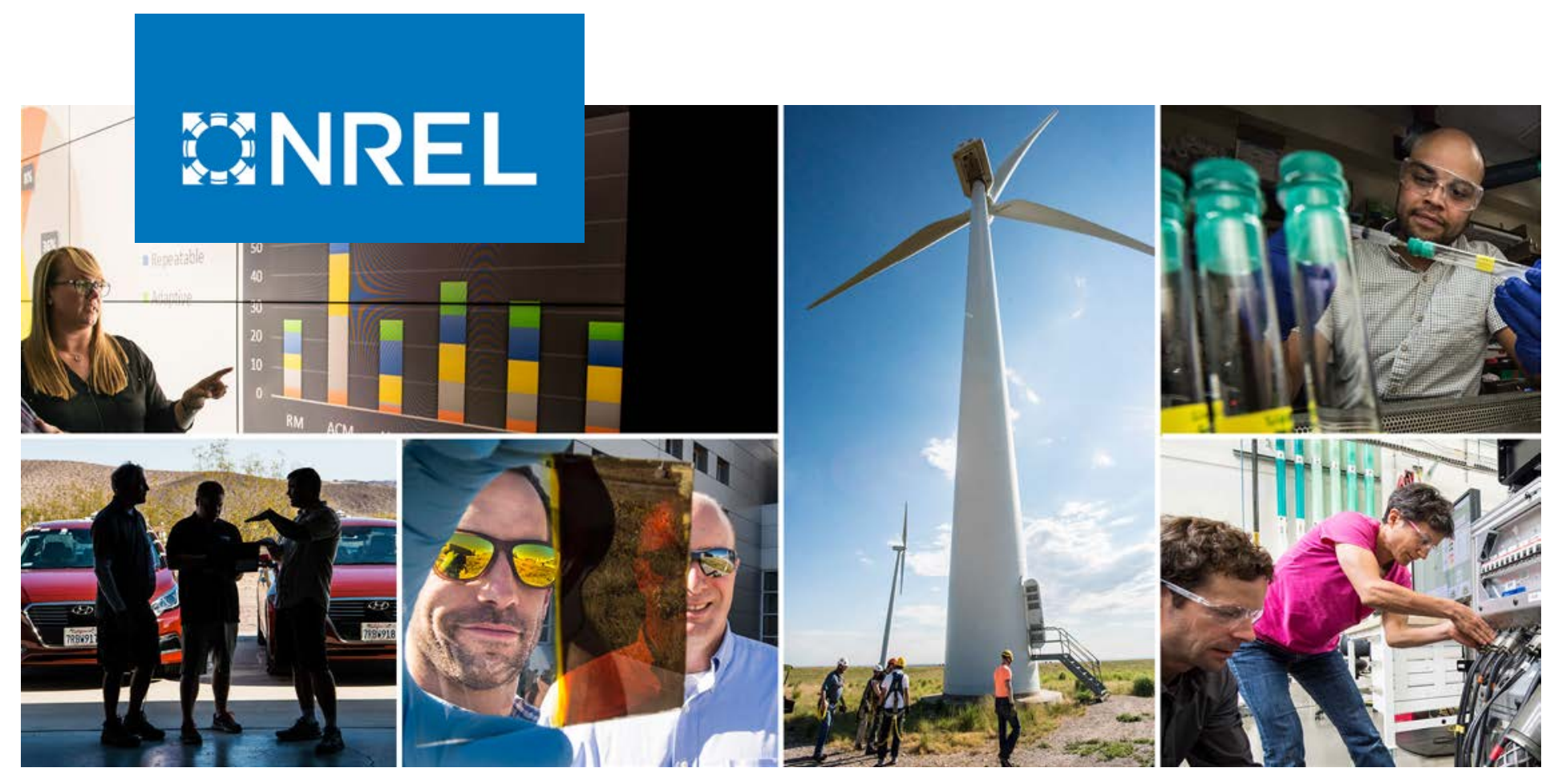

\title{
Uptower Investigation of Main and High-Speed-Shaft Bearing Reliability
}

Jonathan Keller, Yi Guo, and Latha Sethuraman

National Renewable Energy Laboratory

NREL is a national laboratory of the U.S. Department of Energy

Office of Energy Efficiency \& Renewable Energy

Operated by the Alliance for Sustainable Energy, LLC

This report is available at no cost from the National Renewable Energy Laboratory (NREL) at www.nrel.gov/publications.

\section{Technical Report}

NREL/TP-5000-71529

May 2019 


\section{GHREL}

\section{Uptower Investigation of Main and High-Speed-Shaft Bearing Reliability}

Jonathan Keller, Yi Guo, and Latha Sethuraman

National Renewable Energy Laboratory

\section{Suggested Citation}

Keller, Jonathan, Yi Guo, and Latha Sethuraman. 2019. Uptower Investigation of Main and High-Speed-Shaft Bearing Reliability. Golden, CO: National Renewable Energy Laboratory. NREL/TP-5000-71529. https://www.nrel.gov/docs/fy19osti/71529.pdf.

NREL is a national laboratory of the U.S. Department of Energy Office of Energy Efficiency \& Renewable Energy Operated by the Alliance for Sustainable Energy, LLC

This report is available at no cost from the National Renewable Energy Laboratory (NREL) at www.nrel.gov/publications.

Contract No. DE-AC36-08GO28308
Technical Report NREL/TP-5000-71529 May 2019

National Renewable Energy Laboratory 15013 Denver West Parkway Golden, CO 80401

303-275-3000 • www.nrel.gov 


\section{NOTICE}

This work was authored by the National Renewable Energy Laboratory, operated by Alliance for Sustainable Energy, LLC, for the U.S. Department of Energy (DOE) under Contract No. DE-AC36-08GO28308. Funding provided by the U.S. Department of Energy Office of Energy Efficiency and Renewable Energy Wind Energy Technologies Office. The views expressed herein do not necessarily represent the views of the DOE or the U.S. Government.

This report is available at no cost from the National Renewable Energy Laboratory (NREL) at www.nrel.gov/publications.

U.S. Department of Energy (DOE) reports produced after 1991 and a growing number of pre-1991 documents are available free via www.OSTI.gov.

Cover Photos by Dennis Schroeder: (clockwise, left to right) NREL 51934, NREL 45897, NREL 42160, NREL 45891, NREL 48097, NREL 46526.

NREL prints on paper that contains recycled content. 


\section{Acknowledgments}

This work was supported by the U.S. Department of Energy (DOE) under Contract No. DEAC36-08GO28308 with the National Renewable Energy Laboratory. Funding for the work was provided by the DOE Office of Energy Efficiency and Renewable Energy, Wind Energy Technologies Office. This work was also made possible by the contributions of SKF GmbH under cooperative research and development agreement (CRADA) CRD-16-608, Flender Corporation under CRADA CRD-17-694, and SKF USA under CRADA CRD-17-702. 


\section{List of Acronyms}

\section{CRADA}

CRB

DVST

GE

GS-in

GS-out

HSS

$\mathrm{Hz}$

$\mathrm{kNm}$

$\mathrm{kW}$

$\mathrm{mA}$

$\mathrm{ms}$

$\mathrm{m} / \mathrm{s}$

MW

NREL

NWTC

LVRT

RMS

rpm

$\mathrm{RS}$

SRB

TI

WEC cooperative research and development agreement

cylindrical roller bearing

design verification support tool

General Electric

inboard generator side

outboard generator side

high-speed shaft

hertz

kilonewton-meter

kilowatt

milliampere

millisecond

meters per second

megawatt

National Renewable Energy Laboratory

National Wind Technology Center

low-voltage ride-through

root-mean-square

revolutions per minute

rotor side

spherical roller bearing

turbulence intensity

white-etching crack 


\section{Table of Contents}

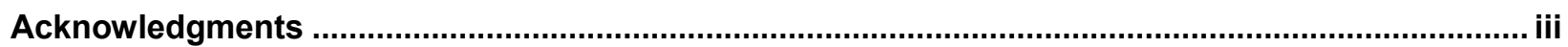

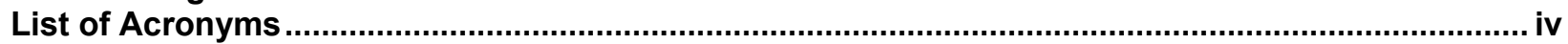

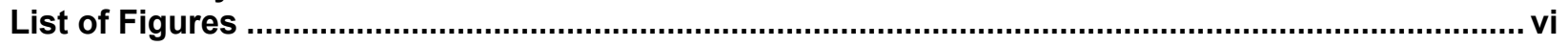

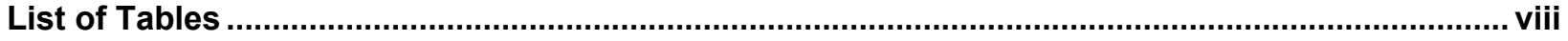

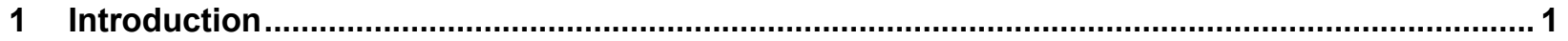

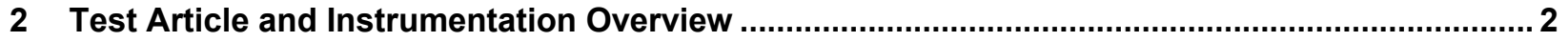

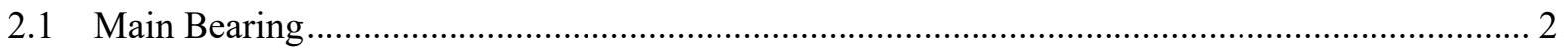

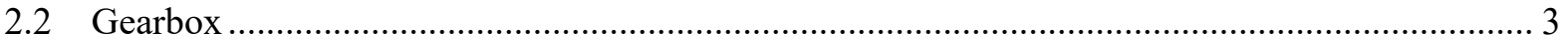

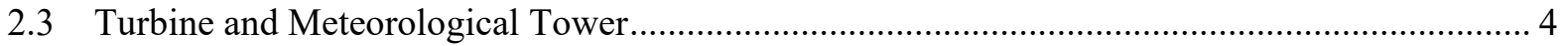

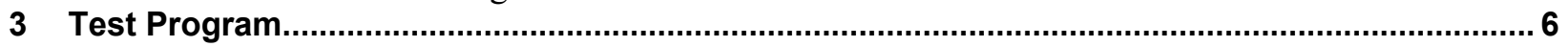

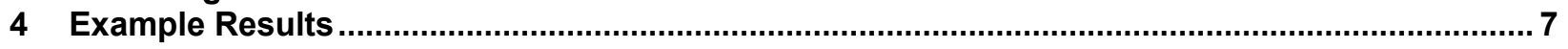

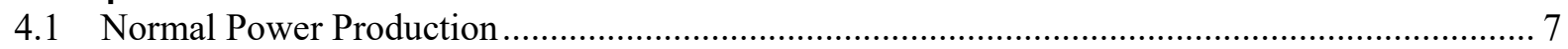

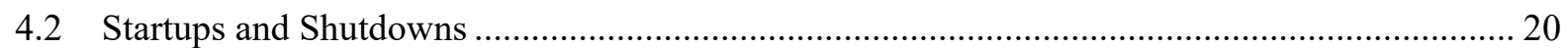

4.3 Parked/Idling ..................................................................................... 28

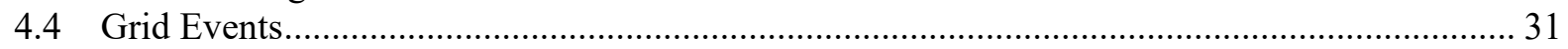

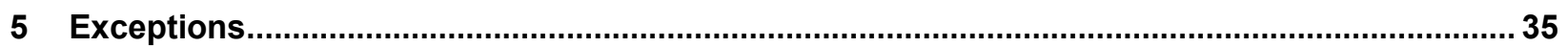

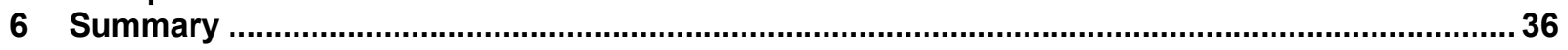

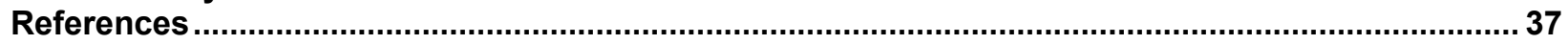

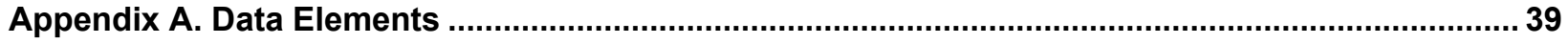




\section{List of Figures}

Figure 1. SKF SRB-Wind main bearing (left) and instrumentation (right). Photos by Jonathan Keller and Jerry Hur, NREL 49379 and 49959.

Figure 2. Winergy PEAB 4410.4 gearbox side (left) and rear (right) view. Photos by Jonathan Keller, NREL 49044 and 49045.

Figure 3. High-speed-shaft instrumentation schematic ............................................................. 4

Figure 4. Gearbox swap (left) and installation in turbine (right). Photos by Dennis Schroeder, NREL 49409 and 49413

Figure 5. Normal power production data acquisition durations

Figure 6. Power (left), rotor speed (middle), and blade pitch angle (right) in normal power production .

Figure 7. Main bearing proximity probe raw (left) and filtered (right) measurements in a normal

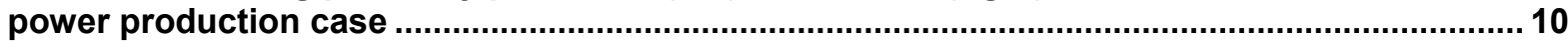

Figure 8. Main shaft net axial motion in normal power production ............................................... 11

Figure 9. Main bearing generator-side (left) and rotor-side (right) electrical current in a normal power production case

Figure 10. Main bearing generator-side (left) and rotor-side (right) stray electrical current in normal power production ..................................................................................................................... 12

Figure 11. High-speed-shaft generator-side-in (left) and rotor-side (right) bearing roller speed in normal power production cases .................................................................................................. 12

Figure 12. High-speed-shaft generator-side-in (left) and rotor-side (right) bearing cage speed in normal power production cases ............................................................................................ 13

Figure 13. High-speed-shaft generator-side-in (left) and rotor-side (right) bearing roller speeds at $900 \mathrm{rpm}$ and $257 \mathrm{~kW}$

Figure 14. High-speed-shaft generator-side-in (left) and rotor-side (right) bearing roller speeds at

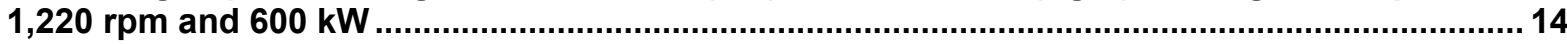

Figure 15. High-speed-shaft generator-side-in (left) and rotor-side (right) bearing roller speeds at rated speed and power .................................................................................................. 15

Figure 16. High-speed-shaft generator-side-in (left) and rotor-side (right) bearing roller speed in

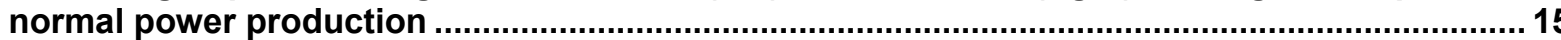

Figure 17. High-speed-shaft generator-side-in (left) and rotor-side (right) bearing cage speed in

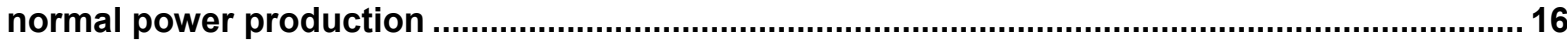

Figure 18. Unfiltered high-speed-shaft torque in normal power production .................................... 16

Figure 19. Filtered high-speed-shaft torque in normal power production ....................................... 17

Figure 20. Filtered high-speed-shaft $Y$ (left) and $Z$ (right) bending moment at $B$ in normal power production

Figure 21. Filtered high-speed-shaft $Y$ (left) and $Z$ (right) bending moment at $C$ in normal power

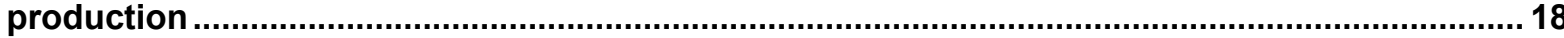

Figure 22. Gearbox and generator stray electrical current in a normal power production case...... 18 Figure 23. High-speed-shaft generator-side-out (left), generator-side-in (middle), and rotor-side (right) stray electrical current in normal power production.

Figure 24. High-speed-shaft generator-side-out (left), generator-side-in (middle), and rotor-side (bottom) bearing outer raceway temperature in normal power production ................................. 19

Figure 25. Gearbox oil water activity (left) and temperature (right) in normal power production.... 20 Figure 26. Gearbox air and dew point temperature difference during normal power production.... 20 Figure 27. Main shaft torque and speed during a normal startup......................................................21

Figure 28. Main bearing axial motion during a normal start-up ................................................... 22

Figure 29. Main bearing generator-side (left) and rotor-side (right) stray electrical current during a normal start-up.

Figure 30. High-speed-shaft generator-side-in (left) and rotor-side (right) bearing roller speed during a normal start-up ......................................................................................................... 23

Figure 31. High-speed-shaft generator-side-in (left) and rotor-side (right) bearing cage speed

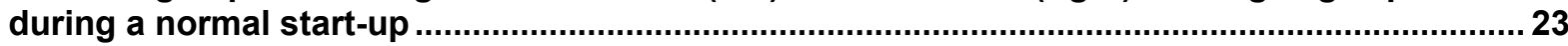

Figure 32. High-speed-shaft torque and speed during a normal shutdown ..................................... 24

Figure 33. Main bearing axial motion during a normal shutdown ................................................. 24 
Figure 34. Main bearing generation-side (left) and rotor-side (right) stray electrical current during a

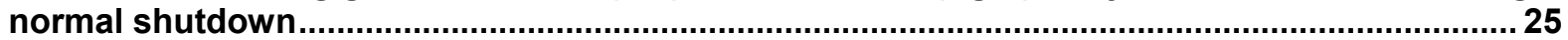

Figure 35. High-speed-shaft generator-side-in (left) and rotor-side (right) bearing roller speed

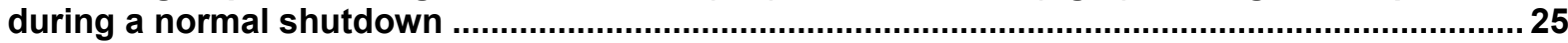

Figure 36. High-speed-shaft generator side-in (left) and rotor-side (right) bearing cage speed

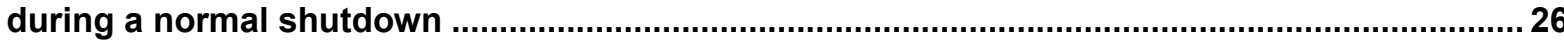

Figure 37. Main shaft torque and speed during an emergency stop.............................................26

Figure 38. Main bearing axial motion during an emergency stop................................................. 27

Figure 39. Main bearing generator-side (left) and rotor-side (right) stray electrical current during an emergency stop

Figure 40. High-speed-shaft generator-side-in (left) and rotor-side (right) bearing roller speed

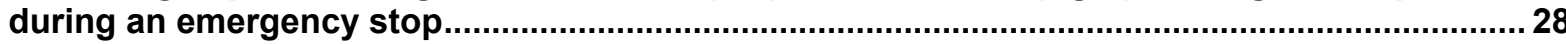

Figure 41. High-speed-shaft generator-side-in (left) and rotor-side (right) bearing cage speed

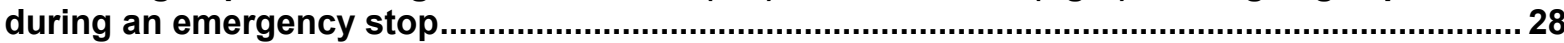

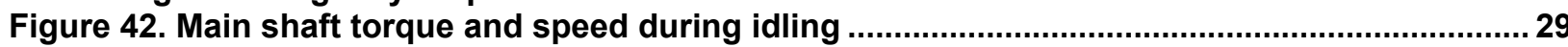

Figure 43. Main bearing axial motion during idling ..................................................................... 29

Figure 44. Main bearing generator-side (left) and rotor-side (right) stray electrical current during idling

Figure 45. High-speed-shaft generator-side-in (left) and rotor-side (right) bearing roller speed

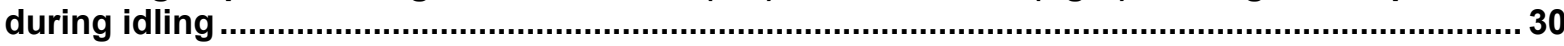

Figure 46. High-speed-shaft generator-side-in (left) and rotor-side (right) bearing roller speed

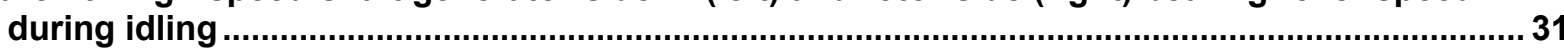

Figure 47. High-speed-shaft torque and speed during a low-voltage ride-through.......................... 32

Figure 48. Main bearing axial motion during a low-voltage ride-through ...................................... 32

Figure 49. Main bearing generator-side (left) and rotor-side (right) stray electrical current during a low-voltage ride-through ....

Figure 50. High-speed-shaft generator-side-in (left) and rotor-side (right) bearing roller speed during a low-voltage ride-through

Figure 51. High-speed-shaft generator-side-in (left) and rotor-side (right) bearing roller speed during a low-voltage ride-through 


\section{List of Tables}

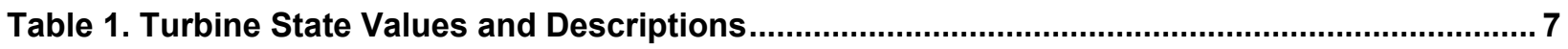

Table 2. Capture Matrix for Normal Power Production ................................................................... 8

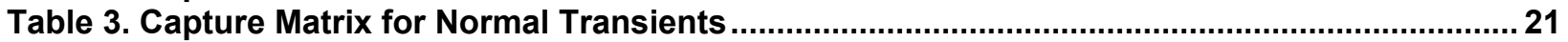

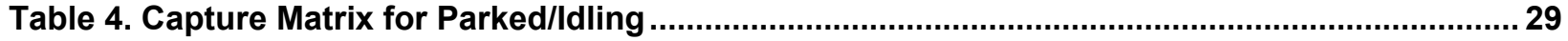

Table 5. Capture Matrix for Low-Voltage Ride-Throughs .......................................................... 31

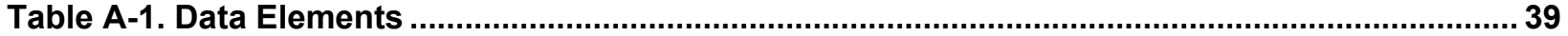




\section{Introduction}

The cost of energy from wind has declined tremendously during the past three decades because of a combination of lower capital costs, higher production, and more efficient operation [1]. However, wind power plant operations and maintenance costs remain an appreciable contributor to the overall cost of wind energy. In 2016, the U.S. Department of Energy (DOE) sponsored a drivetrain reliability workshop led by the National Renewable Energy Laboratory (NREL) and Argonne National Laboratory [2]. The purpose of the workshop was to explore the state of the art in wind turbine drivetrain mechanical system reliability as well as research and development challenges that, if solved, could have significant benefits. Workshop attendees, including many wind plant owners and operators, reported that a significant portion of the wind turbine operation and maintenance costs are related to drivetrain reliability - in particular, continuing premature main bearing and gearbox bearing failures. Specifically related to these failures and highlighted in this drivetrain reliability workshop [2] and other works [3,4] are the importance of main shaft spherical roller bearing (SRB) micropitting wear and the phenomenon of gearbox bearing whiteetch flaking (a.k.a. white-etch cracking [WEC] or axial cracking). Neither of these failure modes are related to classical rolling contact fatigue and are thus not accounted for in current design standards. These failures can occur well before the equipment's predicted design life; for gearbox bearing WECs, after as little as 5\%-20\% [4], and for main bearing wear, after less than 6 years [5]. Although these types of failures have been reported for more than a decade, the conditions leading to them and the reasons for their apparent prevalence in wind turbines is not universally agreed upon.

A multipronged research program supported by DOE at Argonne National Laboratory and NREL is examining the causes of main bearing micropitting wear and WECs in wind turbine gearbox bearings as recommended in the drivetrain reliability workshop report [2]. For each failure mode, the research program strives to:

- Conduct benchtop tests to determine the detrimental physical conditions and mechanisms at the material level that replicate the premature failures [6-11]

- Conduct full-scale wind turbine tests to determine the operations that result in these detrimental physical conditions at the material level within the components of interest [1113]

- Assess the benchtop and full-scale test results and make recommendations for mitigation solutions $[7,13,14]$.

This purpose of this report is to summarize progress in the second step in the research program, conducting full-scale wind turbine tests to determine the operations conducive to premature main bearing wear and gearbox bearing axial cracking failures. The report expands upon previous initial analyses $[12,13]$ and fully describes the series of tests conducted and measurements gathered in the first wind season of testing - from commissioning of the instrumented drivetrain in January 2018 through June 14, 2018. 


\section{Test Article and Instrumentation Overview}

The test article is a specially instrumented, commercial 1.5-megawatt (MW) drivetrain. The instrumented portion of the drivetrain consists of a SKF SRB-Wind main bearing and a Winergy 4410.4 gearbox, described herein. The drivetrain is mounted in a three-point configuration consisting of the main bearing, which largely supports the rotor weight and forces, and the two torque-arms on the gearbox, which react the torque and any rotor moments.

\subsection{Main Bearing}

The main bearing is a new SRB-Wind bearing model BS2-8115/C2H produced by SKF. Although similar to a standard 240/600 double-row series SKF Explorer SRB, its design was updated to optimize internal geometry, use a new cage, provide better sealing and improve lubrication [15]. It is housed in a SKF model HC-Z 7051 BF housing and was first filled with SKF Winter Grade LGWM2 grease in September 2017. The main bearing and associated instrumentation are shown in Figure 1.
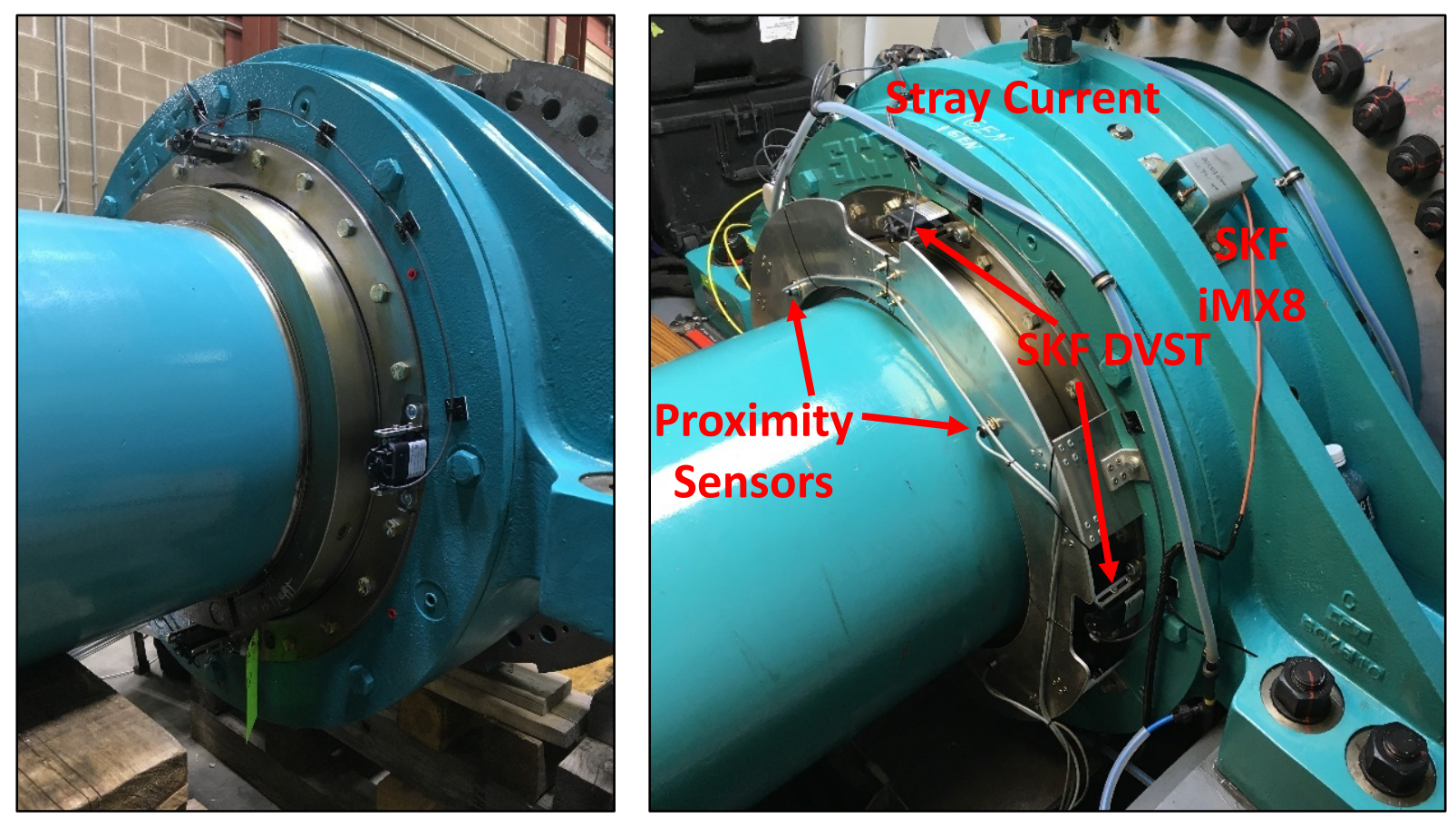

Figure 1. SKF SRB-Wind main bearing (left) and instrumentation (right). Photos by Jonathan Keller and Jerry Hur, NREL 49379 and 49959

Instrumentation on the main bearing comes in three categories: proximity sensors for motion, Rogowski coils for electrical current, and the design verification support tool (DVST) instruments, described as follows. Four inductive sensors spaced around the circumference of a custom frame installed just behind the generator side (GS or position B) row of the main bearing measure the axial motion of the main bearing locknut (and main shaft and inner race of the main bearing) with respect to the bearing housing (and outer race of the main bearing). Combined with the main rotor azimuth, these axial motions can be resolved to account for geometric errors such as out-of-squareness [16]. Rogowski coils attached to the rotor side (RS or position A) and GS of the main bearing housing measure any "stray" electrical current being conducted through the main shaft and main bearing, most likely a result of pitch motors [17]. Separately, a total of eight 
DVSTs, split evenly between the two sides of the main bearing, measure strain, acoustic emission, vibration, and temperature at four locations around the circumference of each bearing row [12]. The main bearing, auxiliary equipment, and some instrumentation was contributed to the project by SKF USA under cooperative research and development agreement (CRADA) CRD-17-702.

\subsection{Gearbox}

The gearbox is a Winergy model PEAB 4410.4 produced by the Flender Corporation. It has a nominal power rating of 1,660 kilowatts $(\mathrm{kW})$. With a gearbox ratio of 78.292 , it increases a main rotor speed of 18.39 revolutions per minute (rpm) to an output shaft speed of 1,440 rpm. The gearbox is composed of a single planetary stage followed by two parallel stages with helical gearing. The test gearbox and main shaft, shown while in storage in Figure 2, were contributed by Flender to the project under CRADA CRD-17-694.
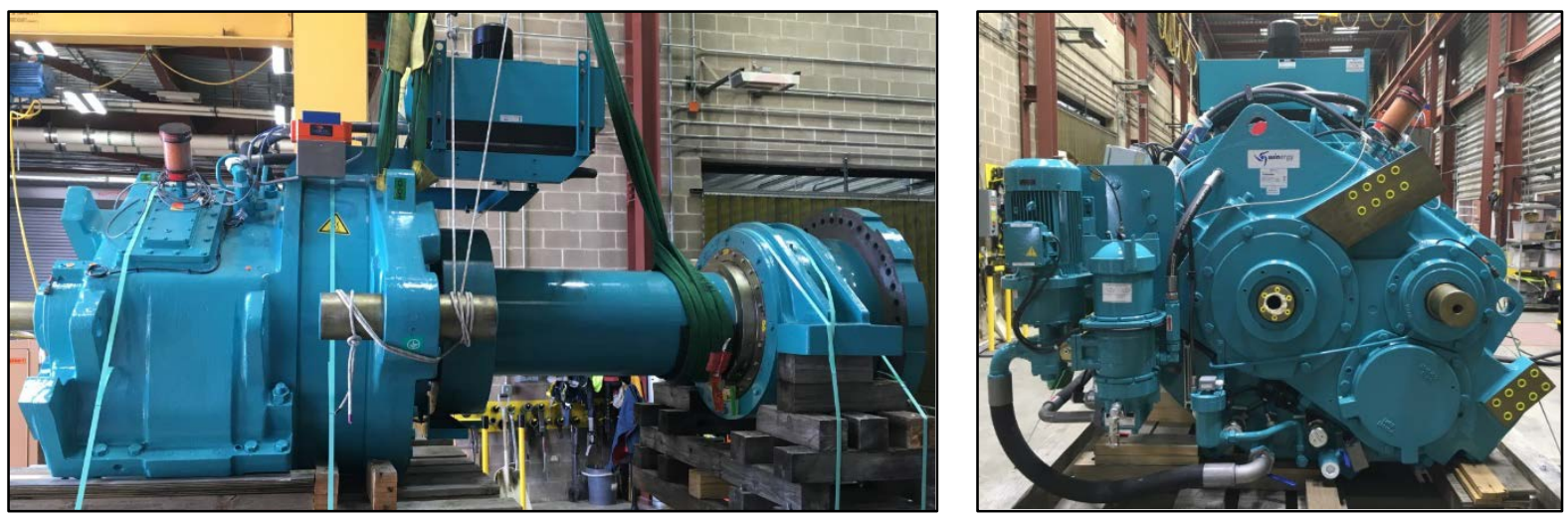

Figure 2. Winergy PEAB 4410.4 gearbox side (left) and rear (right) view. Photos by Jonathan Keller, NREL 49044 and 49045

The primary gearbox instrumentation is focused on the high-speed shaft (HSS) and support bearings [18] as shown in Figure 3. The shaft speed is measured with an encoder, and torque and bending moments are measured with strain gauges. The NU 2326 ECML/L4BC3 and NU 232 ECML/L4BC3 cylindrical roller bearings (CRBs) on the RS (or position "A") and GS inboard (GS-in or position "B") of the pinion, respectively, each have a magnetized roller and patented instrumentation developed by SKF. The bearings and these devices measure rolling element speed [19] and were contributed to the project by SKF GmbH under CRADA CRD-16608. Commercial proximity switches detect the passing of a single metal pin in the cages each cage revolution, thus determining the average cage speeds over the revolution and indicating the precise circumferential position of the magnetized roller. Additional instrumentation measures the tribological environment of the RS and GS-in bearings and the outboard GS (GS-out or position " $C$ ") bearing, including the bearing inner and outer ring temperatures, Amsoil PTN 320 lubricant temperature and water content, air temperature and humidity within the gearbox cavity with respect to the wind turbine nacelle, and any stray electrical current across the bearings. 


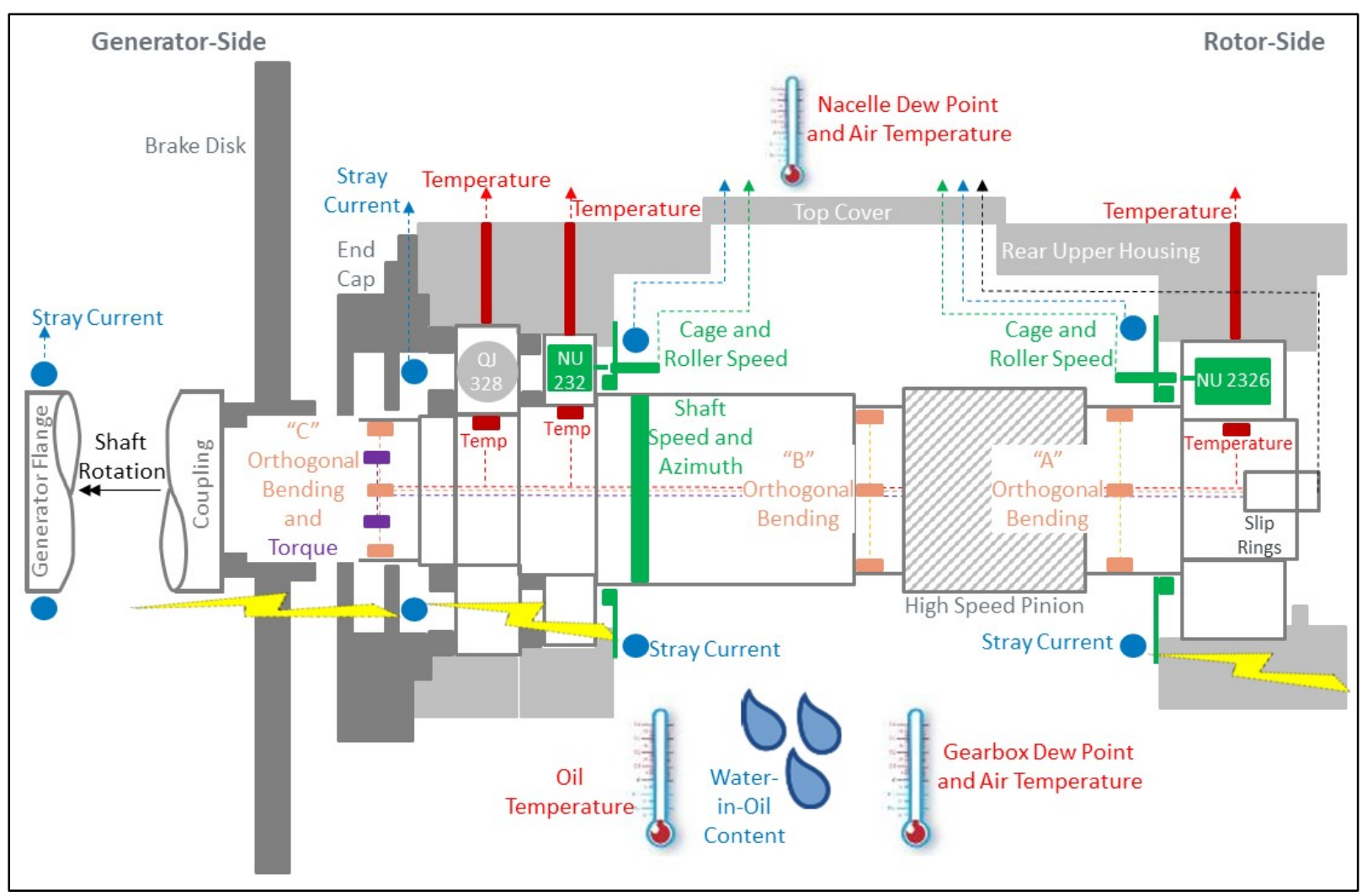

Figure 3. High-speed-shaft instrumentation schematic

The drivetrain data acquisition enclosure is mounted to the right side of the rear upper housing of the gearbox. All the gearbox measurements, plus the main bearing motion measurements and stray electrical current, are collected by this National Instruments-based system. The measurements are time-synchronized with the other collected meteorological and turbine operational parameters described in the next section. These drivetrain data acquisition rates are 1 hertz $(\mathrm{Hz}), 50 \mathrm{~Hz}$, and 5 kilohertz of varying durations, depending on the purpose and measurement of interest.

Finally, a standard SKF IMx-8 condition monitoring system [20] was installed on the drivetrain, measuring vibration at two locations on the main bearing, five on the gearbox, and one on the generator. A Poseidon Trident DM4500 wear debris monitor [21] and two LogiLube SmartGear systems [22] were installed as part of the gearbox lubrication system. Each of these systems records data in their native formats, separate and apart from the data described in this report.

\subsection{Turbine and Meteorological Tower}

DOE installed a General Electric (GE) 1.5-MW wind turbine at the National Wind Technology Center (NWTC) over the winter of 2008 and 2009. This turbine, hereafter referred to as the DOE 1.5 , is an integral part of several research initiatives for the DOE Wind Program and other industry research initiatives. The DOE 1.5 is built on the platform of the GE 1.5 SLE commercial wind turbine model, but was installed in a nonstandard configuration. Therefore, these and other test results may not represent the performance capabilities of other GE 1.5 SLE turbines. Important for this project and others is the fact that the DOE 1.5 is equipped with an ESS Mk 6 controller [12,23]. 
A series of tests were previously conducted to characterize the baseline properties and performance of the DOE 1.5, including mechanical loads per International Electrotechnical Commission 61400-11 in March 2011 [23]. The test program included specially installed instrumentation throughout the turbine and on a meteorological tower in front of the turbine. These measurements from the original test program are in many cases identical to the drivetrain tests described in this report, but important deviations are detailed herein. Routine measurements acquired on the meteorological tower are air temperature, pressure, and humidity; wind speed and direction at several heights, plus nacelle direction, rotor speed, and blade pitch angles; main shaft, tower, and blade loads; turbine power; and several supervisory control and data acquisition (SCADA) channels. A full list of data channels recorded by this system are described in Appendix A. These turbine and meteorological data acquisition rates are $1 \mathrm{~Hz}$ and $50 \mathrm{~Hz}$, also depending on the purpose and measurement of interest. Data at $1 \mathrm{~Hz}$ are collected for 24 hours in duration, while data at $50 \mathrm{~Hz}$ are collected for 10-minute periods. 


\section{Test Program}

After production acceptance testing of the gearbox and instrumentation checkout at the Flender facility in September 2017 [12,18], the gearbox, main bearing, and main shaft were mated together. The assembled drivetrain was delivered to the NWTC on October 18. The exposed instrumentation on the main bearing and gearbox lubrication system were installed after delivery. The existing GE Transportation Services 7GA87E2 gearbox and main bearing were then removed and the new drivetrain was installed on December 16, 2017, as shown in Figure 4. This original drivetrain had produced approximately 6 million kilowatt-hours of energy in 14.17 thousand hours of grid operation time. After an additional maintenance procedure to replace the generator coupling and brake disk assembly, the turbine and new drivetrain were recommissioned on January 5, 2018.
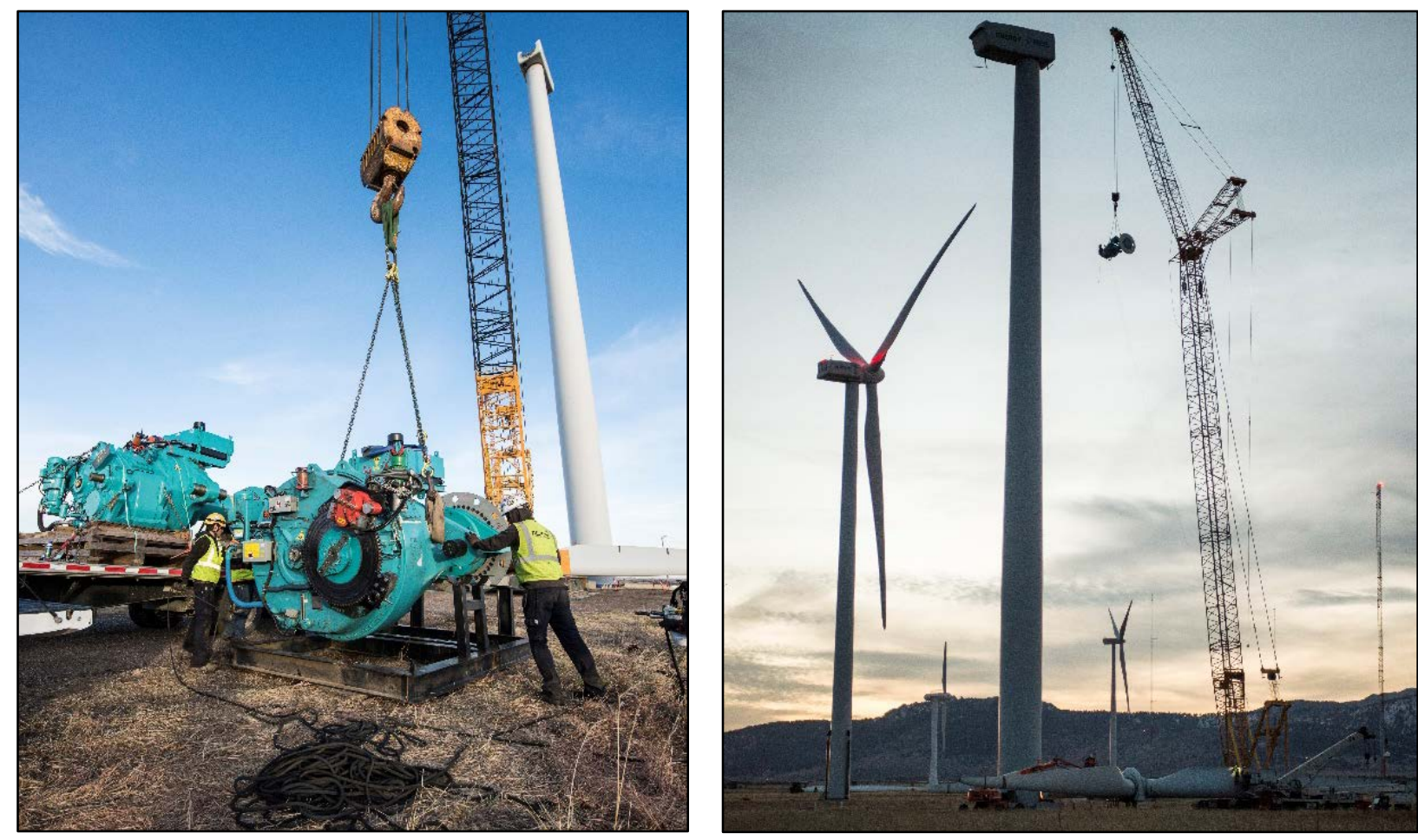

Figure 4. Gearbox swap (left) and installation in turbine (right). Photos by Dennis Schroeder, NREL 49409 and 49413

An additional two weeks were required to install, power, and network connect the drivetrain data acquisition system equipment, with the first gearbox data collection tests occurring on January 18. One additional week was required to reinstall some of the associated turbine data acquisition equipment, with the first tests including measurements from the meteorological tower, other turbine instrumentation, and SKF IMx-8 system occurring on January 25. The first measurements by the SKF DVST and LogiLube systems were acquired February 7. Finally, the main shaft bending and torque measurements were installed on February 13. The tests described in this report then continued through June 14, 2018. During that period, the new drivetrain had produced an additional 0.21 million kilowatt-hours (6.21 kilowatt-hours total) of energy in 290 hours (14.46 thousand hours total) of grid operation time. 


\section{Example Results}

Example results of main bearing and gearbox measurements are described in the following sections for a range of test states. Much like the mechanical loads test report [23], this report divides the test states into normal power production, normal transients, and parked/idling conditions. Additional to this test report are the induced stops, emergency stops, and grid events.

When interpreting the gearbox and main bearing data, determining the turbine operational status is an important consideration. It can be ascertained through some of the recorded SCADA channels described in Appendix A. These SCADA channels are given certain integer values listed in Table 1 depending on operational status of the turbine or fault messages. The table also includes the authors' observation of the meaning of the value based on analysis of the recorded turbine and drivetrain data, including rotor seed, blade pitch angle, and active power. The operational state channel (signal name OPC_OpCt1_TurbineStatus) used in this report is only assigned values between 1 and 11 . The state fault channel includes additional information and can be assigned values between 1 and $1000+x$, where $x$ is the value of a turbine controller message.

Table 1. Turbine State Values and Descriptions

\begin{tabular}{ccc}
\hline Value & Description & Observation \\
\hline 1 & Turbine OK & Turbine not running, grid disconnected \\
2 & Turbine with grid connection & Turbine not running with grid connection \\
3 & Run up/idling & Turbine startup \\
7 & Weather conditions & Normal stop because of high wind \\
9 & Stopped (manual stop, if turbine OK) & Manual stop \\
11 & Emergency stop & Emergency stop \\
$1000+x$ & Event message $\mathrm{x}$ is active & Appears after emergency stop event \\
\hline
\end{tabular}

\subsection{Normal Power Production}

The recorded data files were filtered by the following criteria to identify normal power production cases:

- Main shaft speed $>10.5 \mathrm{rpm}$, equivalent to an HSS speed $>822 \mathrm{rpm}$

- Blade 1 pitch angle $<50^{\circ}$

- Active power $>0 \mathrm{~kW}$.

The resulting capture matrix of simultaneous drivetrain, turbine, and meteorological data during normal power production operation of the turbine is provided in Table 2. The results are binned according to the measured wind speed (signal name OPC_In_WindSpd), from cut-in at 3.5 meters per second (m/s) to cut-out at $25 \mathrm{~m} / \mathrm{s}$ [23], and turbulence intensity (TI). 
Table 2. Capture Matrix for Normal Power Production

\begin{tabular}{|c|c|c|c|c|c|c|c|c|c|c|c|c|c|c|c|c|}
\hline \multicolumn{17}{|c|}{ Wind Speed, m/s } \\
\hline $\mathrm{TI}$ & $3-5$ & $5-6$ & $6-7$ & $7-8$ & $8-9$ & $\begin{array}{c}9- \\
10.5\end{array}$ & $\begin{array}{c}10.5- \\
11.5\end{array}$ & $\begin{array}{c}11.5- \\
12.5\end{array}$ & $\begin{array}{c}12.5- \\
13.5\end{array}$ & $\begin{array}{c}13.5- \\
15.5\end{array}$ & $\begin{array}{c}15.5- \\
17.5\end{array}$ & $\begin{array}{c}17.5- \\
19.5\end{array}$ & $\begin{array}{c}19.5- \\
21.5\end{array}$ & $\begin{array}{c}21.5- \\
23.5\end{array}$ & $\begin{array}{c}23.5- \\
25\end{array}$ & Total \\
\hline$<3 \%$ & 5 & 8 & 6 & 8 & 1 & 4 & 0 & 0 & 0 & 0 & 0 & 0 & 0 & 0 & 0 & 32 \\
\hline $3-5 \%$ & 5 & 9 & 5 & 9 & 3 & 9 & 4 & 1 & 1 & 1 & 0 & 0 & 0 & 0 & 0 & 47 \\
\hline $5-7 \%$ & 6 & 3 & 1 & 4 & 2 & 5 & 2 & 1 & 0 & 1 & 0 & 0 & 0 & 0 & 0 & 25 \\
\hline $7-9 \%$ & 2 & 7 & 8 & 5 & 3 & 5 & 1 & 1 & 1 & 0 & 0 & 0 & 0 & 1 & 0 & 34 \\
\hline $9-11 \%$ & 2 & 1 & 6 & 1 & 2 & 2 & 0 & 0 & 0 & 0 & 0 & 0 & 0 & 1 & 0 & 15 \\
\hline $11-13 \%$ & 1 & 2 & 7 & 5 & 0 & 0 & 2 & 1 & 0 & 0 & 0 & 2 & 0 & 0 & 0 & 20 \\
\hline $13-15 \%$ & 2 & 4 & 3 & 4 & 1 & 2 & 0 & 0 & 0 & 0 & 1 & 0 & 0 & 0 & 0 & 17 \\
\hline $15-17 \%$ & 3 & 4 & 2 & 2 & 1 & 0 & 0 & 0 & 0 & 0 & 0 & 0 & 1 & 0 & 0 & 13 \\
\hline $17-19 \%$ & 1 & 3 & 3 & 1 & 0 & 1 & 0 & 0 & 0 & 0 & 0 & 0 & 0 & 0 & 0 & 9 \\
\hline $19-21 \%$ & 0 & 1 & 0 & 1 & 1 & 0 & 0 & 0 & 0 & 0 & 0 & 0 & 0 & 0 & 0 & 3 \\
\hline $21-23 \%$ & 0 & 2 & 0 & 0 & 0 & 0 & 0 & 0 & 0 & 0 & 0 & 0 & 0 & 0 & 0 & 2 \\
\hline $23-25 \%$ & 0 & 0 & 0 & 0 & 0 & 0 & 0 & 0 & 0 & 0 & 0 & 0 & 0 & 0 & 0 & 0 \\
\hline $25-27 \%$ & 0 & 0 & 1 & 0 & 0 & 0 & 0 & 0 & 0 & 0 & 0 & 0 & 0 & 0 & 0 & 1 \\
\hline $27-29 \%$ & 0 & 1 & 0 & 0 & 0 & 0 & 0 & 0 & 0 & 0 & 0 & 0 & 0 & 0 & 0 & 1 \\
\hline$>29 \%$ & 2 & 0 & 0 & 0 & 0 & 0 & 0 & 0 & 0 & 0 & 0 & 0 & 0 & 0 & 0 & 2 \\
\hline Total & 29 & 45 & 42 & 40 & 14 & 28 & 9 & 4 & 2 & 2 & 1 & 2 & 1 & 2 & 0 & 221 \\
\hline
\end{tabular}


For these recorded normal power production cases, the duration of each data acquisition varies as shown in Figure 5. Note that because of the focus on the drivetrain and the need for data collection at rates up to 5 kilohertz, the data acquisitions described in this report are mostly short in duration. They are not for the typical duration of 10 minutes; except for a few that lasted up to 5 minutes, the majority of the data acquisitions are less than 25 seconds (s) in length.

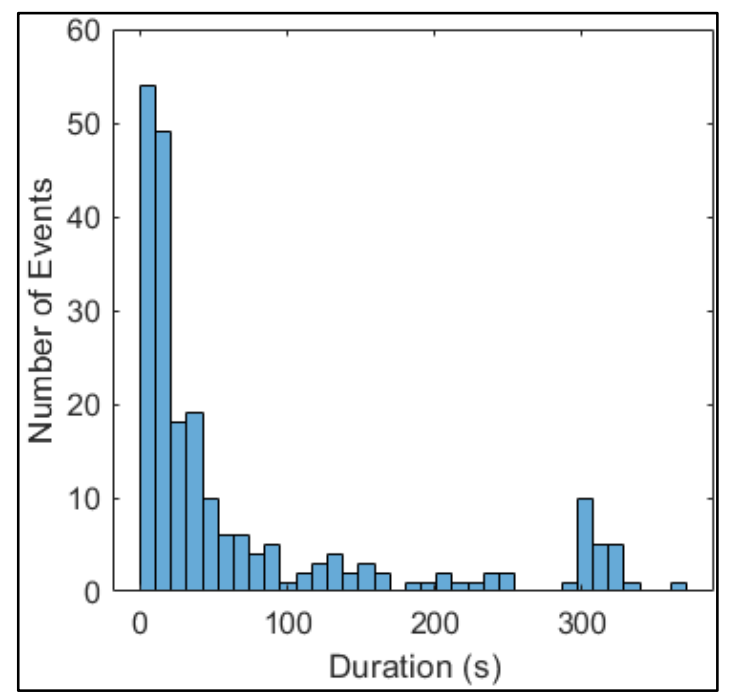

Figure 5. Normal power production data acquisition durations

The statistics for the turbine active power, rotor speed, and blade pitch angle for all the normal power production cases captured are shown in Figure 6. As listed in Table 2, most of the data were measured within a wind speed range from cut-in to the rated wind speed of $14 \mathrm{~m} / \mathrm{s}$ [23], with a few events at wind speeds just below cut-out. Measured power ranged from near zero to as high as $1,800 \mathrm{~kW}$. In the rated wind speed region, the rotor speed ranged from 17 to $19.4 \mathrm{rpm}$, although the average value is the rated rotor speed of $18.39 \mathrm{rpm}$.
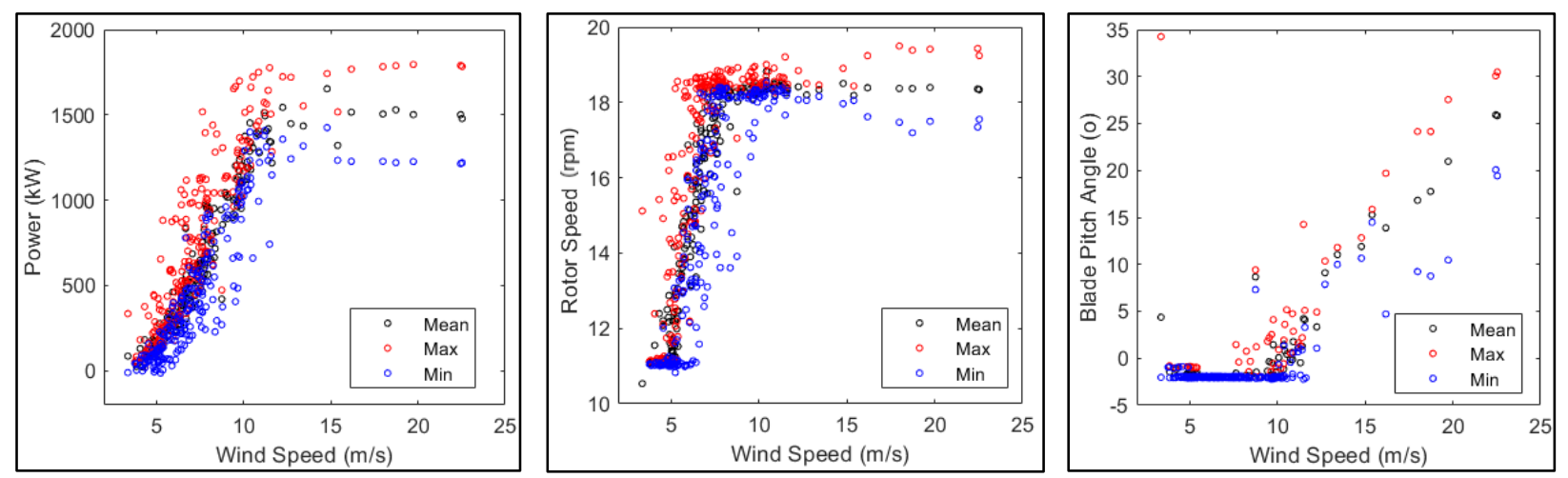

Figure 6. Power (left), rotor speed (middle), and blade pitch angle (right) in normal power production

In the following sections, typical main bearing and gearbox measurements are discussed for these normal power production cases. Both example time series and scatter plots as a function of wind speed near the rotor hub height are examined. 


\subsubsection{Main Bearing Axial Motion Measurements}

Example main bearing proximity probe measurements are shown in Figure 7 (filename "DRC15_fast_2018_04_02_16_42_18.h5"). Each measurement is shown with respect to the time-synchronized main shaft azimuth over multiple revolutions of the shaft. Normal measurement values are less than 1 millimeter $(\mathrm{mm})$. Each measurement does show an excursion from these nominal values to $20 \mathrm{~mm}$. This excursion is a result of a slot in the locknut, visible in Figure 1, and is not meaningful in and of itself. Because the probes are $90^{\circ}$ apart, this excursion occurs at approximately $35^{\circ}, 125^{\circ}, 215^{\circ}$, and $305^{\circ}$ azimuth values for probes $1,2,3$, and 4 , respectively. To make the proximity probe measurements more useful, the excursions can be selectively filtered out by using a window around these azimuths up to $30^{\circ}$ in width. The resulting filtered signals are also shown in Figure 7.
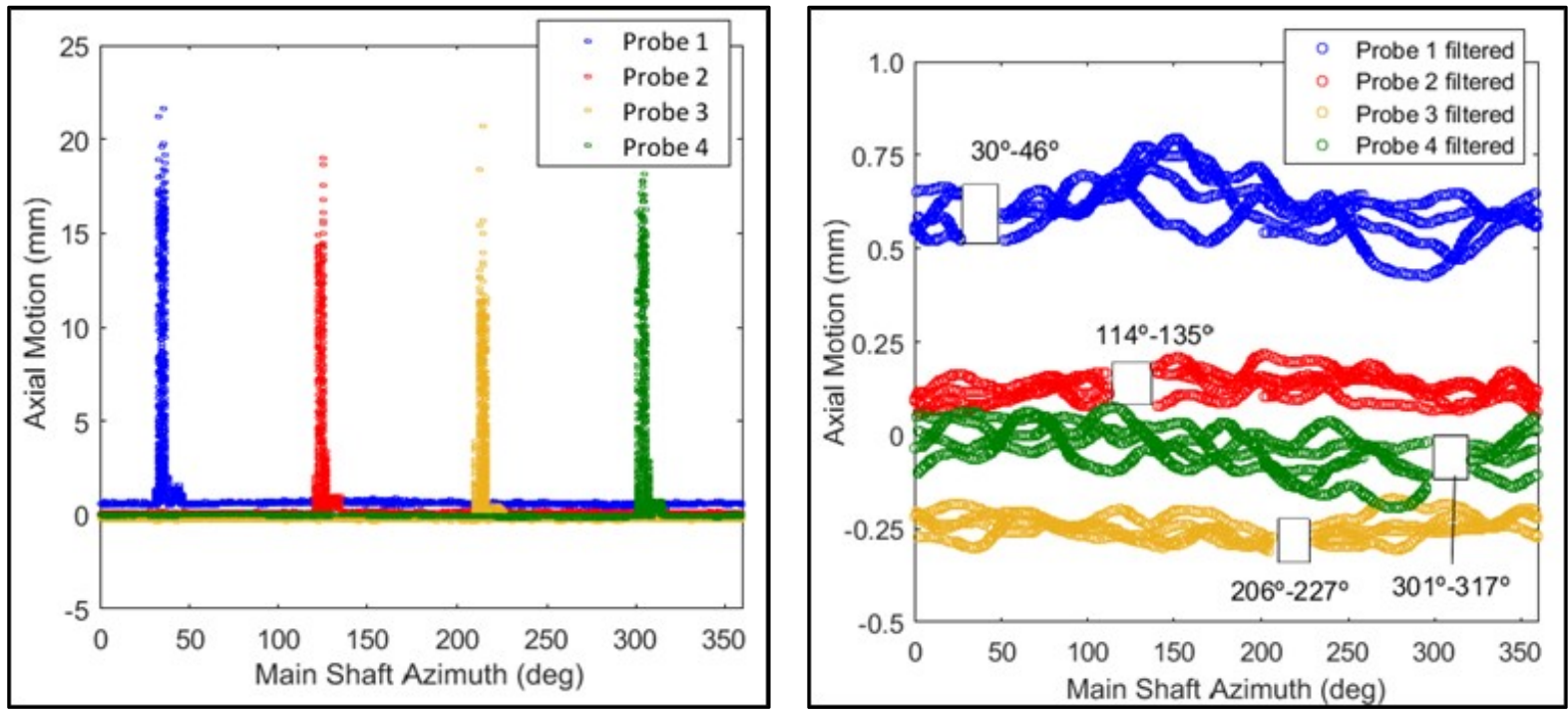

Figure 7. Main bearing proximity probe raw (left) and filtered (right) measurements in a normal power production case

The filtered time-history data from each probe were further smoothed by applying a $0.1 \mathrm{~s}$ (500 point) moving average to remove short-term fluctuations. The net axial motion of the main bearing is then the instantaneous average of the smoothed time histories of each probe, excluding the periods where the filter has been applied to any probe. The descriptive statistics for the maximum, minimum, and mean of main bearing net axial motion across the range of normal power cases is shown in Figure 8. The net axial motion generally follows the same shape as the thrust curve for the turbine, with the maximum axial displacement occurring at the rated wind speed. Overall, the main bearing moves downwind (i.e., the distance decreases as the bearing moves closer to the probe) over $1 \mathrm{~mm}$ from its central resting position at very low wind speeds or in idling conditions to its position at the rated wind speed. The correlation between the range of motion and the turbulence intensity for each wind speed is being investigated. 


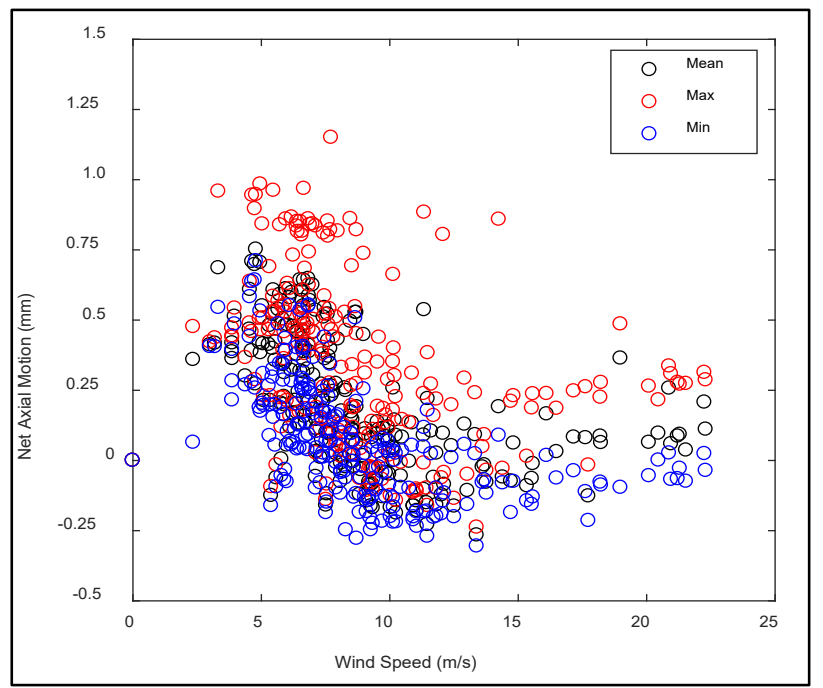

Figure 8. Main shaft net axial motion in normal power production

\subsubsection{Main Bearing Electrical Current Measurements}

Example time histories of stray electrical currents measured on both sides of the main bearing are shown in Figure 9 (filename "DRC15_fast_2018_04_02_16_42_18.h5"). In general, these measurements exhibited noncontinuous, near-symmetric time-varying oscillations of current on the order of tens to hundreds of milliampere (mA).
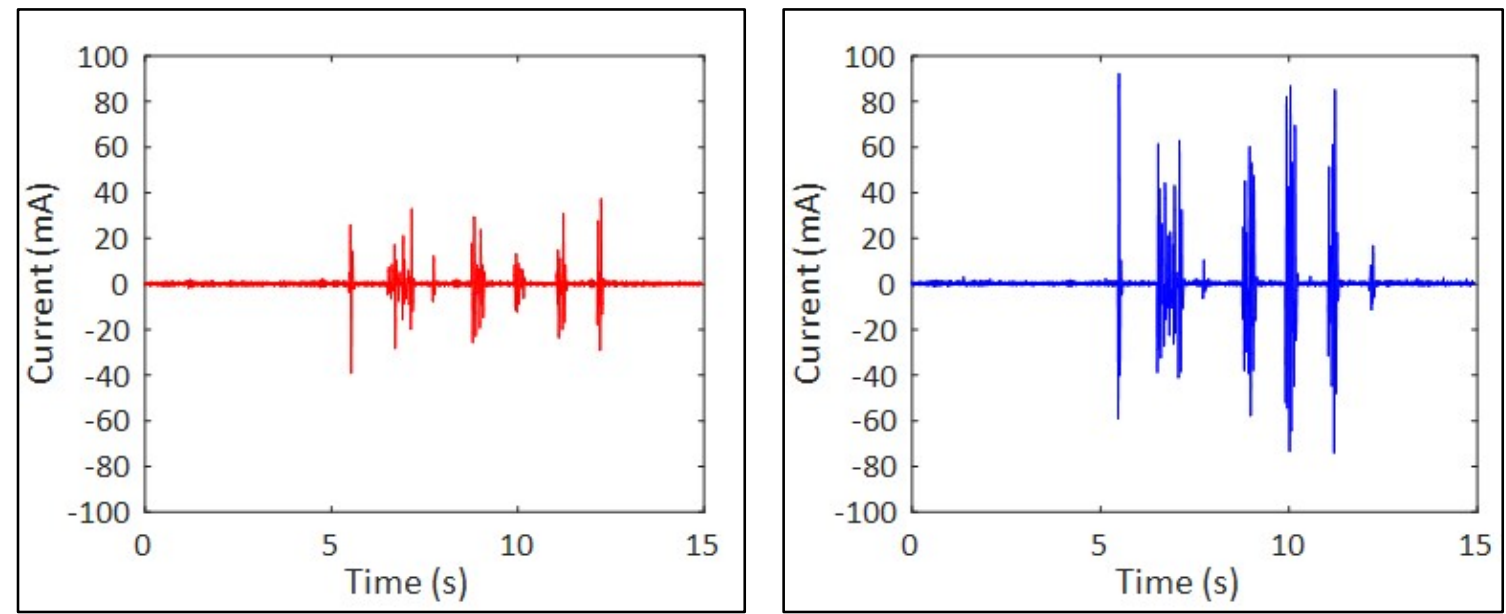

Figure 9. Main bearing generator-side (left) and rotor-side (right) electrical current in a normal power production case

The descriptive statistics for the maximum, minimum, and root-mean-square (RMS) level of main bearing electrical current across the range of normal power cases is shown in Figure 10. The correlation between these measurements and blade pitch motor activity [17] or other parameters is being investigated; however, the largest currents up to almost $800 \mathrm{~mA}$ were observed on the RS Rogowski coil in the variable speed operating region for the turbine from 3 to $14 \mathrm{~m} / \mathrm{s}$. The measurements on the GS coil are similar, but lower in magnitude. The RMS current is on the order of $10 \mathrm{~mA}$ because of the noncontinuous nature of the measurement as seen in Figure 9. 

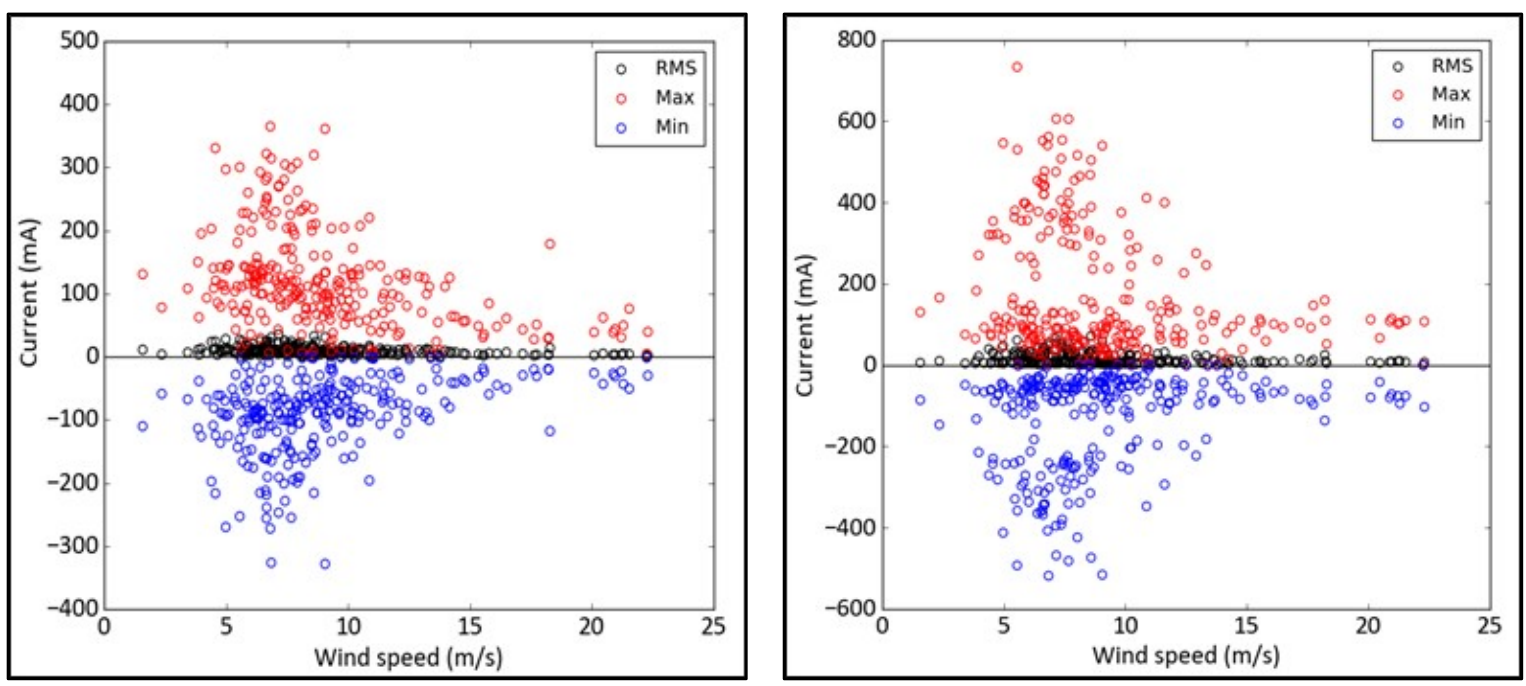

Figure 10. Main bearing generator-side (left) and rotor-side (right) stray electrical current in normal power production

\subsubsection{Gearbox High-Speed Shaft Cylindrical Roller Bearing Speed Measurements}

Example 5-second time histories of the rotational speed of the rollers in the CRBs supporting the HSS are shown in Figure 11. Three different wind speed cases, $5 \mathrm{~m} / \mathrm{s}, 9 \mathrm{~m} / \mathrm{s}$, and $12 \mathrm{~m} / \mathrm{s}$, are shown (filenames "DRC15 fast_2018_04_06_17_56_34.h5", "DRC15 fast_2018_04 10_19_20_45.h5", and "DRC15_fast_Normal power_1500KW2018_03_04_21_55_27.h5"). As expected, the measured roller speeds increase as the wind speed, drivetrain speed, and torque increase. In each case, the roller speeds exhibit roughly a sinusoidal behavior, in which the maximum roller speed is reached when the roller is in the bearing load zone. In this situation, it achieves a pure rolling condition as evidenced by the measured speed reaching the theoretical speed for the pure rolling condition. The maximum roller speed for the $12 \mathrm{~m} / \mathrm{s}$ and $9 \mathrm{~m} / \mathrm{s} \mathrm{cases}$ reach the speed for pure rolling, while for $5 \mathrm{~m} / \mathrm{s}$ it only reaches two-thirds of that value. As the rollers leave the load zone, they decelerate and the minimum roller speed typically occurs just prior to them re-entering the bearing load zone.
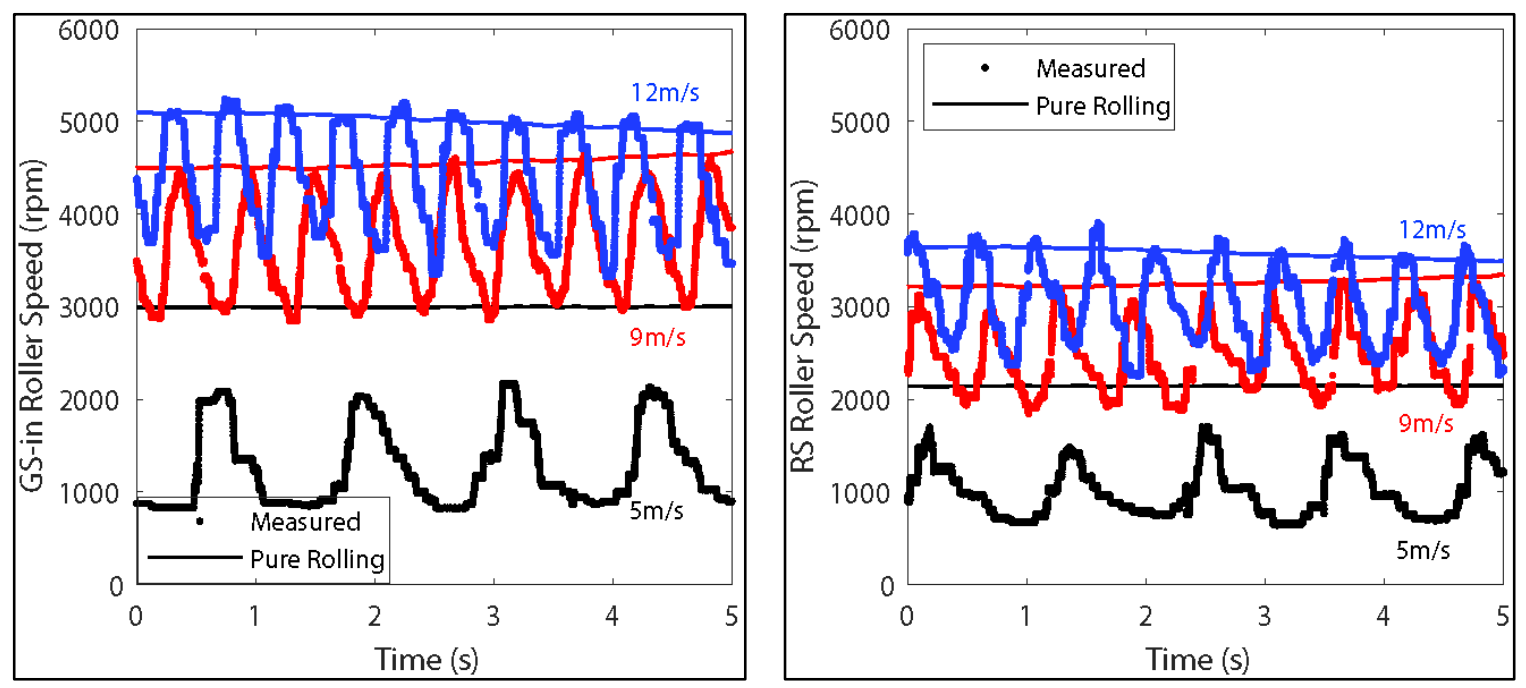

Figure 11. High-speed-shaft generator-side-in (left) and rotor-side (right) bearing roller speed in normal power production cases 
Example time histories of both CRB cage speeds are shown in Figure 12 for the same conditions. In each case, the measured cage speed is nearly constant, as the measured HSS speed that determines the cage speed in pure rolling conditions is also nearly constant. The measured cage speed at $12 \mathrm{~m} / \mathrm{s}$ wind speed is almost exactly equal to the theoretical speed, whereas the measured cage speed at $9 \mathrm{~m} / \mathrm{s}$ is slightly less than the speed for pure rolling conditions. In contrast, the measured cage speed at $5 \mathrm{~m} / \mathrm{s}$ wind speed is about two-thirds of the speed for pure rolling conditions. Like the roller speed results in Figure 11, this indicates that significant sliding of the rollers is occurring even within the bearing load zone.
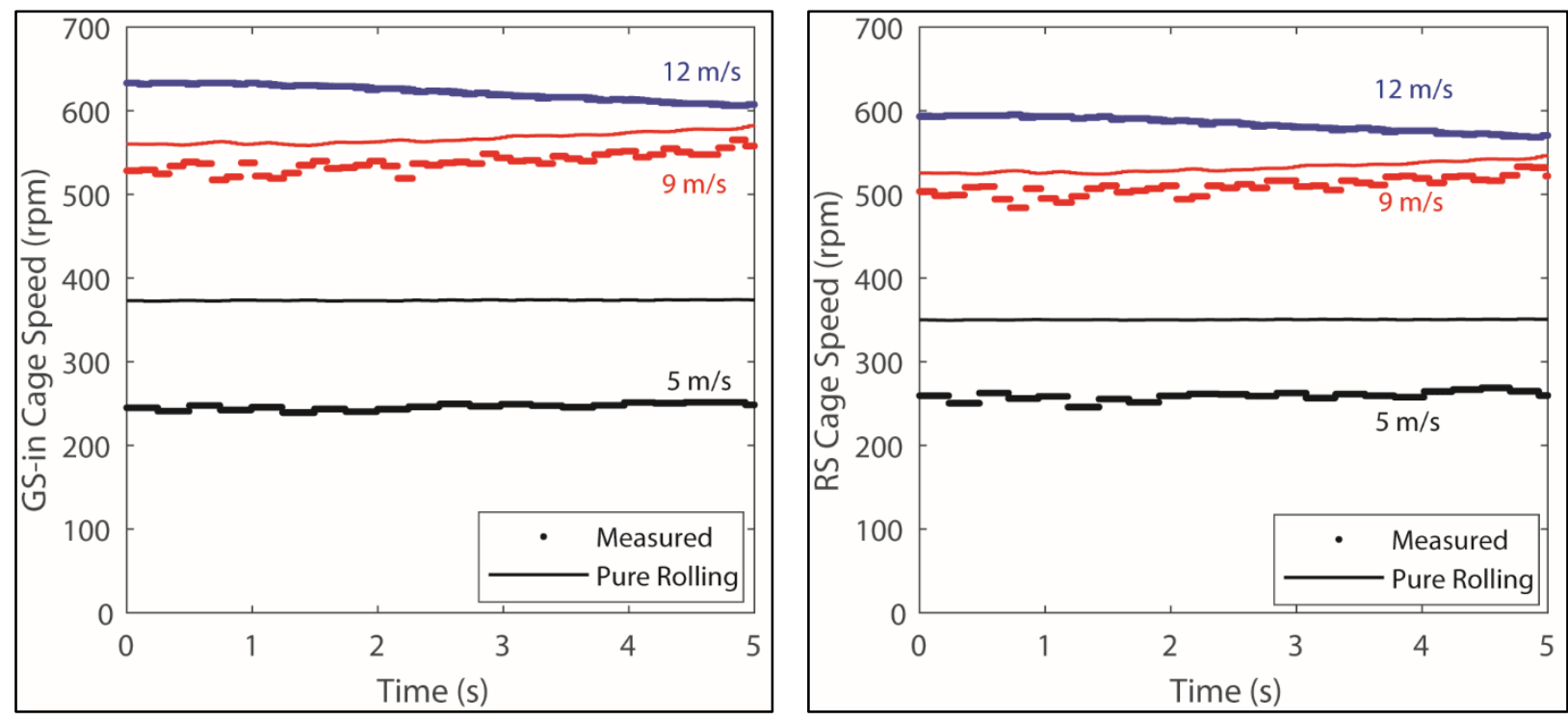

Figure 12. High-speed-shaft generator-side-in (left) and rotor-side (right) bearing cage speed in normal power production cases

The bearing roller speeds can also be examined as they proceed around the circumference of the bearing with the cage as shown in Figure 13 to Figure 15. The orientation of the figure is viewed from the generator looking upwind toward the rotor with the rollers and cage rotating around the circumference in the counterclockwise direction. The applied forces to the bearing consist of a combination of the weight of the shaft, pointing downward, and the gear mesh force, pointing to the right for this gearbox [18]. For medium and higher load cases, the center of the bearing load zone points to the right at an azimuth of $270^{\circ}$, whereas for the lowest load cases gravity makes a greater contribution than the gear mesh force and the load zone points downward and to the right. The measured speeds from the uptower tests can be compared to the theoretical values for pure rolling conditions and the measurements acquired during previous production acceptance testing [18], which was conducted in steady-state conditions at three different drivetrain speeds and power settings. At the lowest $900 \mathrm{rpm}$ and $257 \mathrm{~kW}$ setting shown in Figure 13, the measured roller speeds are much slower than the theoretical values, suggesting that every roller is sliding, even when the rollers are in the middle of the load zone. 

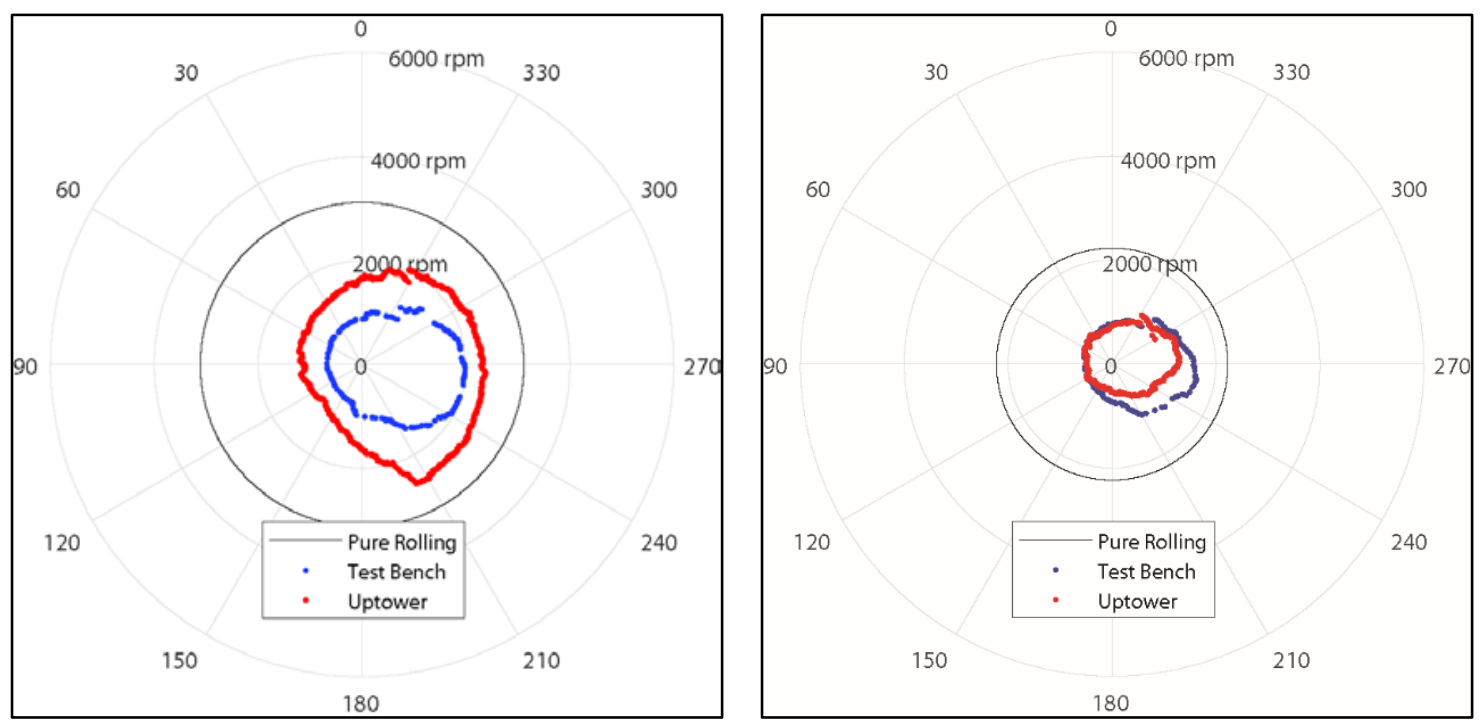

Figure 13. High-speed-shaft generator-side-in (left) and rotor-side (right) bearing roller speeds at $900 \mathrm{rpm}$ and $257 \mathrm{~kW}$

At the mid 1,220 rpm and $600 \mathrm{~kW}$ condition shown in Figure 14, the measured roller speeds briefly approach the theoretical values at the center of the load zone; however, aside from this point, the speeds are slower and indicate sliding in the rest of the load zone. There is also good correlation between the production acceptance and uptower test results, especially for the RS bearing.
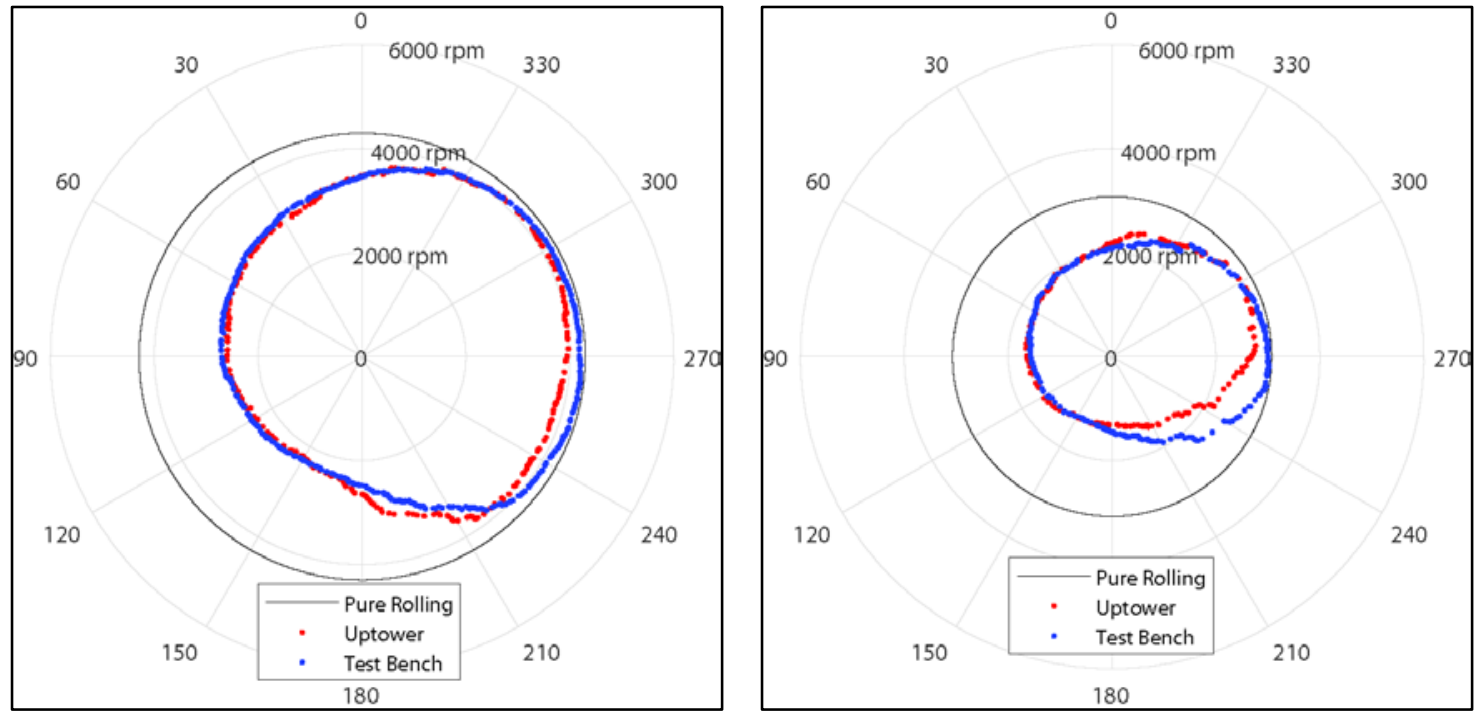

Figure 14. High-speed-shaft generator-side-in (left) and rotor-side (right) bearing roller speeds at $1,220 \mathrm{rpm}$ and $600 \mathrm{~kW}$

At the rated speed and power condition shown in Figure 15, the rollers are in pure rolling conditions for the almost the entire width of the load zone, which extends from approximately $195^{\circ}$ to $345^{\circ}$. As the rollers leave the load zone near $345^{\circ}$, they slowly decelerate until they reach the re-entry to the load zone near $195^{\circ}$. The roller acceleration at the entrance to the load zone is very evident. The correlation between the test bench results and the uptower measurements is also very good for both bearings. 

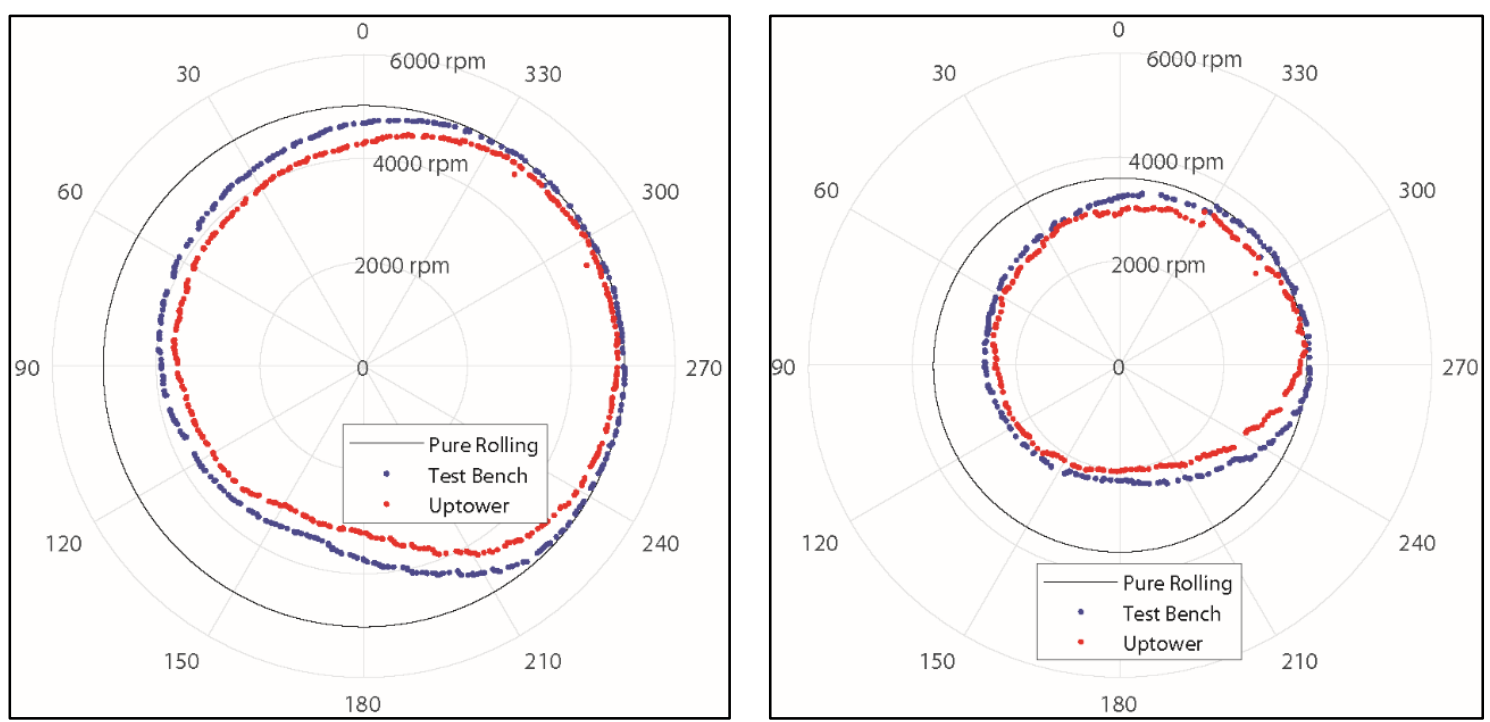

Figure 15. High-speed-shaft generator-side-in (left) and rotor-side (right) bearing roller speeds at rated speed and power

The maximum, mean, and minimum values of the roller and cage speeds for the GS-in and RS bearings across all the normal power cases are shown in Figure 16 and Figure 17, respectively. As shown in Figure 16, the maximum measured roller speed values do achieve pure rolling conditions relatively quickly, except for the very slowest wind speed conditions of less than 5 $\mathrm{m} / \mathrm{s}$. Because the measured rotor speed frequently exceeds the rated rotor speed, as shown in Figure 6, the maximum measured roller speed also exceeds the value assumed for rated conditions. The minimum roller speed is typically three-fifths $(60 \%)$ of the pure rolling condition at more than $8 \mathrm{~m} / \mathrm{s}$ wind speed; however, it decreases to approximately one-third (33\%) at the slowest wind speeds.
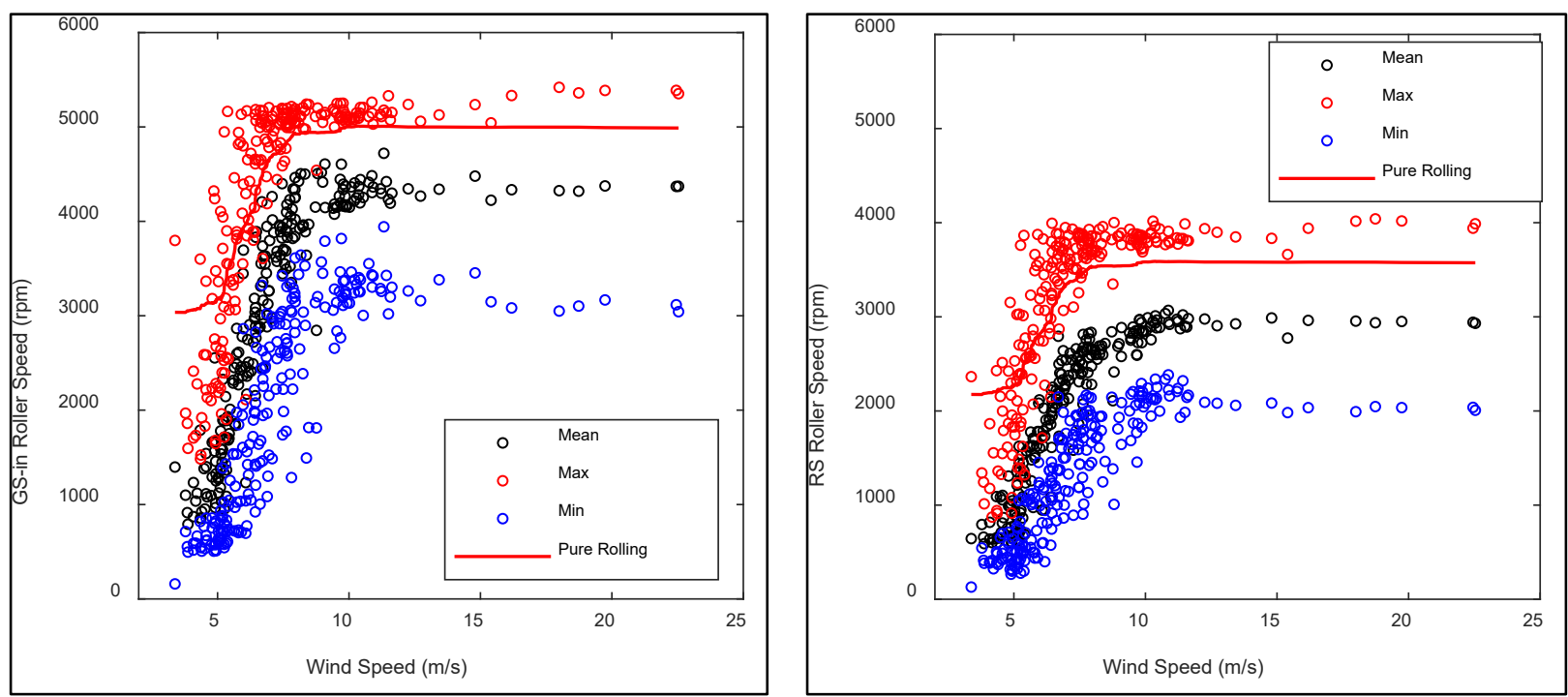

Figure 16. High-speed-shaft generator-side-in (left) and rotor-side (right) bearing roller speed in normal power production 
As shown in Figure 17, the measured cage speed typically matches the speed for pure rolling conditions when the wind speed is more than $8 \mathrm{~m} / \mathrm{s}$. However, at less than this wind speed, the cage speed decreases and the amount of sliding in the roller set increases.
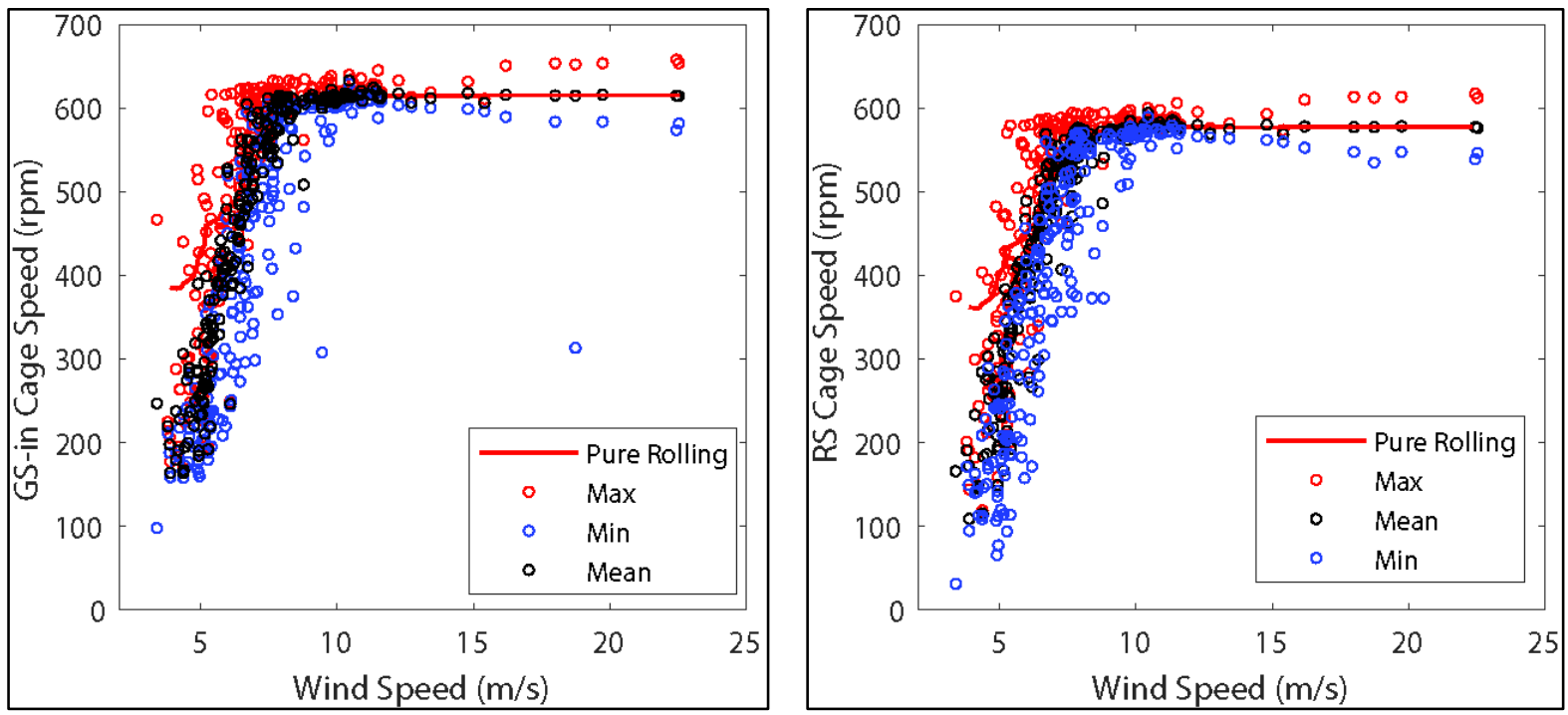

Figure 17. High-speed-shaft generator-side-in (left) and rotor-side (right) bearing cage speed in normal power production

\subsubsection{Gearbox High-Speed Shaft Load Measurements}

The HSS torque and bending moments are presented in this section, calculated from calibration measurements acquired from bench testing [18]. The processed statistics for the HSS torque from the normal power production cases are shown in Figure 18. Unfortunately, the torque and bending moments became increasingly dominated by noise, likely because of degradation of the slip ring or associated wiring during the test period. By the beginning of March, interpretation of a single value or a time history of these signals is no longer possible as the maximum values are many times the rated values. After April, the maximum values have become saturated by noise.

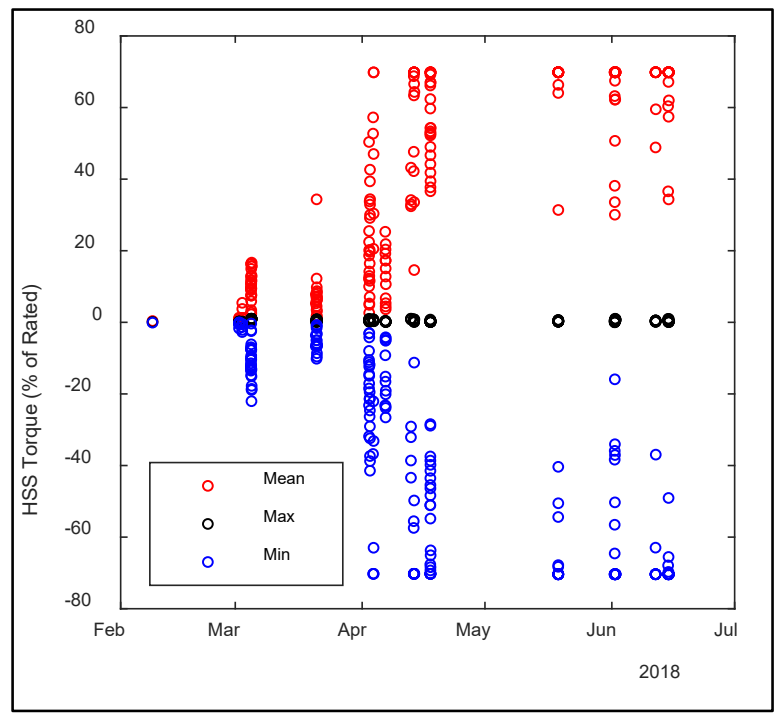

Figure 18. Unfiltered high-speed-shaft torque in normal power production 
Various physical troubleshooting steps have to date been unsuccessful in removing the signal noise. However, various signal filters have been applied to yield some reasonable HSS torque and bending moment results. Figure 19 shows the same torque statistics after a 1-Hz low-pass filter and moving mean was applied. The filtered torque increases with wind speed from cut-in to $12 \mathrm{~m} / \mathrm{s}$ at which point it reaches its rated value of slightly more than 10 kilonewton-meter $(\mathrm{kNm})$.

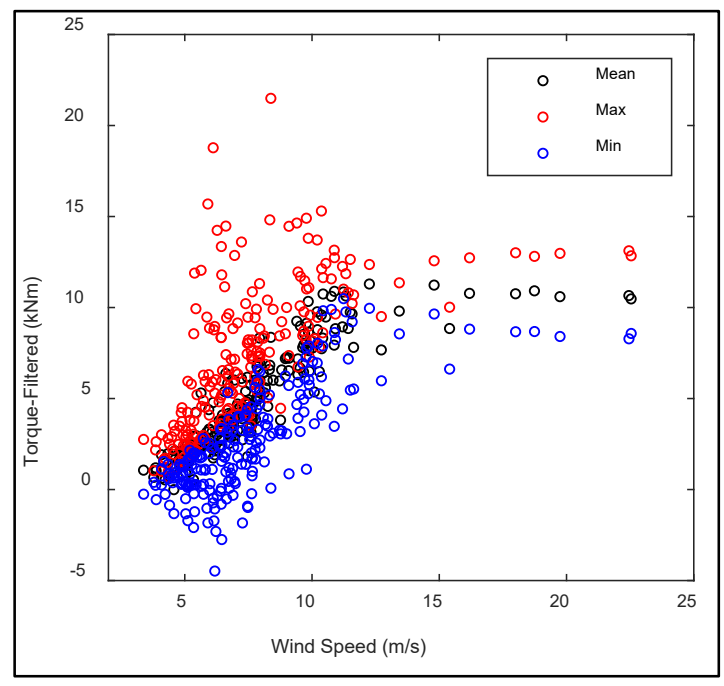

Figure 19. Filtered high-speed-shaft torque in normal power production

Applying the same low-pass filter to the bending moments yields the statistics shown in Figure 20 and Figure 21 for two other locations on the HSS, in the fixed coordinate system. Similar to the bearing designations of $\mathrm{A}$ through $\mathrm{C}$, the terminology $\mathrm{A}, \mathrm{B}$, and $\mathrm{C}$ has been used to indicate the location of the bending moments from the RS to the GS. The A and B strain gauges are just upwind and downwind of the HS pinion, while the $\mathrm{C}$ strain gauges are just downwind of the GSout bearing. As shown in Figure 20 for the B strain gauges, the torque and the resulting tangential component of the gear mesh force result in a clear negative moment about the vertical (Z) direction and very little moment about the lateral (Y) direction.
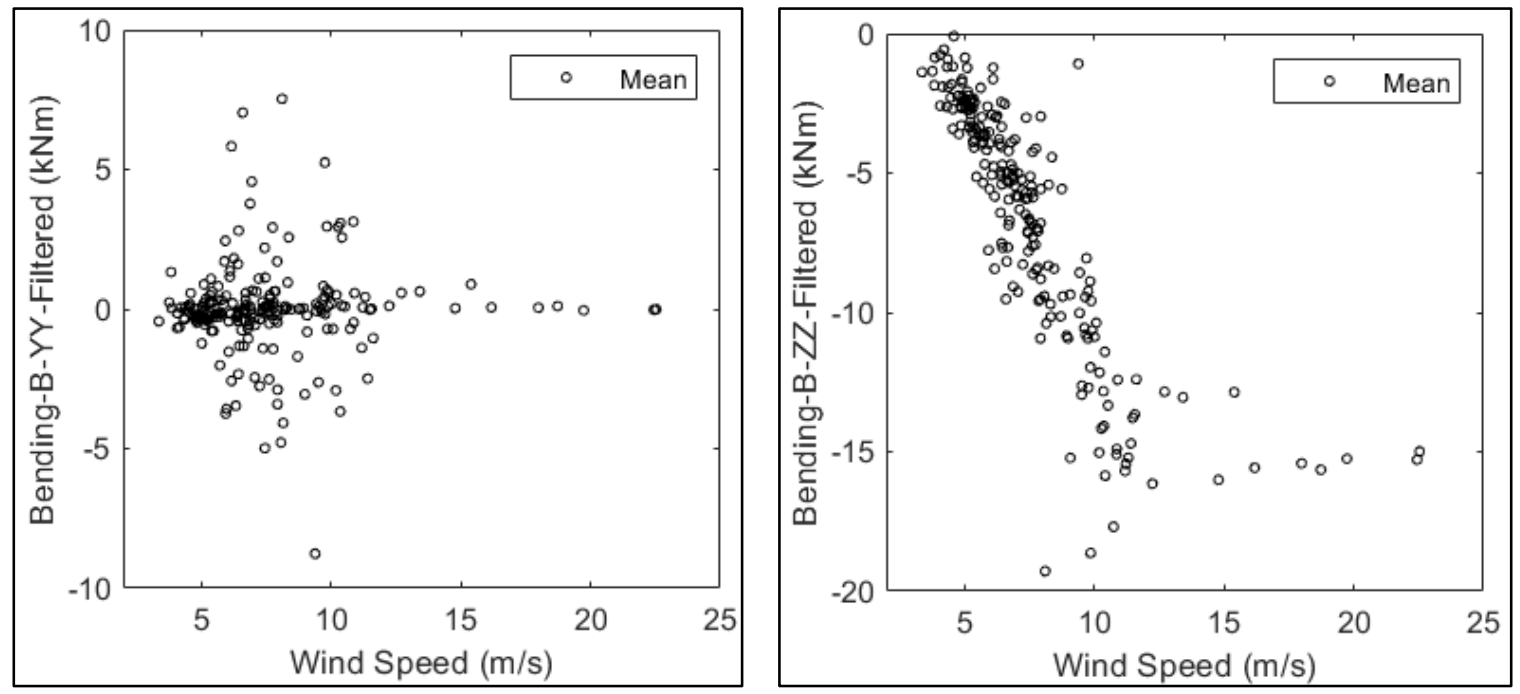

Figure 20. Filtered high-speed-shaft $Y$ (left) and $Z$ (right) bending moment at $B$ in normal power production 
As shown in Figure 21, the bending moments at $\mathrm{C}$ are far fewer than the bending moments at $\mathrm{B}$. Because the $\mathrm{C}$ strain gauges are downwind of the GS-out bearing, they are not influenced by the gear mesh force. Instead, they only experience moments induced from motion of the gearbox and the generator coupling stiffness.
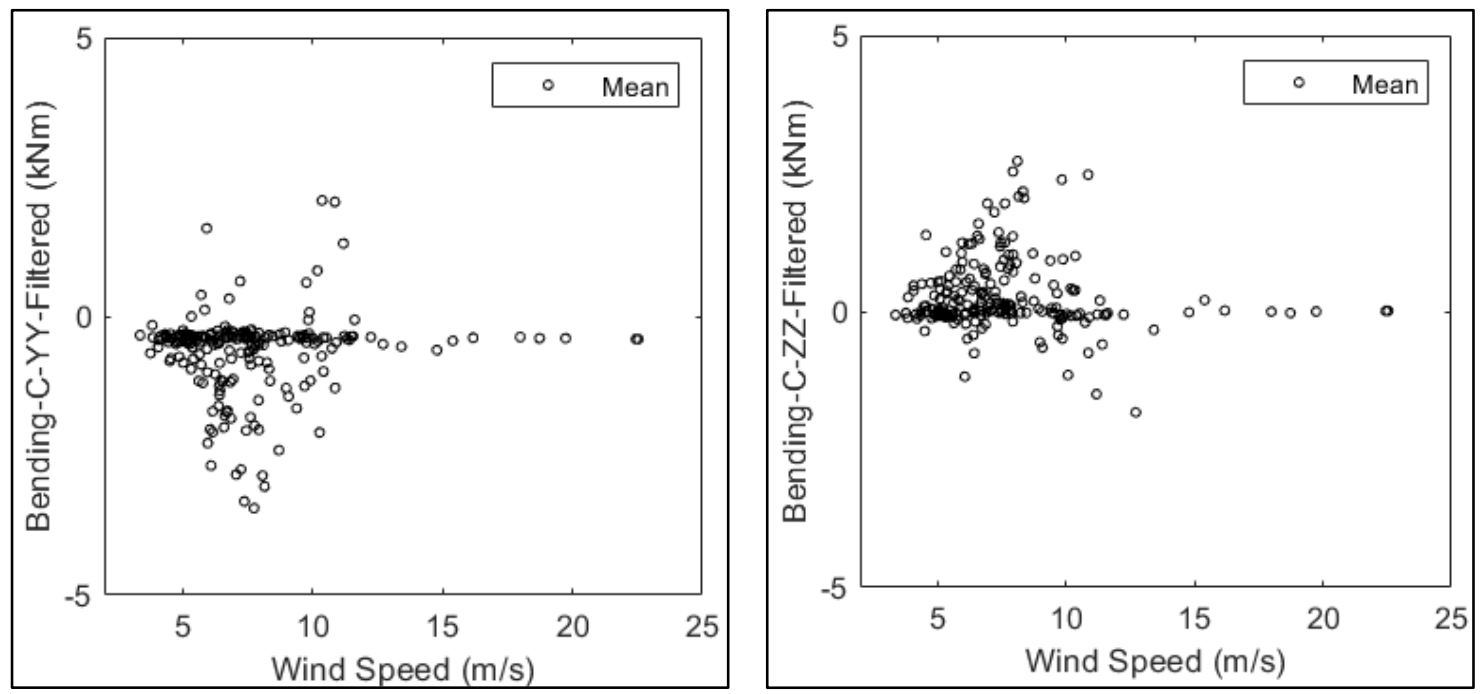

Figure 21. Filtered high-speed-shaft $Y$ (left) and $Z$ (right) bending moment at $C$ in normal power production

\subsubsection{Gearbox Electrical Current Measurements}

Example time histories of stray electrical currents measured in the gearbox are shown in Figure 22 (filename "DRC15 fast_2018_04_02_16_42_18.h5"). In general, these measurements exhibit a different behavior than the main bearing electrical currents shown in Figure 9. For the electrical current measurements, location $\mathrm{A}$ is just upwind of the pinion, location $\mathrm{B}$ is just upwind of the GS-in bearing, and location $\mathrm{C}$ is just downwind of the GS-out bearing. The current measured at location $\mathrm{C}$ is up to $1,000 \mathrm{~mA}(1 \mathrm{~A})$. Electrical currents at locations $\mathrm{A}$ and $\mathrm{B}$ are much lower.

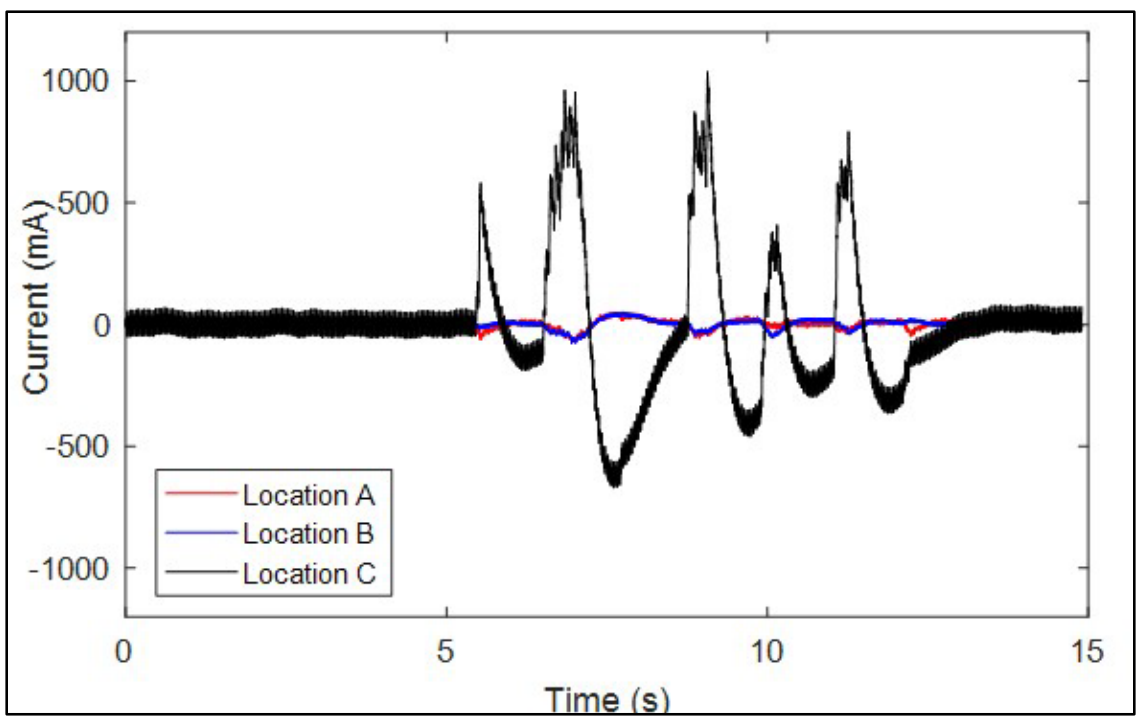

Figure 22. Gearbox and generator stray electrical current in a normal power production case 
The descriptive statistics for the maximum, minimum, and RMS level of gearbox electrical current at each location across the range of normal power cases is shown in Figure 23. The correlation between these measurements' other parameters is being investigated; however, the largest currents up to $1.5 \mathrm{~A}$ were observed in the variable speed operating region for the turbine from 3 to $12 \mathrm{~m} / \mathrm{s}$.
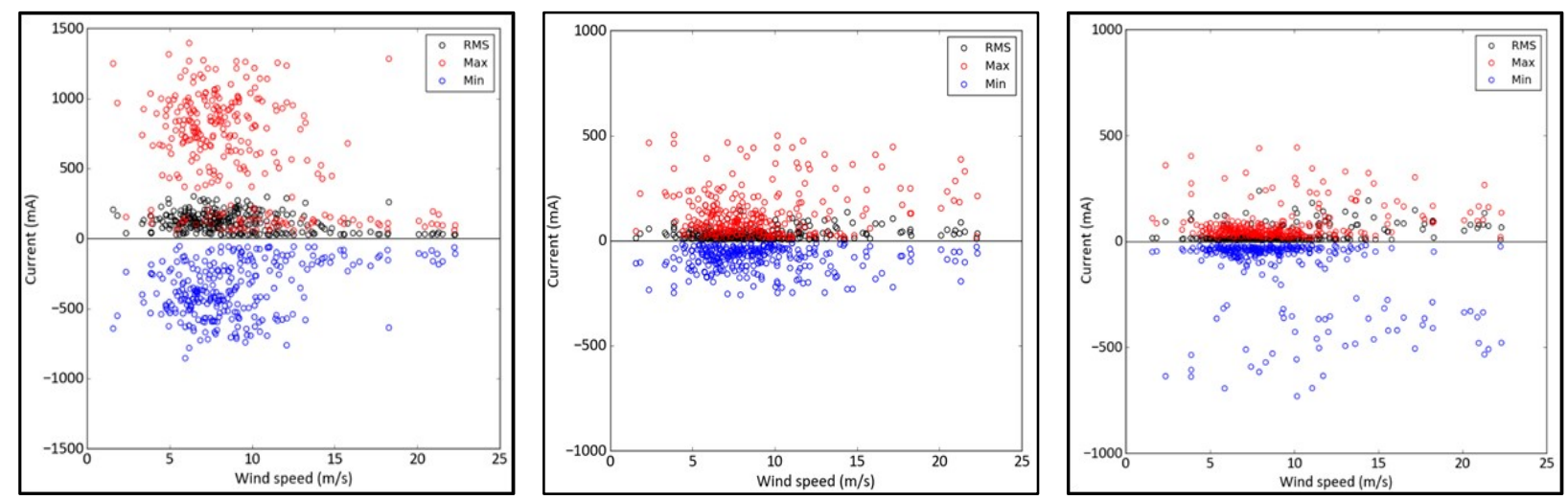

Figure 23. High-speed-shaft generator-side-out (left), generator-side-in (middle), and rotor-side (right) stray electrical current in normal power production

\subsubsection{Gearbox Temperature Measurements}

The gearbox bearing and air temperature measurements are presented in this section. Like the load measurements, the HSS CRB inner ring measurements became increasingly dominated by noise after January because they are transmitted by the same slip ring. However, the outer ring measurements shown in Figure 24 are acquired by contact probes and provide useable results for the entire test period. Like the speed and loading behavior of the bearings, the temperatures follow the same behavior as the power curve. The maximum temperature of the outer ring for each bearing is less than $70^{\circ} \mathrm{C}$. The lowest bearing temperatures are approximately $25^{\circ} \mathrm{C}$, occurring just after cold starts in the early portions of the test in January through March.
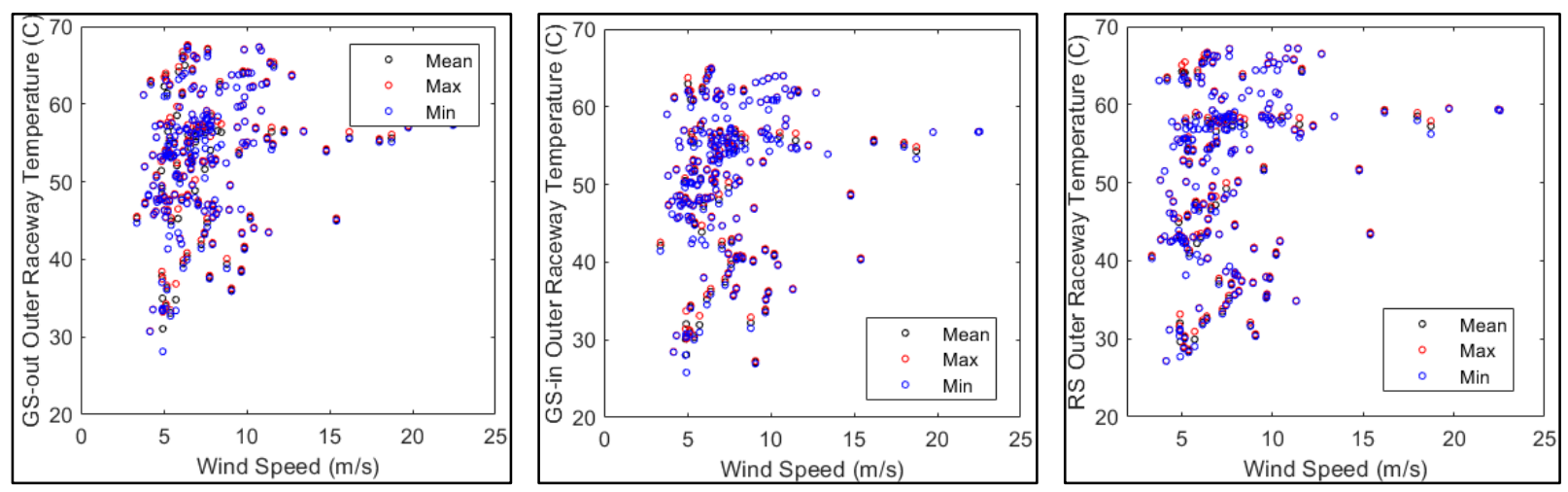

Figure 24. High-speed-shaft generator-side-out (left), generator-side-in (middle), and rotor-side (bottom) bearing outer raceway temperature in normal power production

The gearbox water activity, a measure of the amount of water in the gearbox oil supply, is shown in Figure 25. The measured water activity was less than 0.2 for the entire test period, indicating that the oil has little dissolved water content. Oil temperatures ranged from quite cold conditions as low as $15^{\circ} \mathrm{C}$ after startups in the winter months to as high as $65^{\circ} \mathrm{C}$. 

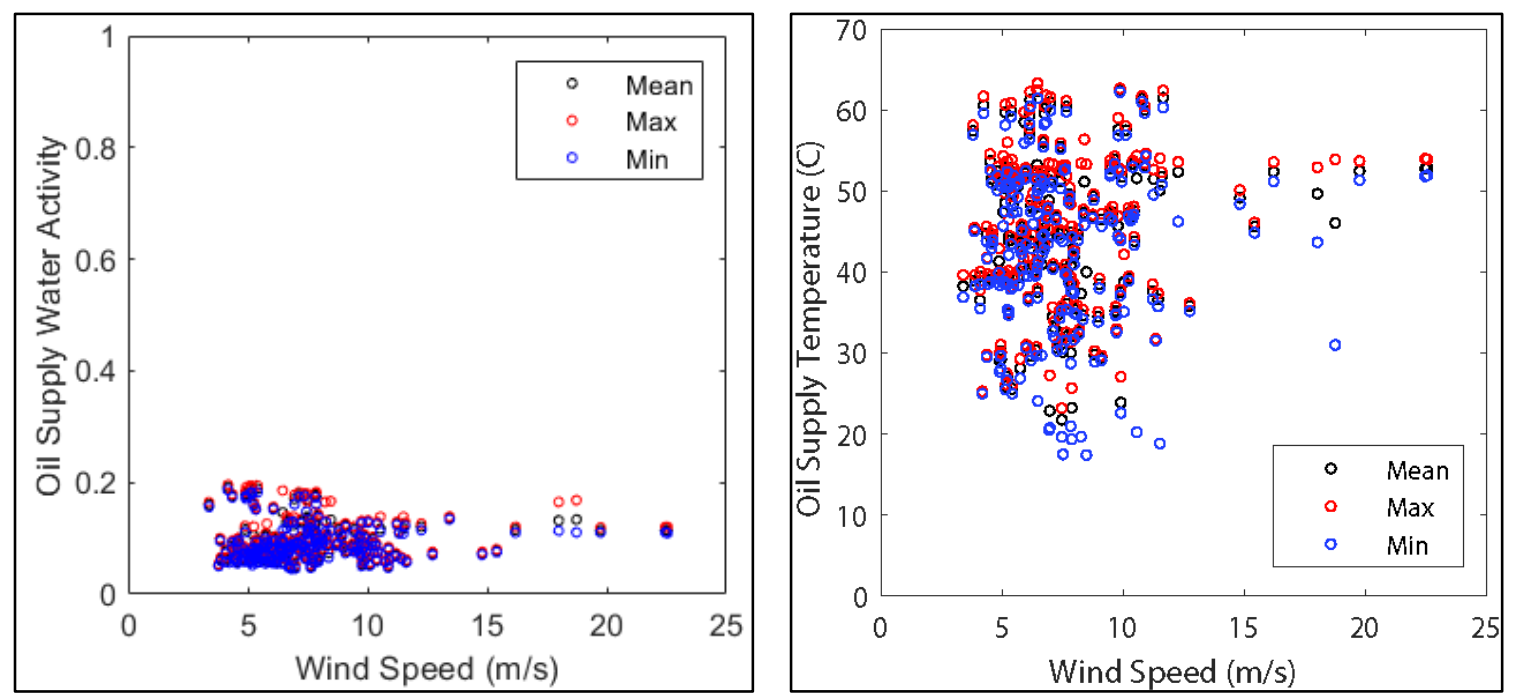

Figure 25. Gearbox oil water activity (left) and temperature (right) in normal power production

Finally, the difference between the gearbox air and dew point temperatures is summarized in Figure 26 . The air temperature is anywhere from $20^{\circ} \mathrm{C}$ to $50^{\circ} \mathrm{C}$ above the dew point, indicating that at least while in normal power production conditions there is no water vapor that would be condensing within the gearbox itself.

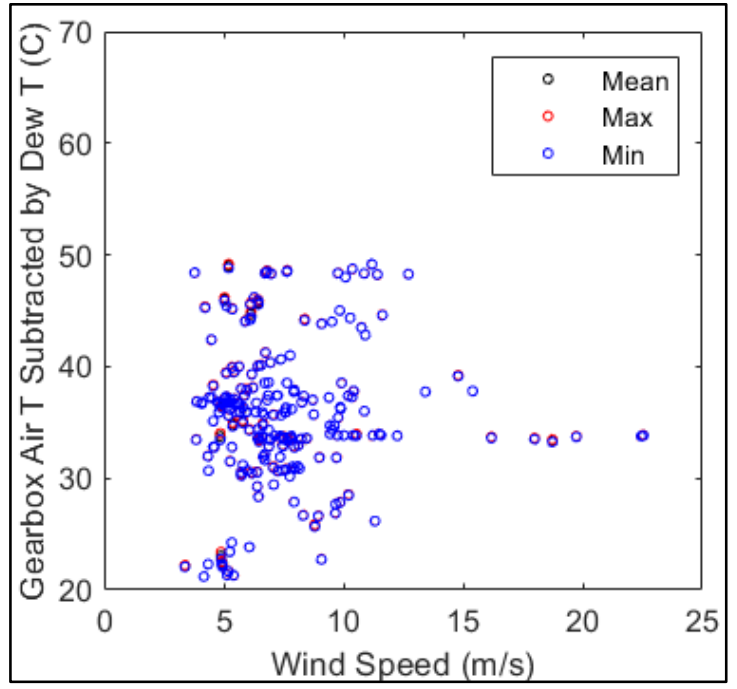

Figure 26. Gearbox air and dew point temperature difference during normal power production

\subsection{Startups and Shutdowns}

The capture matrices for startup and shutdown events are provided in Table 3. These transient events are identified by tracking the turbine status values (signal OPC_OpCtl_TurbineStatus) to identify cases where the turbine goes from producing power to not generating power (shutdown) or vice versa (startup). Example transient events are described in the following sections. 
Table 3. Capture Matrix for Normal Transients

\begin{tabular}{cccc}
\hline Event & Wind Speed Range & Duration(s) & Obtained \\
\hline Normal Startup & $3-12 \mathrm{~m} / \mathrm{s}$ & $164-299$ & 7 \\
& $12-16 \mathrm{~m} / \mathrm{s}$ & $92-195$ & 2 \\
& $>16 \mathrm{~m} / \mathrm{s}$ & $166-278$ & 2 \\
Normal Shutdown & $3-12 \mathrm{~m} / \mathrm{s}$ & $17-157$ & 2 \\
& $12-16 \mathrm{~m} / \mathrm{s}$ & $141-243$ & 2 \\
& $>16 \mathrm{~m} / \mathrm{s}$ & 195 & 1 \\
Emergency Stops & $3-12 \mathrm{~m} / \mathrm{s}$ & 45 & 1 \\
& $12-16 \mathrm{~m} / \mathrm{s}$ & $45-60$ & 3 \\
& $>16 \mathrm{~m} / \mathrm{s}$ & - & 0 \\
\hline
\end{tabular}

\subsubsection{Normal Startup}

There are three phases during a startup event for this turbine that can be seen in an example startup in Figure 27. In the initial phase, the drivetrain speed increases to approximately $900 \mathrm{rpm}$, or a rotor speed of $11.5 \mathrm{rpm}$, while under no appreciable load. Upon reaching this speed, in the second phase the turbine governs this speed for approximately 1 minute until the generator engages and the drivetrain begins to transmit torque and generate electrical power. If the winds are strong enough, in the third phase the drivetrain will continue to accelerate up to the rated speed of 1,440 rpm or a rotor speed of $18.4 \mathrm{rpm}$. This behavior is illustrated in Figure 27 for a startup on March 4 (filename "DRC15_fast_Start_command2018_03_04_22_24_19.h5"). In this case, the time required to reach just over rated power conditions is almost $300 \mathrm{~s}$, or 5 minutes.

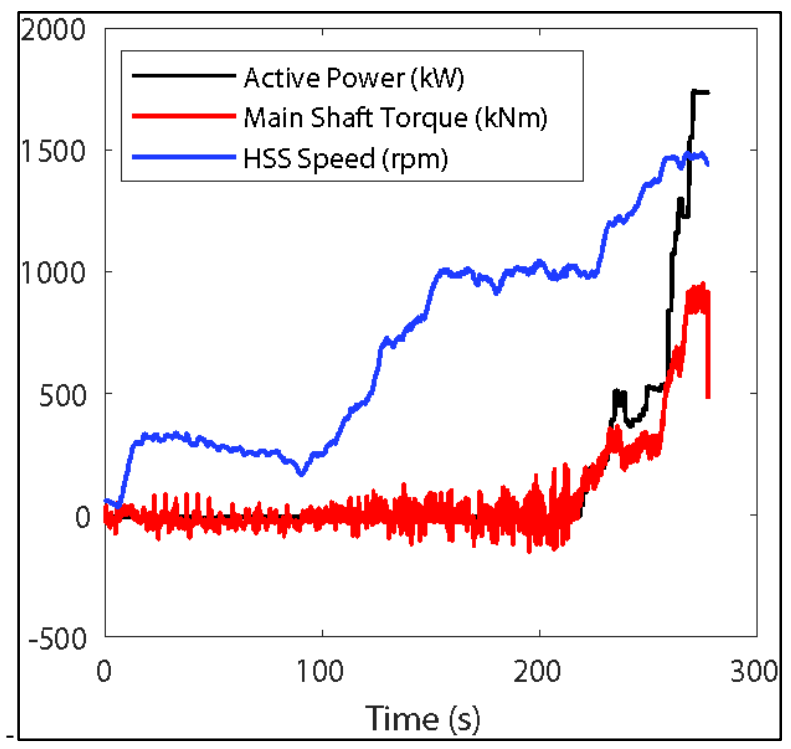

Figure 27. Main shaft torque and speed during a normal startup

The main bearing axial motion during this startup is shown in Figure 28. Prior to engagement of the generator, very little thrust is produced, so the main bearing remains at its central resting position of nearly $0.6 \mathrm{~mm}$. After the generator engages and rotor thrust and torque increases, the 
main bearing moves downwind approximately $0.6 \mathrm{~mm}$. The gaps apparent in the net axial motion are the result of exclusion of periods of time where the main bearing locknut was in front of the proximity probe as described in Section 4.1.1.

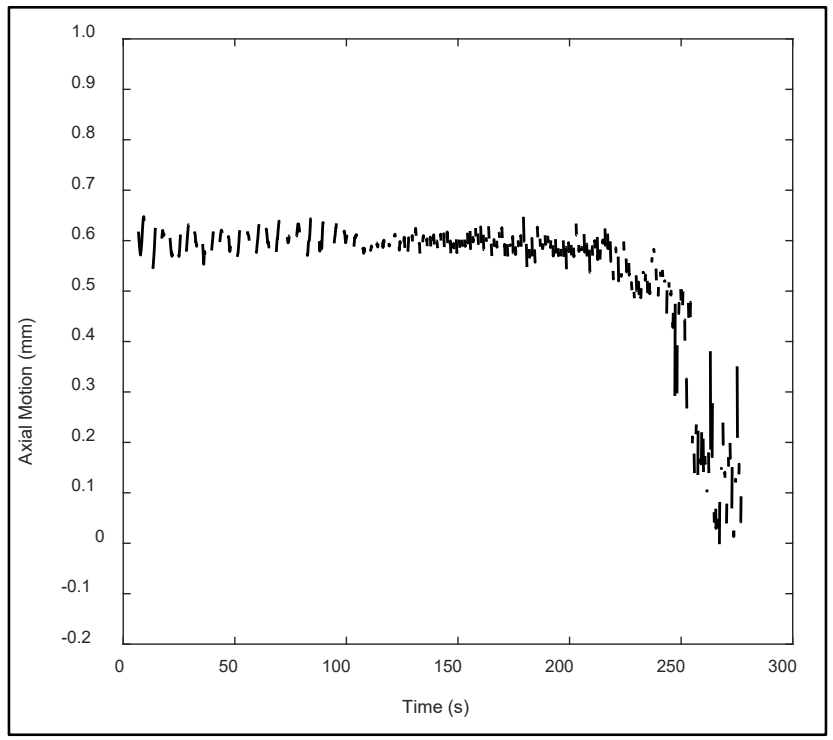

Figure 28. Main bearing axial motion during a normal start-up

The electrical current measurements through the main bearing during this start-up event are shown in Figure 29. Currents of up to $200 \mathrm{~mA}$ were observed throughout the event, regardless of the engagement of the generator, which occurs at approximately $200 \mathrm{~s}$ as shown in Figure 27.
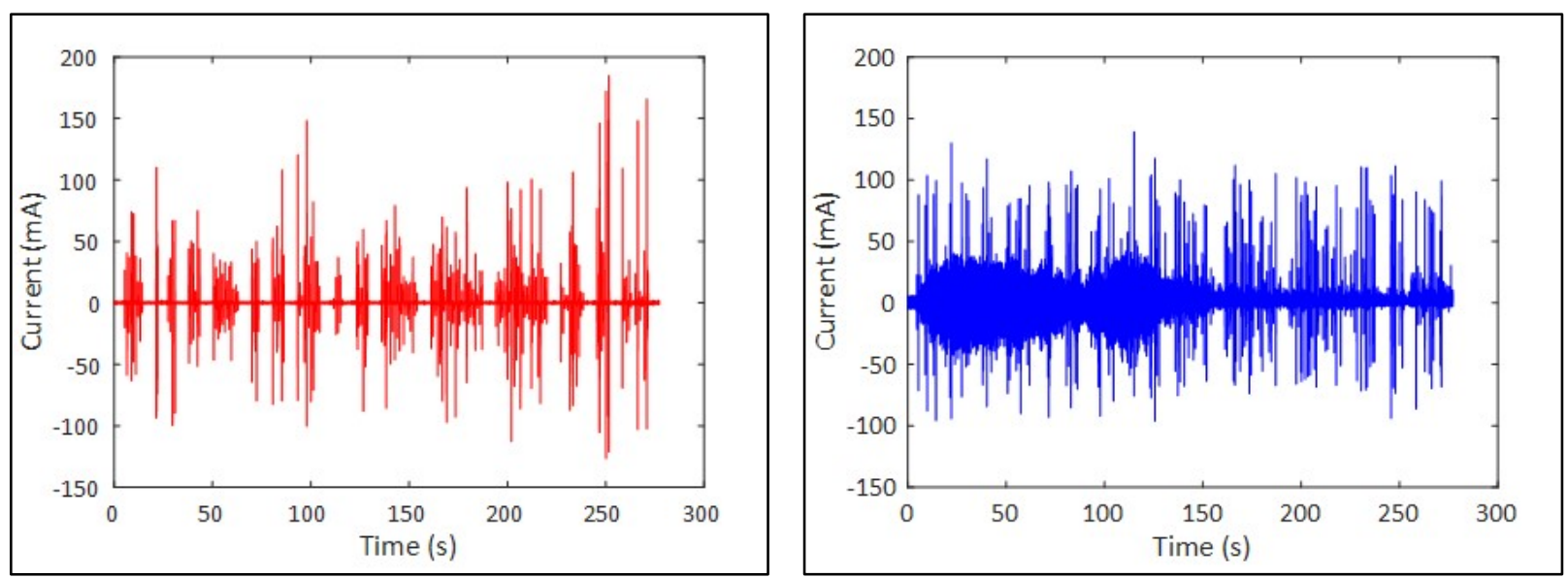

Figure 29. Main bearing generator-side (left) and rotor-side (right) stray electrical current during a normal start-up

Figure 30 and Figure 31 show the HSS bearing roller and cage speeds, respectively. In each figure, the measured values are compared to the theoretical value for the pure rolling condition in the bearing. Pure rolling conditions are only achieved when the bearings are loaded by the drivetrain torque. Without appreciable load, the rollers have a combination of rolling and sliding with the bearing races. In extreme low-load conditions, the rollers cease to rotate and simply slide against the races. Prior to the engagement of the generator, the roller and cage speeds for both bearings are well below their theoretical values for pure rolling conditions. For a portion of 
the rotation, the minimum measured roller speed is close to pure sliding conditions (that is, a roller speed of zero). After engagement of the generator, the maximum measured roller speed and cage speed for each bearing quickly reach the theoretical value for pure rolling conditions in the bearing load zone. The same behavior can be seen in the measured cage speeds during the event. In comparing the two bearings, the GS-in bearing demonstrates lower sliding than the RS bearing.
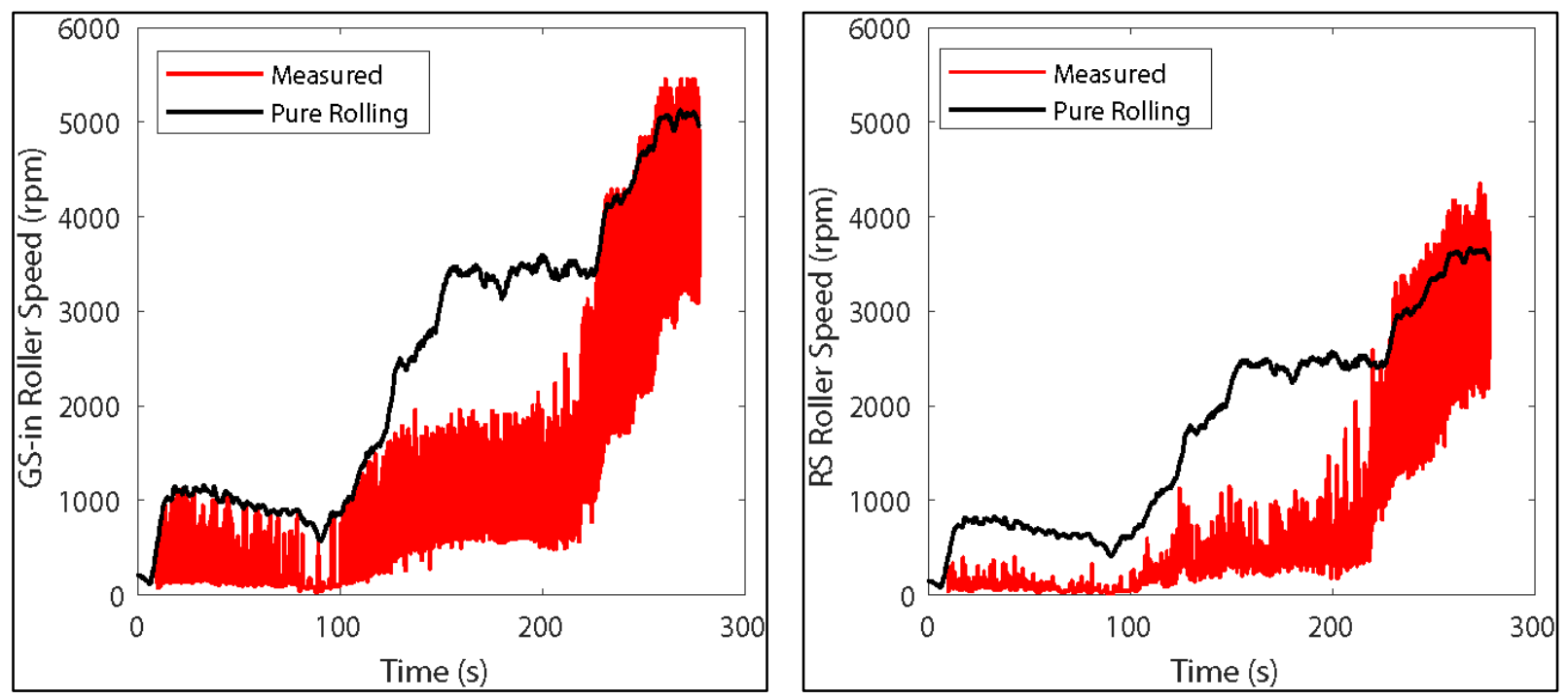

Figure 30. High-speed-shaft generator-side-in (left) and rotor-side (right) bearing roller speed during a normal start-up
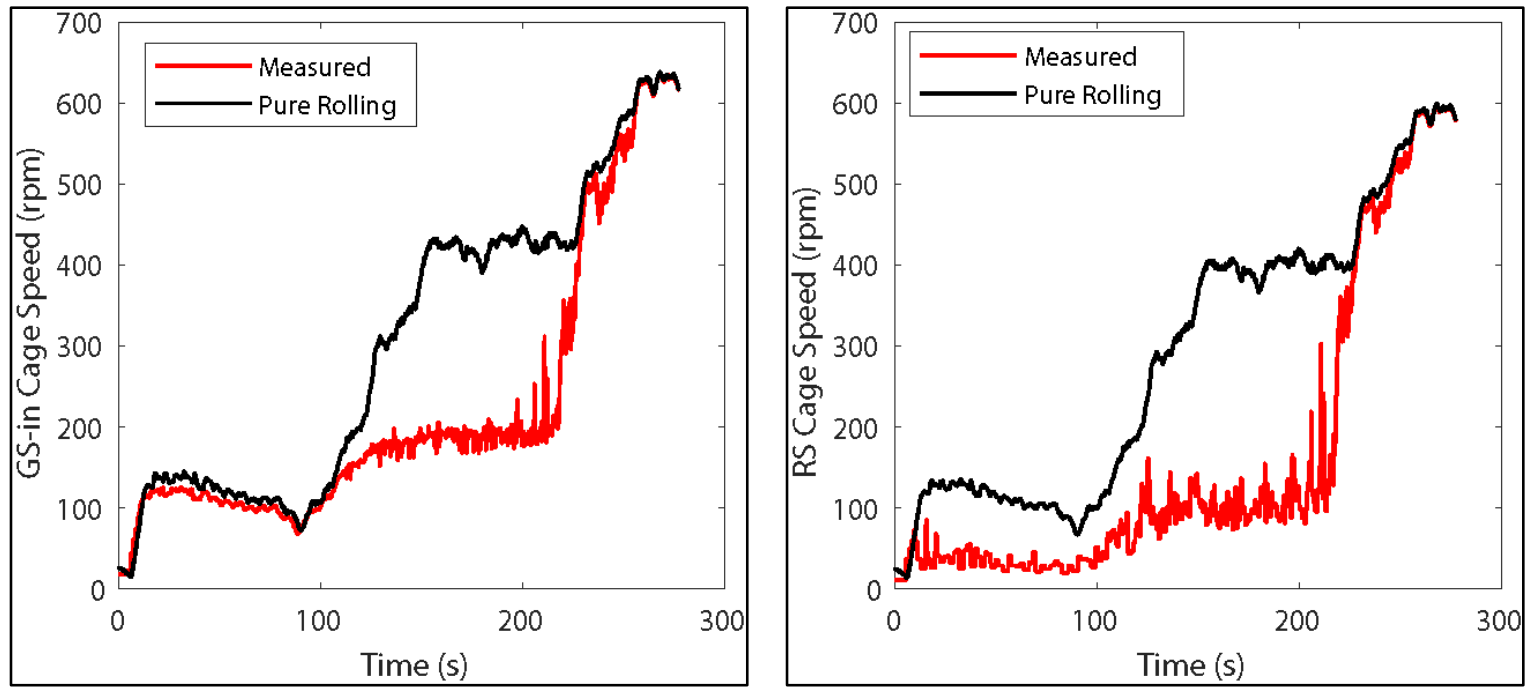

Figure 31. High-speed-shaft generator-side-in (left) and rotor-side (right) bearing cage speed during a normal start-up

\subsubsection{Normal Shutdown}

An example of a manually-induced stop event is described in this section (filename "DRC15_fast_Stop_command2018_03_04_22_37_51.h5"). The stop was intentionally commanded via the turbine control computer when the turbine was operating above rated power. After the stop command is given, the blades pitch to slow the rotor and reduce power prior to 
disengaging the generator. The rotor then slows to a stop over about a 2-minute period as shown in Figure 32.

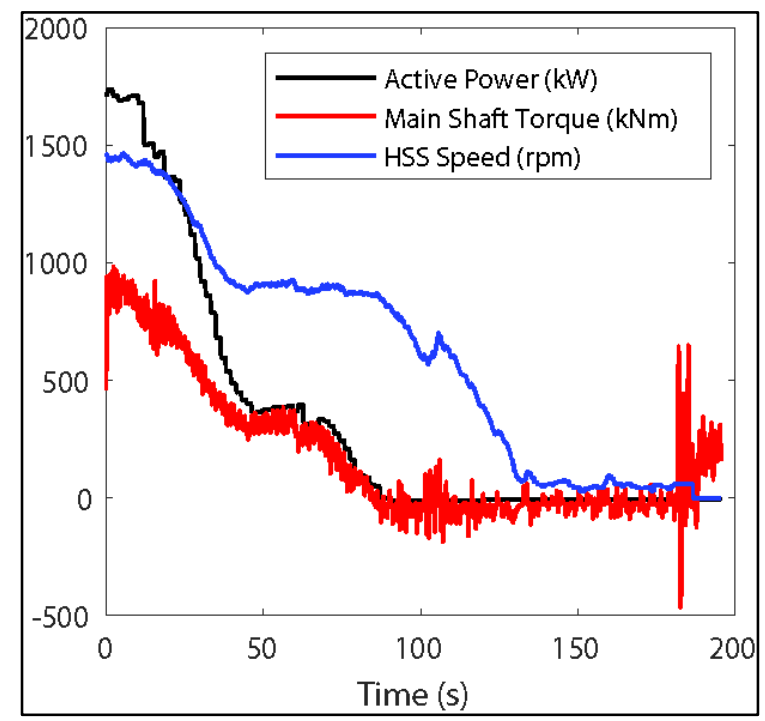

Figure 32. High-speed-shaft torque and speed during a normal shutdown

The main bearing motion during the stop is shown in Figure 33. At the start of the shutdown, the main bearing position oscillates about $0.3 \mathrm{~mm}$ as evidenced in the normal power production cases in Figure 8, but as the rotor slows and power decreases, the rotor moves forward to its central, resting position at slightly less than $0.6 \mathrm{~mm}$. In this case, the gaps in the net axial motion are more apparent because as the rotor slows, the locknut is in front of a probe for a longer period of time, resulting in a wider gap.

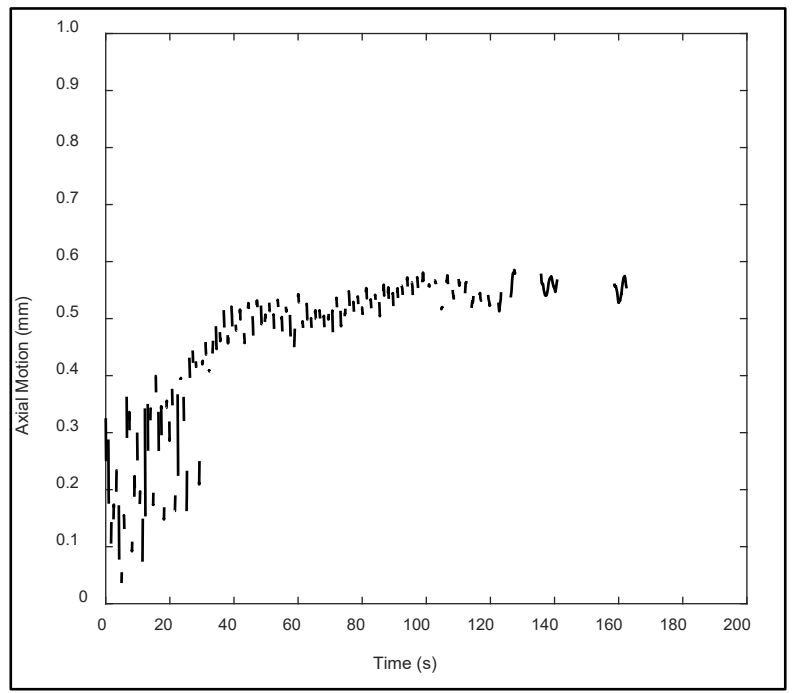

Figure 33. Main bearing axial motion during a normal shutdown

The electrical current measurements through the main bearing during this shutdown event are shown in Figure 34. Like the startup, currents of up to $200 \mathrm{~mA}$ were observed throughout the event, regardless of the engagement of the generator. They continue even after the rotor has come to a complete stop. 

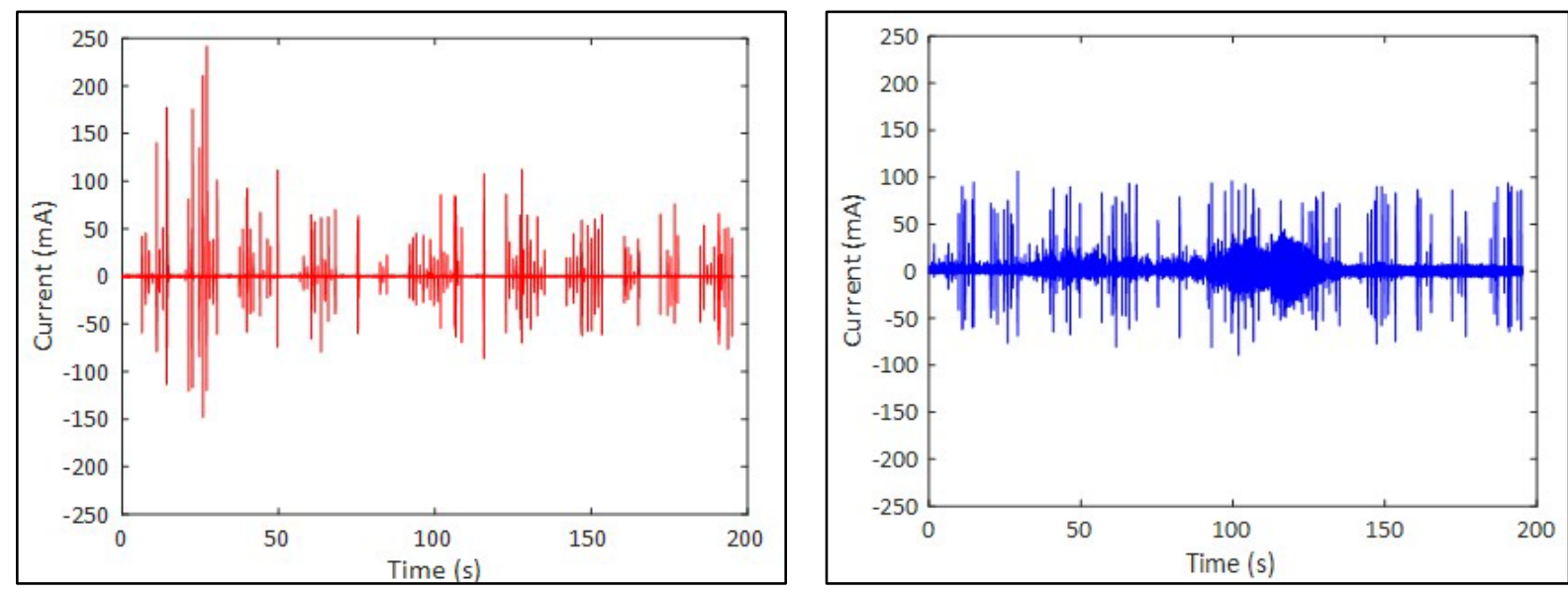

Figure 34. Main bearing generation-side (left) and rotor-side (right) stray electrical current during a normal shutdown

Figure 35 and Figure 36 show the HSS bearing roller and cage speeds during the shutdown, respectively. Prior to the disengagement of the generator, the maximum measured roller and cage speeds for both bearings reach their theoretical values, indicating conditions of pure rolling in the bearing load zone. After disengagement of the generator, the measured roller speeds decrease with the minimum reaching almost pure sliding conditions. Like the start-up event, the GS-in bearing demonstrates less sliding than the RS bearing in terms of both the measured roller speed and the measured cage speed.
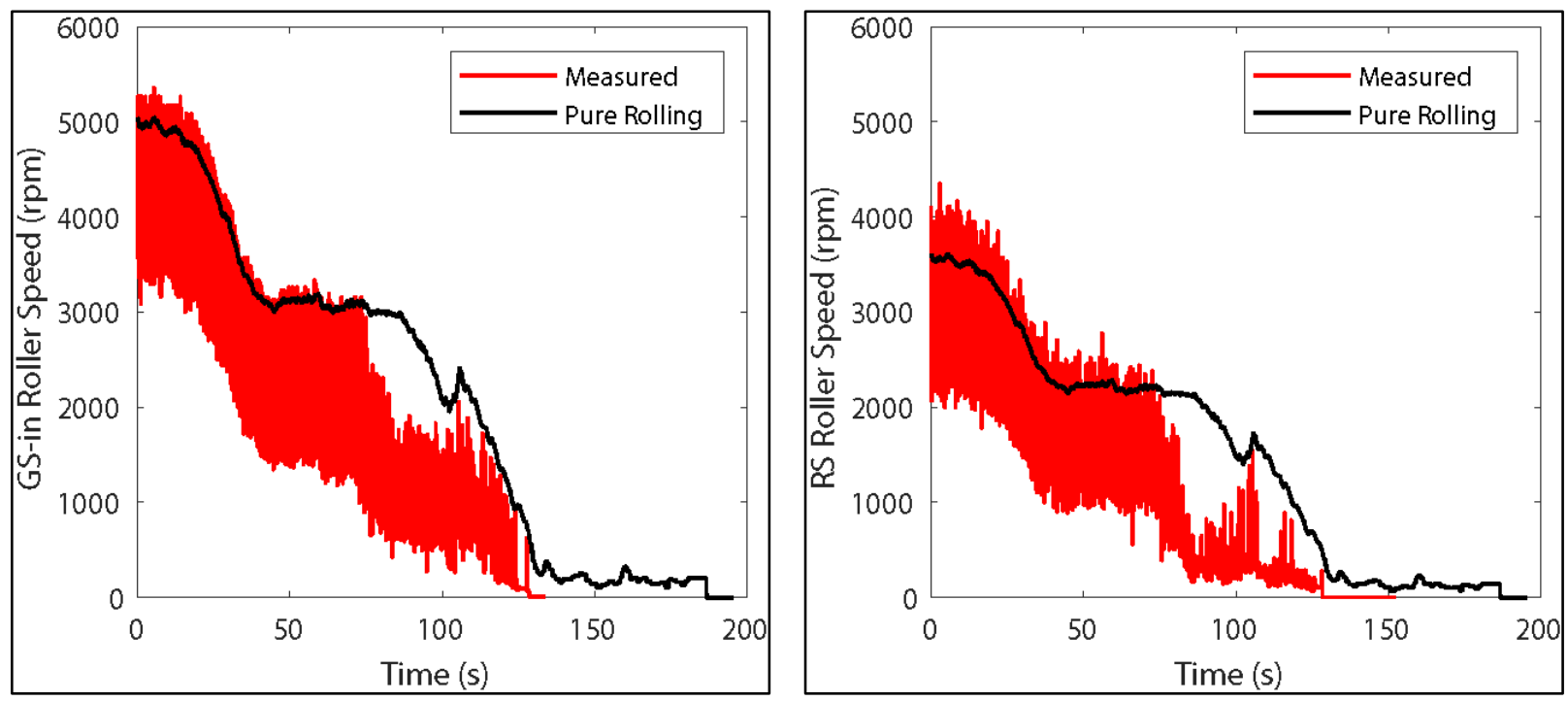

Figure 35. High-speed-shaft generator-side-in (left) and rotor-side (right) bearing roller speed during a normal shutdown 

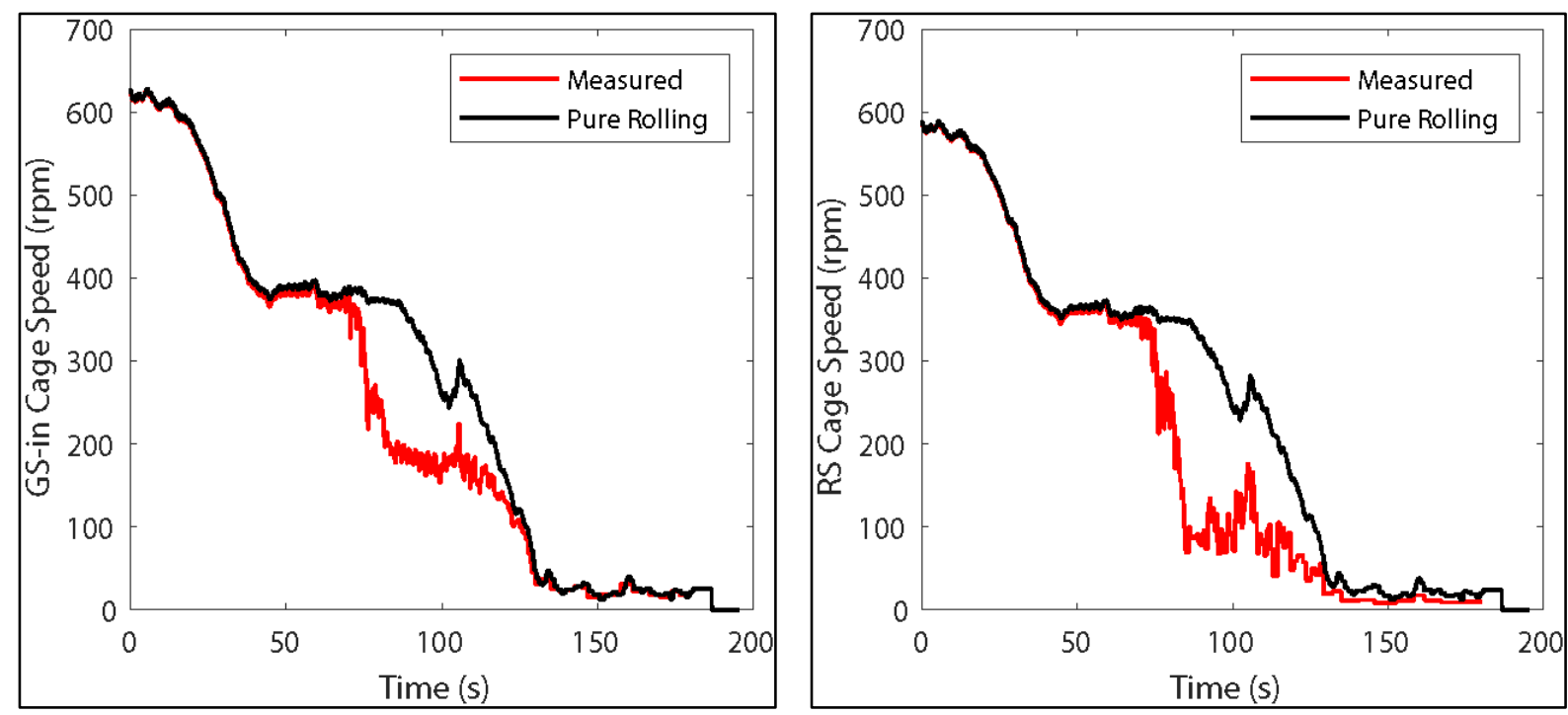

Figure 36. High-speed-shaft generator side-in (left) and rotor-side (right) bearing cage speed during a normal shutdown

\subsubsection{Emergency Stop}

Emergency stops were manually induced by a technician at the base of the tower on two occasions, February 15 and March 4 . Stops at a range of power levels and rotor speeds were conducted to examine their effect on the gearbox and main bearing behavior. In addition to recording the main bearing and gearbox behavior, the hydraulic brake activation signal was also recorded. Upon engaging the brake, the drivetrain quickly decelerates from rated speed to stopped in about $10 \mathrm{~s}$. During this initial braking period, there are severe torque oscillations that typically reach double the initial torque value. After the rotor stops, the drivetrain torque continues to oscillate a few more times with amplitudes up to one-half of rated torque. This behavior is illustrated in Figure 37 for an emergency stop on March 4 (filename "DRC15_fast_manual_estop2018_03_04_21_48_51.h5").

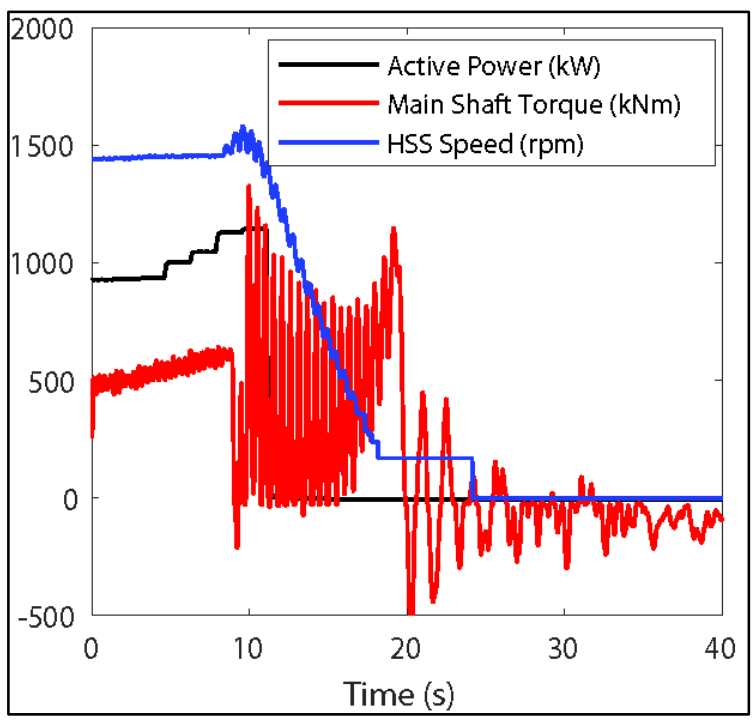

Figure 37. Main shaft torque and speed during an emergency stop 
The main bearing axial motion during the emergency stop is shown in Figure 38. Like previous cases, at rated power the main bearing has moved downwind approximately $0.6 \mathrm{~mm}$ from its central resting position. As soon as the hydraulic brake is engaged and the rotor quickly decelerates, the main bearing quickly moves forward. It actually moves slightly forward of its central resting position before returning to this position of slightly less than $0.6 \mathrm{~mm}$ over several oscillations.

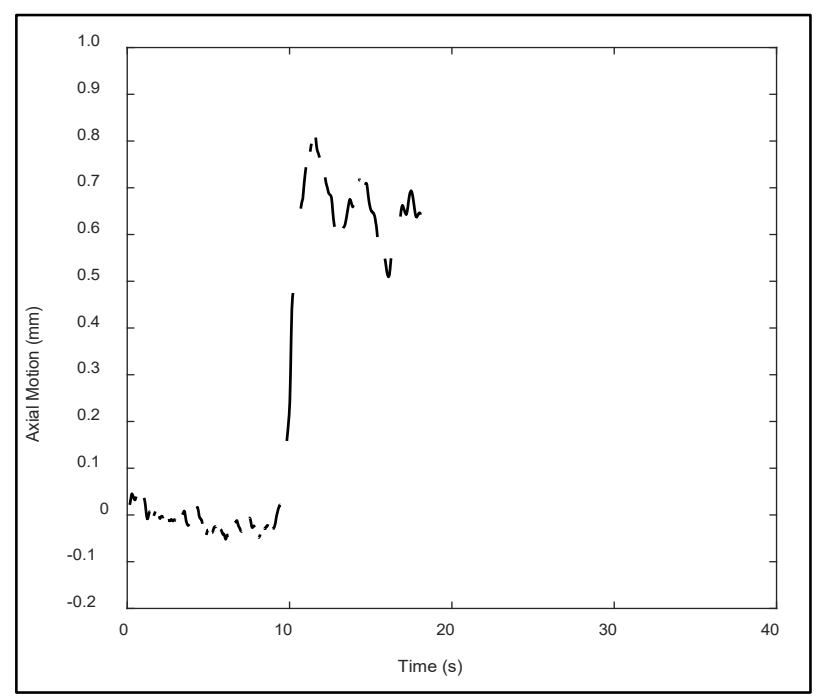

Figure 38. Main bearing axial motion during an emergency stop

The stray electrical currents measured across the main bearing are shown in Figure 39. Like other events, electrical currents of up to $150 \mathrm{~mA}$ were observed regardless of generator engagement or even rotation of the rotor.
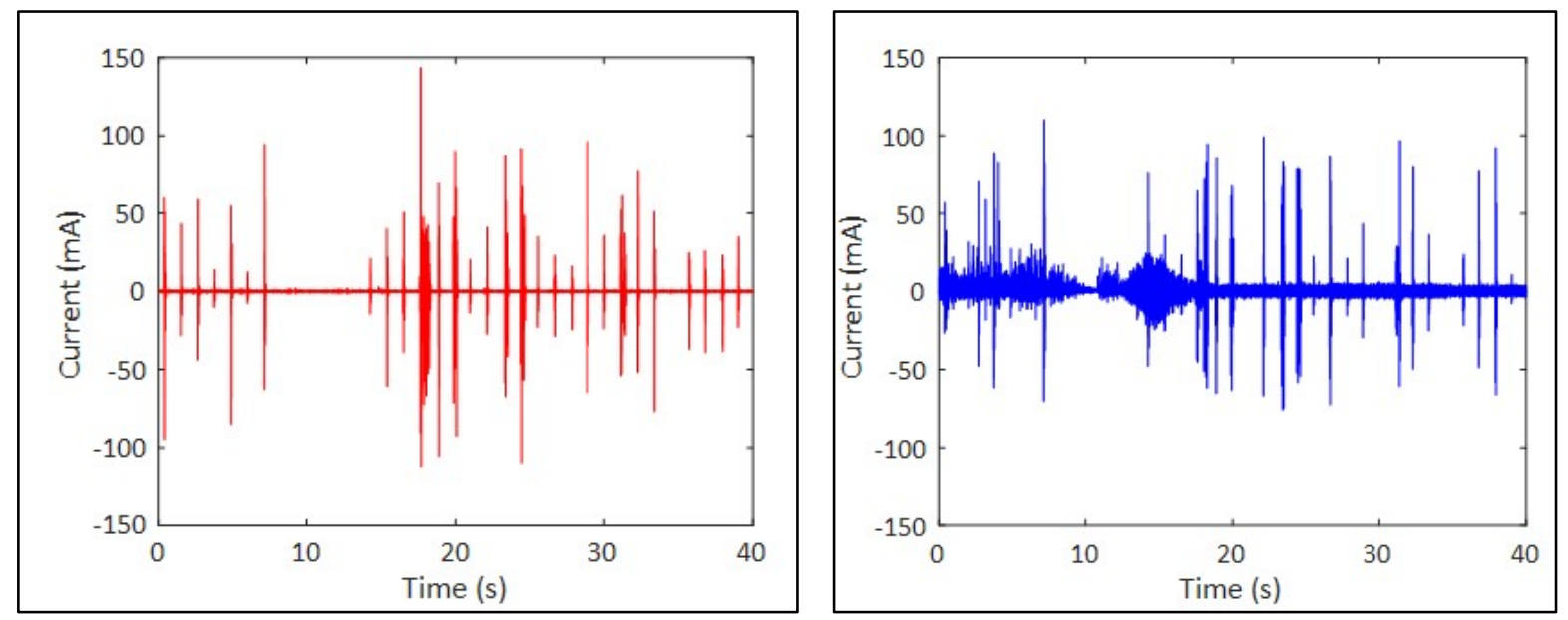

Figure 39. Main bearing generator-side (left) and rotor-side (right) stray electrical current during an emergency stop

Figure 40 and Figure 41 show the HSS bearing roller and cage speeds, respectively. Prior to the engagement of the brake, the maximum measured roller speed and the cage speed for each bearing is equivalent to the theoretical value for pure rolling conditions. When the brake is engaged, the roller and cage speeds drop dramatically. During the deceleration period, the two 
bearings have similar but slightly different behaviors. The cage speed of the GS-in bearing returns to the theoretical value for the remainder of the event. In contrast, the cage speed of the RS bearing oscillates between one-half and full theoretical value.
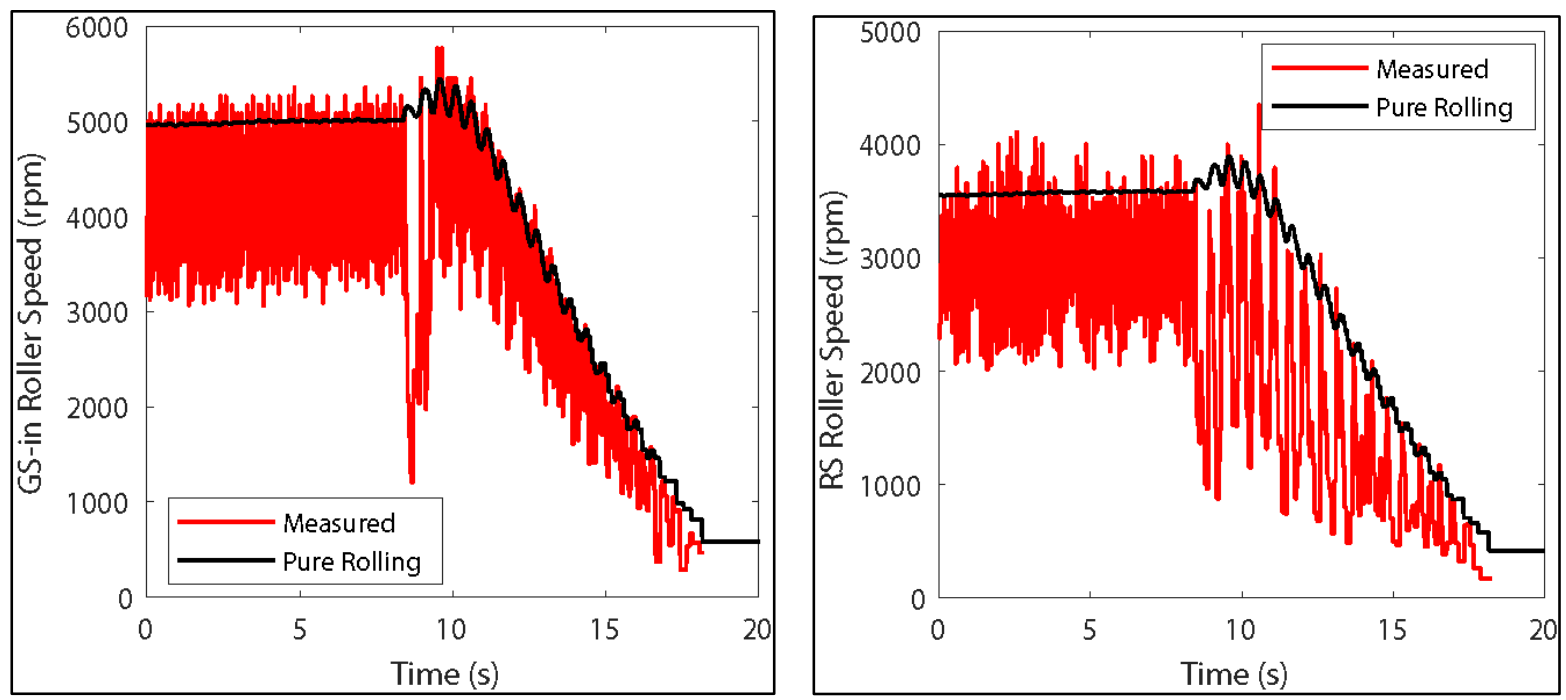

Figure 40. High-speed-shaft generator-side-in (left) and rotor-side (right) bearing roller speed during an emergency stop
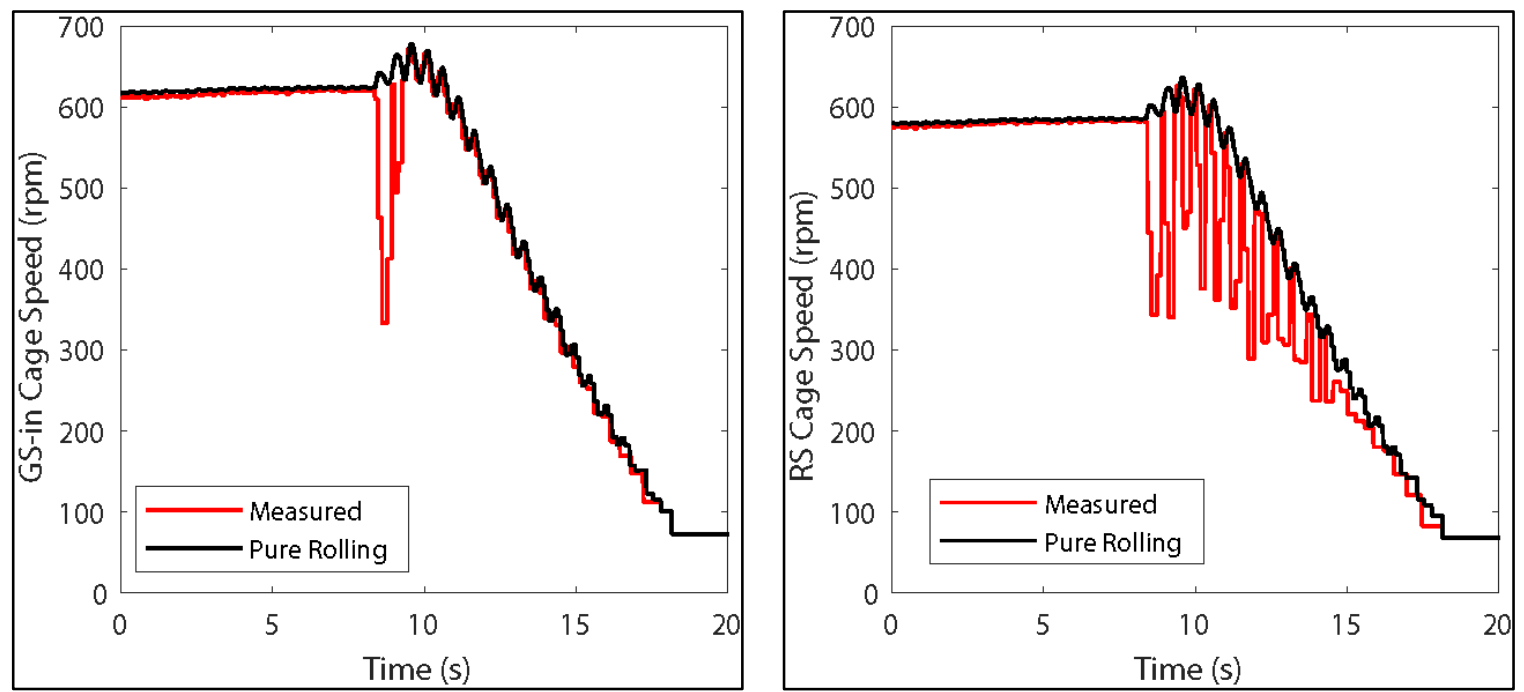

Figure 41. High-speed-shaft generator-side-in (left) and rotor-side (right) bearing cage speed during an emergency stop

\subsection{Parked/ldling}

The capture matrix for the parked events is provided in Table 4. Parked events were identified using the turbine status codes. Four idling events were captured during the testing period. 
Table 4. Capture Matrix for Parked/Idling

\begin{tabular}{cccc}
\hline Event & Wind Speed Range & Duration (s) & Obtained \\
\hline Parked/Idling & $3-12 \mathrm{~m} / \mathrm{s}$ & $19-93$ & 2 \\
& $12-16 \mathrm{~m} / \mathrm{s}$ & 65 & 1 \\
& $>16 \mathrm{~m} / \mathrm{s}$ & 82 & 1
\end{tabular}

An example period that includes both parked and idling conditions is examined in Figure 42 (filename "DRC15_fast_slow_roll2018_03_04_22_52_49.h5"). The rotor turns very slowly at about $2.5 \mathrm{rpm}$, resulting in a HSS speed of approximately $200 \mathrm{rpm}$. No power is being generated, and the drivetrain torque is very low as expected.

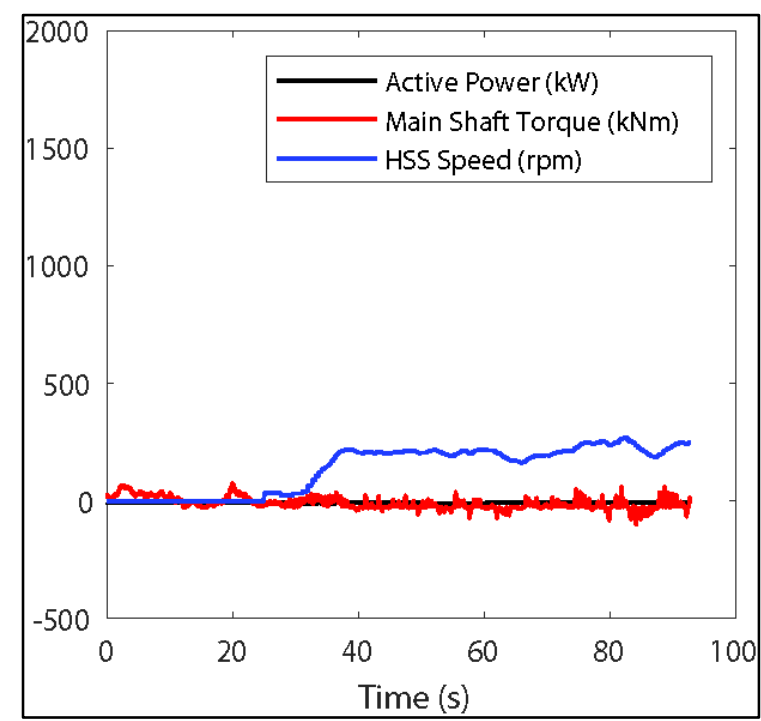

Figure 42. Main shaft torque and speed during idling

The main bearing axial motion during this period, shown in Figure 43, is very low as expected. Essentially, the main bearing remains at its central, resting position of slightly less than $0.6 \mathrm{~mm}$.

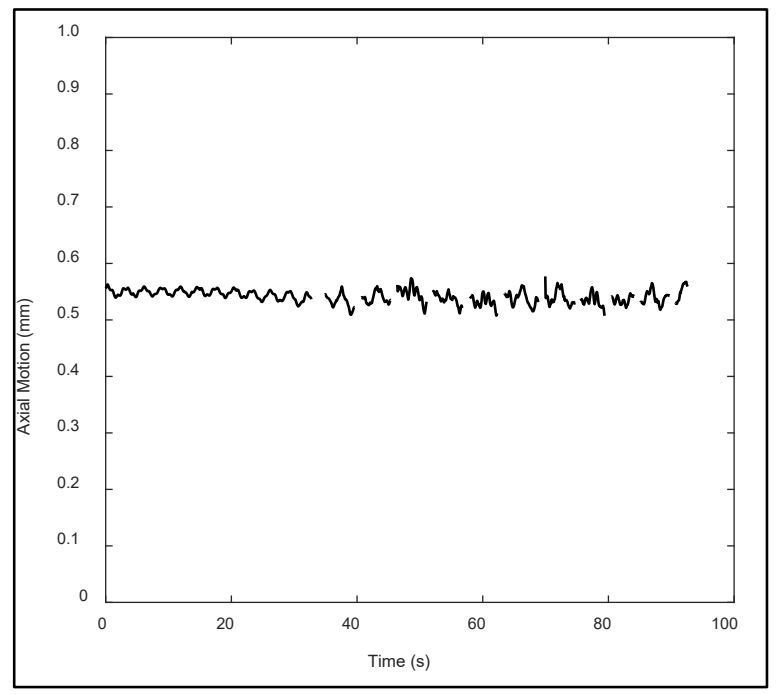

Figure 43. Main bearing axial motion during idling 
The main bearing stray currents have similar magnitudes as other events ranging up to $200 \mathrm{~mA}$ as shown in Figure 44.
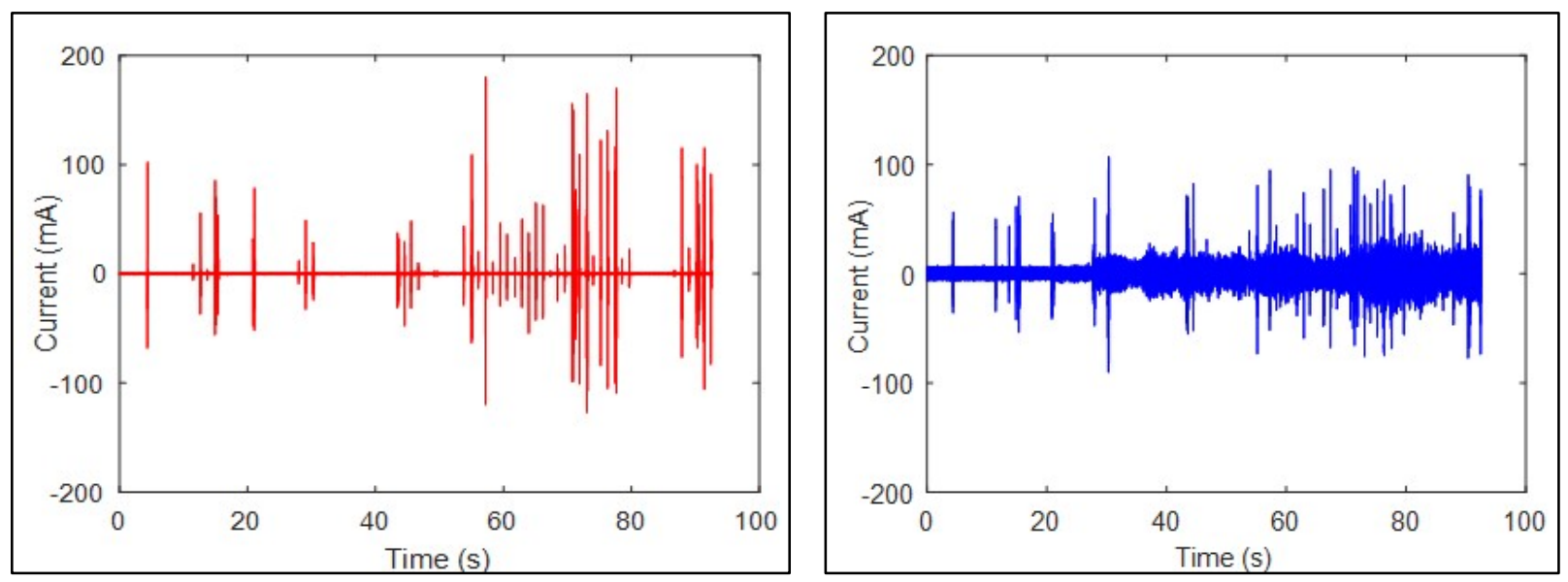

Figure 44. Main bearing generator-side (left) and rotor-side (right) stray electrical current during idling

The HSS roller and cage speeds during this idling condition are presented in Figure 45 and Figure 46. With the only torque transmitted as a result of rotor and generator inertia and drag friction throughout the drivetrain, it is not surprising that the rollers and cages are experiencing sliding conditions. Like the other events previously described, this is especially true for the RS bearing. The GS-in bearing is actually close to pure rolling conditions, which is clearly evident from the cage speed measurement shown in Figure 46. However, the overall shaft, cage, and roller speeds are quite slow, and the loads are very low in this condition.
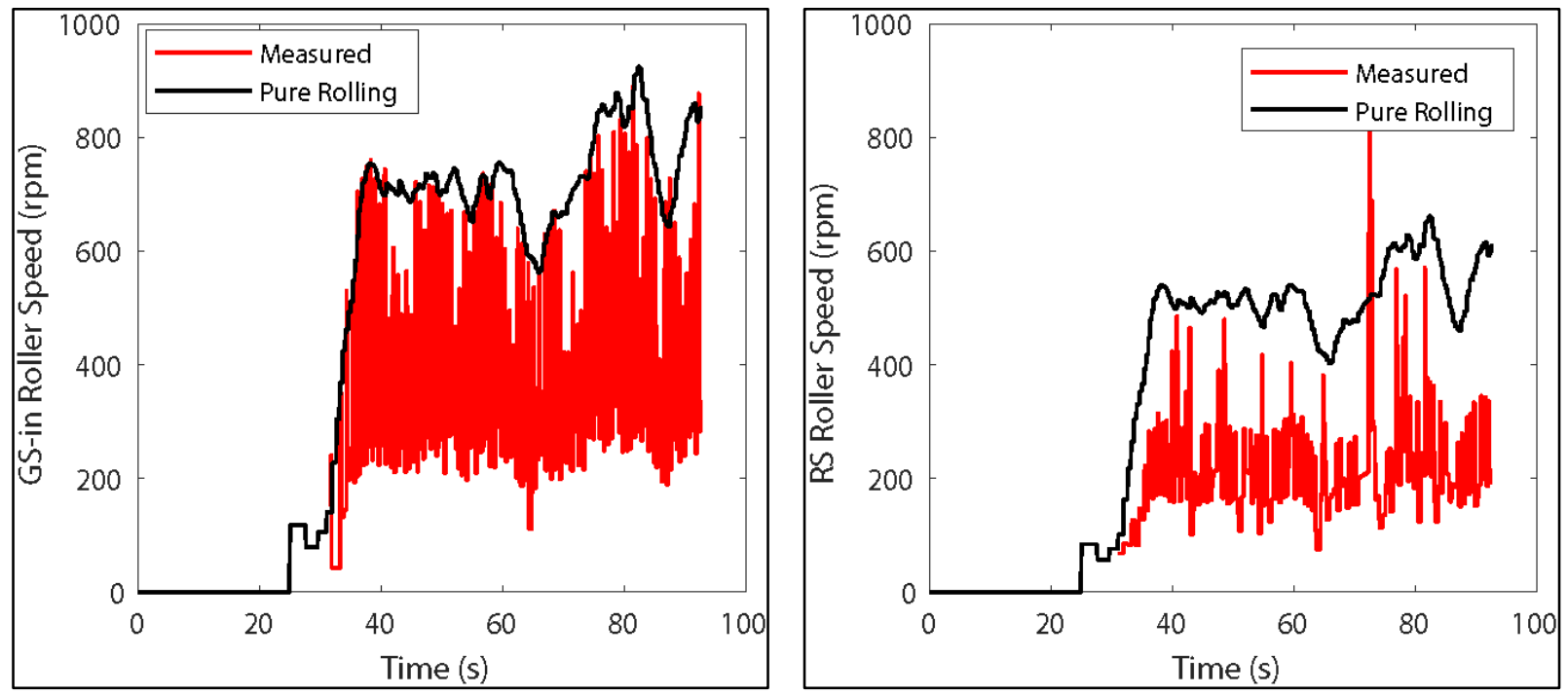

Figure 45. High-speed-shaft generator-side-in (left) and rotor-side (right) bearing roller speed during idling 

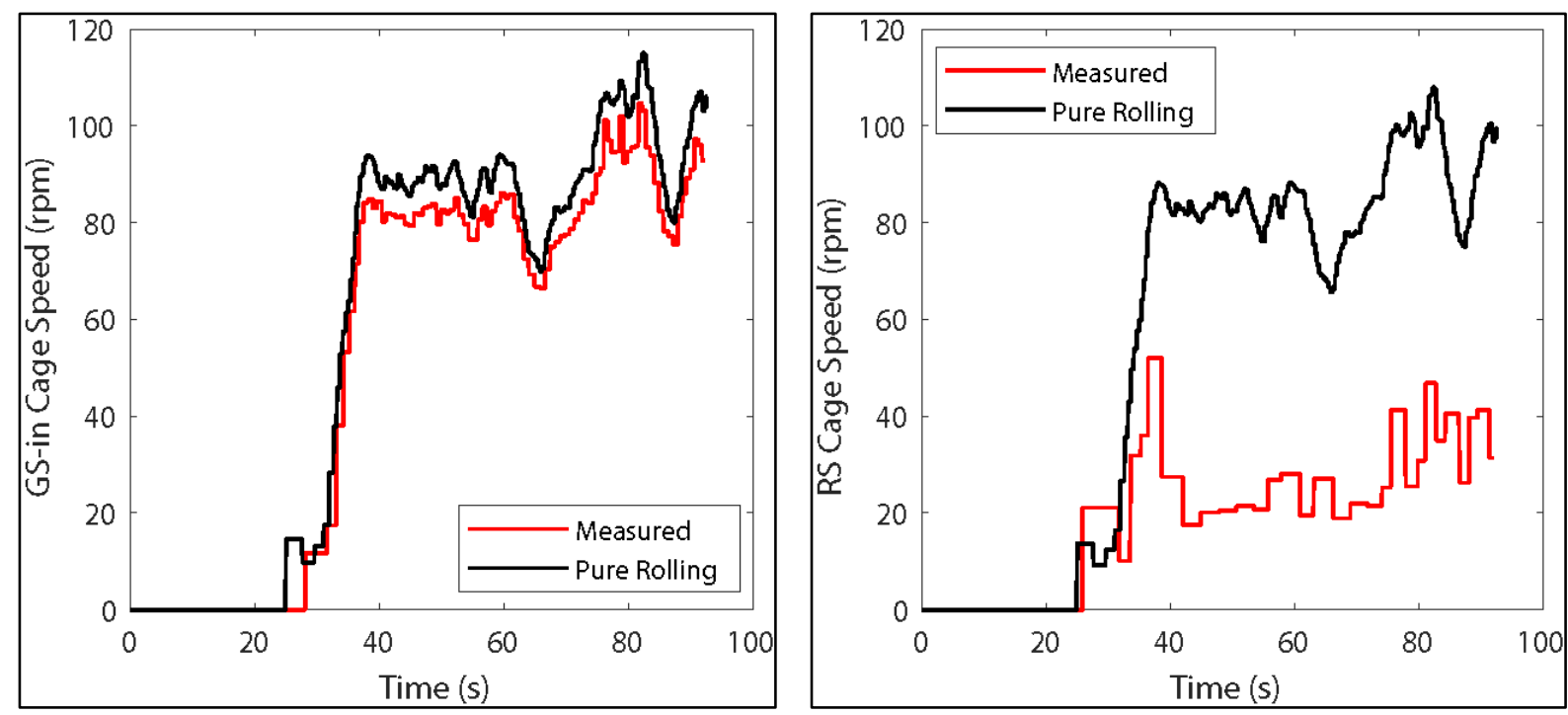

Figure 46. High-speed-shaft generator-side-in (left) and rotor-side (right) bearing roller speed during idling

\subsection{Grid Events}

Two types of grid events, underfrequency and low-voltage ride-through (LVRT), were induced with the NWTC's controllable grid interface in the original test period. Underfrequency events were induced on January 30 and February 8. LVRT events, described in the capture matrix in Table 5, were induced on March 5. The LVRT events were induced with voltage drops of 10\% to $50 \%$ for a duration of 300 milliseconds (ms) at a variety of wind speeds and turbine power levels.

Table 5. Capture Matrix for Low-Voltage Ride-Throughs

\begin{tabular}{cccc}
\hline Event & Drop Percentage & Duration $(\mathbf{m s})$ & Obtained \\
\hline LVRT & 10 & 300 & 6 \\
& 20 & 300 & 6 \\
& 30 & 300 & 6 \\
& 40 & 300 & 5 \\
& 50 & 300 & 3 \\
\hline
\end{tabular}

An example LVRT event for a 50\% voltage drop is shown in Figure 47 (filename "DRC15_fast_50LVRT300ms2018_03_05_21_45_59.h5"). The event occurs just after $10 \mathrm{~s}$ in the figures below at slightly less than the rated power and torque conditions. Unlike the underfrequency events, the drivetrain torque is significantly affected by the LVRT. The torque initially drops as expected, but quite quickly the voltage returns to nominal and the torque oscillates to nearly double the initial value. This behavior is similar to previous dynamometer results [24]. The torque continues to oscillate for many cycles at the natural frequency of the system. The drivetrain speed is largely unaffected by the LVRT, although the effect of the drivetrain torque oscillations are reflected in slight speed oscillations. 


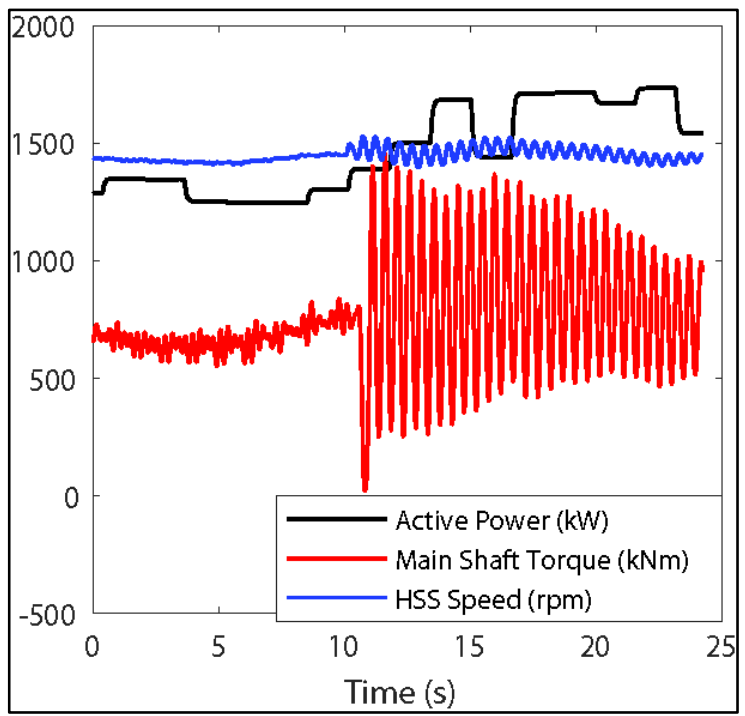

Figure 47. High-speed-shaft torque and speed during a low-voltage ride-through

The main bearing motion during the LVRT is shown in Figure 48. Unlike the drivetrain torque, the main bearing axial motion is not significantly affected by the LVRT event.

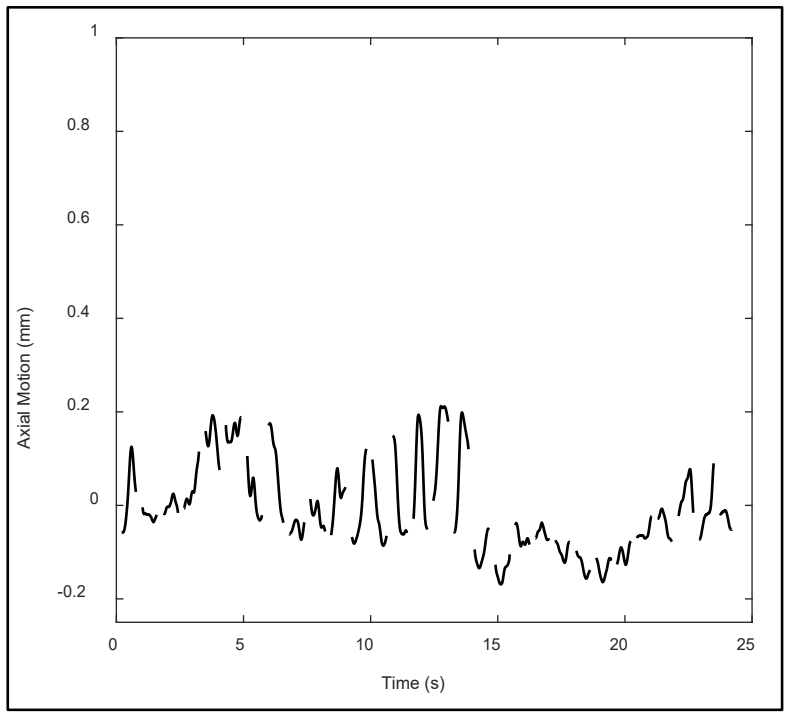

Figure 48. Main bearing axial motion during a low-voltage ride-through

The main bearing stray electrical currents are shown in Figure 49. For this event, larger currents - up to $300 \mathrm{~mA}$ - are measured than in many of the other events previously described; however, it is unclear if they are a result of the LVRT event itself or another phenomenon. 

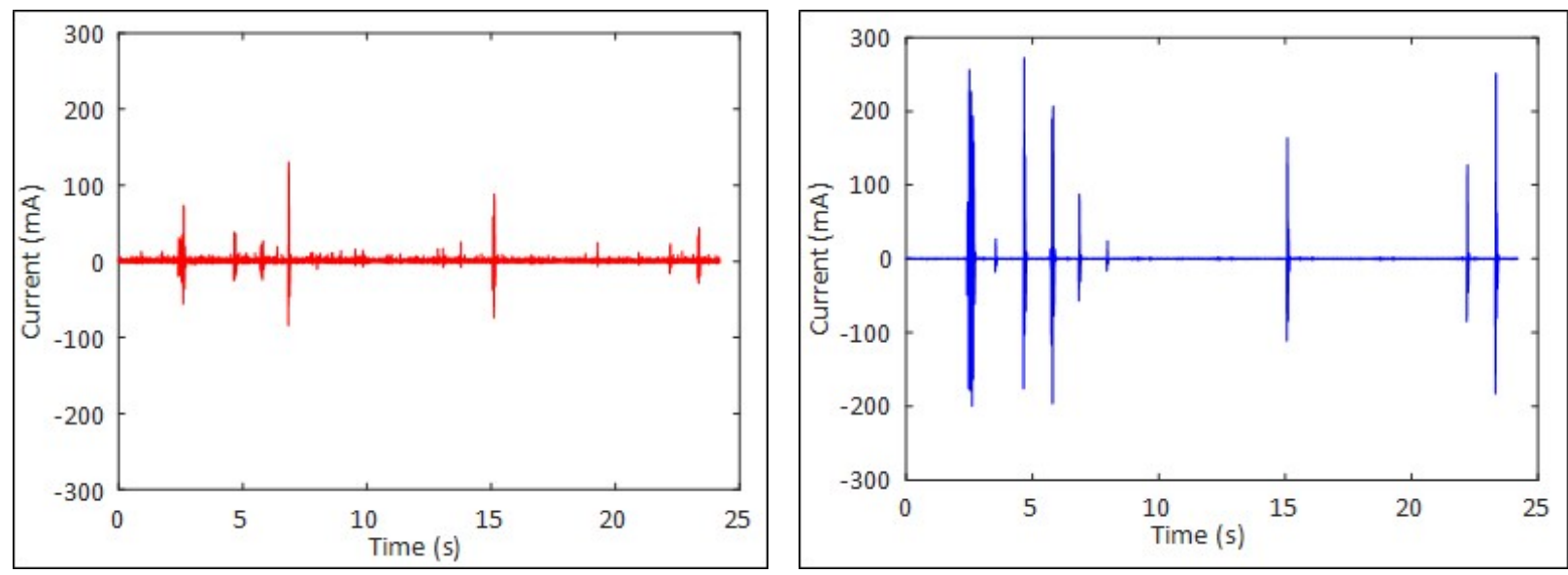

Figure 49. Main bearing generator-side (left) and rotor-side (right) stray electrical current during a low-voltage ride-through

The HSS bearing roller and cage speeds during the event are shown in Figure 50 and Figure 51. Because the LVRT is so short in duration, the period in which the drivetrain torque is low and the roller sliding would be expected to be very short. The measured roller and cage speeds change in behavior only during the $300 \mathrm{~ms}$ period of the LVRT itself and quickly return to normal once the voltage returns to normal.
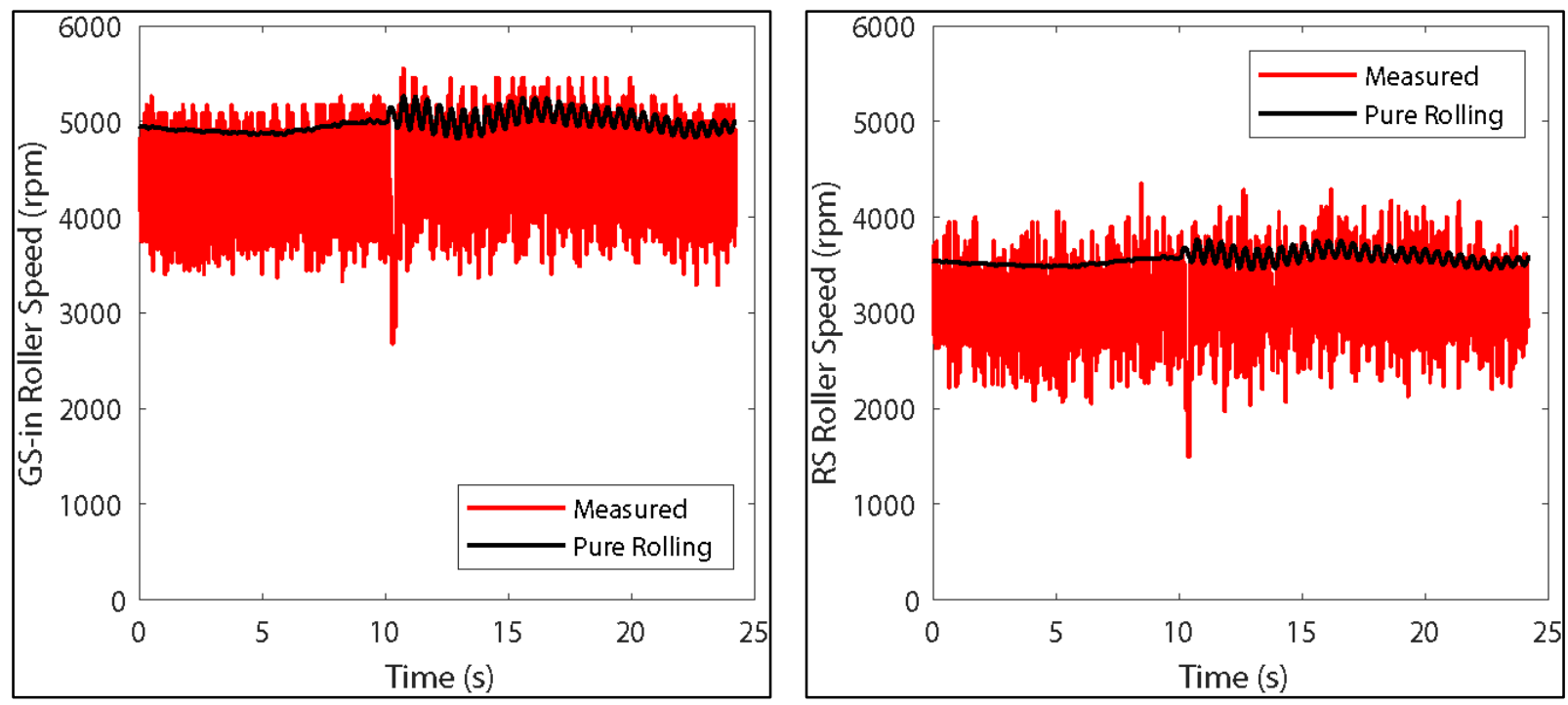

Figure 50. High-speed-shaft generator-side-in (left) and rotor-side (right) bearing roller speed during a low-voltage ride-through

The GS-in cage speed appears to have three additional anomalies in the data, at approximately 6 , $7.5,9$, and $16 \mathrm{~s}$, where the cage speed drops to half its nominal value. It is most likely that the proximity probe switch missed a passing of the pin in the cage, so these particular readings are not believed to be physical. In contrast, the LVRT event itself is readily apparent at $10 \mathrm{~s}$, where the cage speeds drop by approximately $20 \%$. A few similar anomalies can also be seen in the normal power production cases in Figure 17 where the cage speed drops to half its nominal value. Generally speaking, these GS-in cage anomalies are very infrequent. 

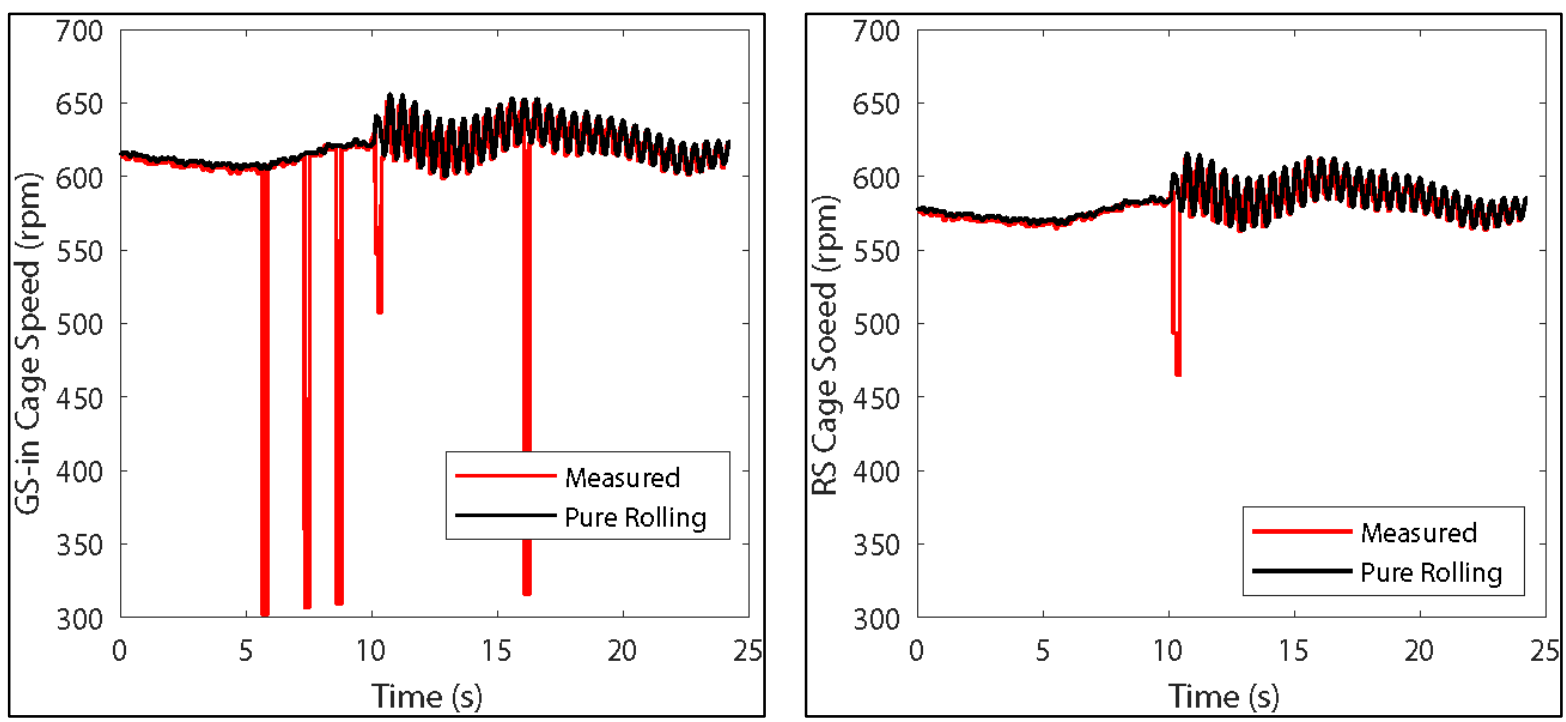

Figure 51. High-speed-shaft generator-side-in (left) and rotor-side (right) bearing roller speed during a low-voltage ride-through 


\section{Exceptions}

Over the course of the testing period, some deviations in the drivetrain instrumentation did occur as can be expected of these types of tests. Those deviations are summarized here:

- The HSS bending moment measurement (A_Y) was not operable for any of the tests. Upon inspection, the strain gauges appear to have de-bonded from the shaft.

- The HSS torque (TQ), bending moments (A_Z, B_Y, B_Z, C_Y, and C_Z), and bearing inner ring temperatures (A_IR_Temp, B_IR_Temp, and C_IR_Temp) degraded in quality over the test period, especially after the end of February. However, the mean values of these signals can be recovered using band-pass filters as shown in Section 4.1.4.

- The nacelle air temperature and dew point measurements (Nacelle_Air_Temp and Nacelle_Air_Dew) were not operational until February 28.

- Oil supply temperature (Oil_Supply_Temp) measurements from the period of April 3 to April 6 were excluded because of unexplained anomalies resulting in unrealistically low temperatures.

- The gearbox voltage potential (voltage direct current) signal was disconnected May 9. 


\section{Summary}

Main and gearbox bearing failures continue to have a significant impact on the reliable operation of wind turbines, and the root causes of both failure modes are still a subject of debate. A multipronged DOE research effort is investigating main bearing and gearbox bearing operational conditions to understand the potential causes of these failures. This report specifies the instrumentation package that has been installed on a commercial SKF main bearing and Winergy PEAB 4410.4 gearbox that were then installed in the GE 1.5-MW SLE turbine at the NWTC. The instrumentation focuses on measuring the operational conditions within the main bearing and high-speed stage of the gearbox, including shaft torque and loads, bearing sliding, and the tribological environment.

Over the initial test period from January through June 2018, the turbine was operated for 290 hours and generated 0.21 million kilowatt-hours of energy. Hundreds of data sets were acquired in normal power production up to $1,800 \mathrm{~kW}$, and in induced transient events such as startups, shutdowns, emergency stops, and grid events. Initial results from operational testing demonstrate main bearing motions up to $1.5 \mathrm{~mm}$ and electrical currents on the order of hundreds of $\mathrm{mA}$, along with significant sliding of the gearbox HSS bearing rolling elements, even in steady-state conditions. 


\section{References}

1. U.S. Department of Energy. 2015. "Wind vision: a new era for wind power in the United States.” DOE/GO-102015-4557. U.S. Department of Energy: Washington, DC, 2015. http://energy.gov/sites/prod/files/2015/03/f20/wv full_report.pdf.

2. Keller, J., S. Sheng, J. Cotrell, and A. Greco. 2016. Wind Turbine Drivetrain Reliability Collaborative Workshop: A Recap (Technical Report). DOE/GO-102016-4878. National Renewable Energy Laboratory (NREL), Golden, CO (US). http://www.nrel.gov/docs/fy16osti/66593.pdf.

3. Kotzalas, M.N., and G.L. Doll. 2010. "Tribological advancements for reliable wind turbine performance. Philosophical Transactions of The Royal Society." 368 (2010) 4829-4850. doi: 10.1098/rsta.2010.0194.

4. Greco, A., S. Sheng, J. Keller, and A. Erdemir. 2013. "Material Wear and Fatigue in Wind Turbine Systems." Wear, 302: 1583-1591. doi: 10.1016/j.wear.2013.01.060.

5. Sethuraman, L., Y. Guo, and S. Sheng, S. 2015. Main Bearing Dynamics in Three-Point Suspension Drivetrains for Wind Turbines (Presentation). NREL/PR-5000-64311. National Renewable Energy Laboratory (NREL), Golden, CO (US). http://www.nrel.gov/docs/fy15osti/64311.pdf.

6. Gould, B., and A. Greco. 2016. "Investigating the Process of White Etching Crack Initiation in Bearing Steel.” Tribology Letters, 62 (26). doi: 10.1007/s11249-016-0673-z.

7. Vaes, D. 2016. "Premature bearing failures in wind turbine gear units - Drivers and counter measures." SKF Wind Farm Management Conference, Brussels (Belgium).

8. Stadler, K., D. Vaes, and M. Ersson. "Premature bearing failures \& white etching cracks.” In: Antriebstechnisches Kolloquium (ATK), Aachen (Germany).

9. Stadler, K., E. Vegter, M. Ersson, and D. Vaes. 2016. "White Etching Cracks - A symptom of bearing failures." In: FVA Bearing World Conference, Hanover (Germany).

10. Holweger, W., and L.S. John. 2017. "WEC Review - Field Experience from a Gearbox Manufacturer." Conference for Wind Power Drives, Aachen, Germany.

11. Keller, J., B. Gould, and A. Greco. 2017. Investigation of Bearing Axial Cracking: Benchtop and Full-Scale Test Results (Technical Report). NREL/TP-5000-67523. National Renewable Energy Laboratory (NREL), Golden, CO (US). http://www.nrel.gov/docs/fy17osti/67523.pdf.

12. Keller, J. 2018. Investigating Main and High-Speed Shaft Bearing Reliability Through Uptower Testing (Presentation). NREL/PR-5000-70958. National Renewable Energy Laboratory (NREL), Golden, CO (US). http://www.nrel.gov/docs/fy18osti/70958.pdf. 
13. Vaes, D. 2018. Uptower measurements to understand roller slip in HS-S bearings. Presented at the Drivetrain Reliability Collaborative Meeting (Presentation). Feb 21.

https://www.dropbox.com/s/u101tu9zmxb3ay6/02\%20Uptower\%20Measurements $\% 20$ to $\% 2$ 0Understand $\% 20$ Roller $\% 20$ Slip $\% 20 \mathrm{in} \% 20 \mathrm{HS}-\mathrm{S} \% 20 \mathrm{Bearings.pdf?dl}=0$.

14. Vaes, D., P. Clement, and K. Stadler. 2017. "How does the application of actual standards \& guidelines contribute to robust bearing solution in Multi-MW wind turbine gearboxes?" Conference for Wind Power Drives, Aachen, Germany.

15. James, P. 2018. Optimized Spherical Roller Bearing for Wind Turbine Rotors. Presented at the Drivetrain Reliability Collaborative Meeting. Feb 21.

https://www.dropbox.com/s/1vu6t47fovgaysh/03\%200ptimized\%20Spherical\%20Roller\%20 Bearing.pdf? $\mathrm{dl}=0$.

16. Wendeberg, H. 2016. Axial Motion in Wind Turbine Main Shaft Spherical Roller Bearings. Presented at the Wind Turbine Tribology Seminar. Nov. 16.

17. Raju, D., and O. Bankestrom. 2017. A System Approach to address Main Bearing Reliability. Presented at the Drivetrain Reliability Collaborative Meeting. Feb 21. https://www.dropbox.com/s/q1j8aag6oyz6490/03\%20A\%20System\%20Approach\%20to\%20 Address\%20Main\%20Bearing\%20Reliability.pdf?dl=0.

18. Keller, J., and S. Lambert. 2018. Gearbox Instrumentation for the Investigation of Bearing Axial Cracking (Technical Report). NREL/TP-5000-70639. National Renewable Energy Laboratory (NREL), Golden, CO (US). http://www.nrel.gov/docs/fy18osti/70639.pdf.

19. Volkmuth, M., K. Stadler, and R. Heemskerk. 2009. "Slippage Measurements in Roller Bearings." Antriebstechnisches Kolloquium, Aachen, Germany.

20. SKF Multilog On-line System IMx-8. n.d. http://www.skf.com/us/products/conditionmonitoring/surveillance-systems/on-line-systems/monitoring-systems/skf-multilog-on-linesystem-imx-8/index.html.

21. Poseidon Systems Trident DM4500 Wear Debris Monitor. n.d. https://www.poseidonsys.com/products-and-services/products/wear-debris/trident-dm4500/.

22. LogiLube SmartGear In-Service Gearbox Condition Monitoring. n.d. http://www.logilube.com/smartgear.

23. Santos, R., and J. van Dam. 2015. Mechanical Loads Test Report for the U.S. Department of Energy 1.5-Megawatt Wind Turbine. NREL/TP-5000-63679. National Renewable Energy Laboratory (NREL), Golden, CO (US). http://www.nrel.gov/docs/fy15osti/63679.pdf.

24. Keller, J., B. Erdman, D. Blodgett, and C. Halse. 2016. NREL-Prime Next-Generation Drivetrain Dynamometer Test Report. NREL/TP-5000-66350. National Renewable Energy Laboratory (NREL), Golden, CO (US). http://www.nrel.gov/docs/fy16osti/66350.pdf. 


\section{Appendix A. Data Elements}

Table A-1. Data Elements

\begin{tabular}{|c|c|c|c|}
\hline Source & Nomenclature & Expanded Nomenclature & Units \\
\hline $\mathrm{DAS}^{\mathrm{a}}$ & LabVIEW_Timestamp & Time, seconds since midnight, January 1, 1904 GMT & $\mathrm{s}$ \\
\hline Met tower & Air_Press_1 & Air pressure & $\mathrm{kPa}$ \\
\hline Met tower & Air_Press_2 & Air pressure & $\mathrm{kPa}$ \\
\hline Met tower & Hum1 & Relative humidity & $\%$ \\
\hline Met tower & Temp1 & Air temperature & $\mathrm{C}$ \\
\hline Met tower & Hum2 & Relative humidity & $\%$ \\
\hline Met tower & Temp2 & Air temperature & $\mathrm{C}$ \\
\hline Met tower & WindSpeed_38m & Wind speed, $38 \mathrm{~m}$ height & $\mathrm{m} / \mathrm{s}$ \\
\hline Met tower & WindSpeed_55m & Wind speed, $55 \mathrm{~m}$ height & $\mathrm{m} / \mathrm{s}$ \\
\hline Met tower & WindSpeed_87m & Wind speed, $87 \mathrm{~m}$ height & $\mathrm{m} / \mathrm{s}$ \\
\hline Met tower & WD1_87m & Wind direction, $87 \mathrm{~m}$ height & $\operatorname{deg}$ \\
\hline Met tower & WS2_92m & Wind speed, $92 \mathrm{~m}$ height & $\mathrm{m} / \mathrm{s}$ \\
\hline Met tower & WS1_90m & Wind speed, $90 \mathrm{~m}$ height & $\mathrm{m} / \mathrm{s}$ \\
\hline Met tower & WindDirection_38m & Wind direction, $38 \mathrm{~m}$ height & $\operatorname{deg}$ \\
\hline Met tower & WindSpeed_80m & Wind speed, $80 \mathrm{~m}$ height & $\mathrm{m} / \mathrm{s}$ \\
\hline Met tower & Precipitation & Wetness sensor & V \\
\hline Rotor & Azimuth & Rotor azimuth, blade 1 pointing up at 0 degrees & deg \\
\hline Rotor & Blade_1_Edge & Edge bending moment, blade 1 & V/V \\
\hline Rotor & Blade_1_Flap & Flap bending moment, blade 1 & V/V \\
\hline Rotor & Blade_2_Edge & Edge bending moment, blade 2 & $\mathrm{~V} / \mathrm{V}$ \\
\hline Rotor & Blade_2_Flap & Flap bending moment, blade 2 & $\mathrm{~V} / \mathrm{V}$ \\
\hline Rotor & Blade_3_Edge & Edge bending moment, blade 3 & $\mathrm{~V} / \mathrm{V}$ \\
\hline
\end{tabular}




\begin{tabular}{|c|c|c|c|}
\hline Source & Nomenclature & Expanded Nomenclature & Units \\
\hline Rotor & Pitch_Blade1 & Pitch angle, blade 1 & deg \\
\hline Rotor & Pitch_Blade2 & Pitch angle, blade 2 & $\operatorname{deg}$ \\
\hline Main Bearing & MB_A_I & Main bearing electrical current, rotor-side & A \\
\hline Main Bearing & MB_B_I & Main bearing electrical current, generator-side & A \\
\hline Main Bearing & MB_Prox_1 & Main bearing axial motion, position 1 & $\mathrm{~mm}$ \\
\hline Main Bearing & MB_Prox_2 & Main bearing axial motion, position 2 & $\mathrm{~mm}$ \\
\hline Main Bearing & MB_Prox_3 & Main bearing axial motion, position 3 & $\mathrm{~mm}$ \\
\hline Main Bearing & MB_Prox_4 & Main bearing axial motion, position 4 & $\mathrm{~mm}$ \\
\hline Main Shaft & LSS $_{\text {b RPM }}$ & Mainshaft speed & rpm \\
\hline Main Shaft & Mainshaft_Downwind_Bend_0 & Mainshaft bending moment, rotating & V \\
\hline Main Shaft & Mainshaft_Downwind_Bend_90 & Mainshaft bending moment, rotating & V \\
\hline Main Shaft & Mainshaft_Downwind_Torque & Mainshaft torque & V \\
\hline Gearbox & HSS_RPM & High-speed shaft speed & rpm \\
\hline Turbine & Active_Power & Turbine active power & $\mathrm{kW}$ \\
\hline Turbine & Power_Factor & Turbine power factor & $\mathrm{kW}$ \\
\hline Turbine & Reactive_Power & Turbine reactive power & $\mathrm{kW}$ \\
\hline Turbine & TowerTopAccel_EW & Tower top acceleration, East-West & $g$ \\
\hline Turbine & TowerTopAccel_NS & Tower top acceleration, North-South & $g$ \\
\hline Turbine & TowerTopBending_0 & Tower top bending strain measurement & $\mathrm{V} / \mathrm{V}$ \\
\hline Turbine & TowerTopBending_90 & Tower top bending strain measurement & $\mathrm{V} / \mathrm{V}$ \\
\hline Turbine & TowerTopTorque & Tower top torqueing strain measurement & $\mathrm{V} / \mathrm{V}$ \\
\hline Turbine & Tower_Base_Bend_1 & Tower base bending strain measurement & $\mathrm{V} / \mathrm{V}$ \\
\hline Turbine & Tower_Base_Bend_2 & Tower base bending strain measurement & $\mathrm{V} / \mathrm{V}$ \\
\hline Turbine & Tower_Base_Torque & Tower base torqueing strain measurement & $\mathrm{V} / \mathrm{V}$ \\
\hline Turbine & Yaw_Encoder & Nacelle yaw angle, relative to true north & deg \\
\hline
\end{tabular}




\begin{tabular}{|c|c|c|c|}
\hline Source & Nomenclature & Expanded Nomenclature & Units \\
\hline SCADA & OPC_AI_CuTorqueAct & Turbine generator dynamic torque & $\mathrm{kNm}$ \\
\hline SCADA & OPC_AI_In_GridMonRealPowerAct & Turbine active power & $\mathrm{kW}$ \\
\hline SCADA & OPC_AI_In_PitchAngleCurrent1 & Pitch angle, blade 1 & deg \\
\hline SCADA & OPC_AI_In_PitchAngleCurrent2 & Pitch angle, blade 2 & deg \\
\hline SCADA & OPC_AI_In_PitchAngleCurrent3 & Pitch angle, blade 3 & deg \\
\hline SCADA & OPC_CMD_Close_Brake & Brake command signal & - \\
\hline SCADA & OPC_DI_In_TBDiscBrakeClosed & Brake closure signal & - \\
\hline SCADA & OPC_In_RotorSpd & Main shaft speed & rpm \\
\hline SCADA & OPC_In_WindSpd & Nacelle wind speed & $\mathrm{m} / \mathrm{s}$ \\
\hline SCADA & OPC_OpCtI_TurbineFullState & & - \\
\hline SCADA & OPC_OpCtI_TurbineOperationalState & & - \\
\hline SCADA & OPC_OpCtl_TurbineStatus & & - \\
\hline SCADA & OPC_STATE_FAULT & & - \\
\hline SCADA & OPC_TURB_STATE_SCADA & & - \\
\hline SCADA & OPC_TurbineStatusSCADA & & - \\
\hline SCADA & OPC_Yaw_As_Published & Nacelle yaw position & deg \\
\hline LIDAR & LidarOffset & & - \\
\hline LIDAR & WD_Mod_Active & Wake steering module active & - \\
\hline LIDAR & WD_Nacelle & Wind vane reading, relative to nacelle, $180 \mathrm{deg}$ is aligned & deg \\
\hline LIDAR & WD_Nacelle_Mod & Modified wind vane reading for wake steering research & deg \\
\hline
\end{tabular}

adata acquisition system; blow-speed shaft 